\title{
Rational Design, Synthesis, and Biological Evaluation of Heterocyclic Quinolones Targeting the Respiratory Chain of Mycobacterium tuberculosis
}

W. David Hong, ${ }^{\dagger, \#}$ Peter D. Gibbons, ${ }^{\dagger, \#}$ Suet C. Leung, ${ }^{\dagger}$ Richard Amewu, ${ }^{\ddagger}$ Paul A. Stocks, ${ }^{\dagger}$ Andrew Stachulski, ${ }^{\dagger}$ Pedro Horta, ${ }^{\S}$ Maria L. S. Cristiano, ${ }^{\S}$ Alison E. Shone, ${ }^{\|}$Darren Moss, ${ }^{\perp}$ Alison Ardrey," Raman Sharma," Ashley J. Warman," Paul T. P. Bedingfield," Nicholas E. Fisher," Ghaith Aljayyoussi," Sally Mead," Maxine Caws," Neil G. Berry, ${ }^{\dagger}$ Stephen A. Ward," Giancarlo A. Biagini, ${ }^{*}, \|$ Paul M. O’Neill, ${ }^{\dagger}$ and Gemma L. Nixon* ${ }^{*}{ }^{\dagger}$

${ }^{\dagger}$ Department of Chemistry, University of Liverpool, Liverpool L69 7ZD, U.K.

${ }^{\ddagger}$ Department of Chemistry, University of Ghana, P.O. Box LG56, Legon-Accra, Ghana

${ }^{\S}$ CCMAR and Department of Chemistry and Pharmacy, University of Algarve, 8005-139 Faro, Portugal

"Research Centre for Drugs and Diagnostics, Liverpool School of Tropical Medicine, Pembroke Place, Liverpool L3 5QA, U.K.

${ }^{\perp}$ School of Pharmacy, Keele University, Keele ST5 5BG, U.K.

Supporting Information

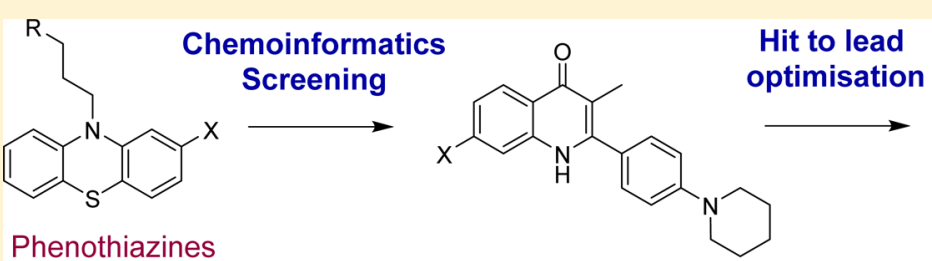

$1, X=H, I_{50}(M t b)=1.5 \mu M$

2, $\mathrm{X}=\mathrm{OMe}, \mathrm{IC}_{50}(\mathrm{Mtb})=730 \mathrm{nM}$

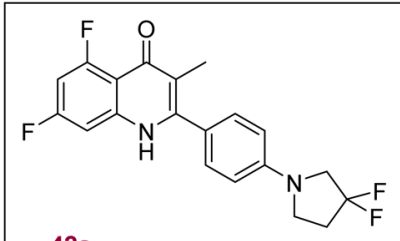

42a

$\mathrm{IC}_{50}($ Rep Mtb) $=525 \mathrm{nM}$

$\mathrm{IC}_{50}($ Wayne Mtb) $=76 \mathrm{nM}$

$\mathrm{IC}_{50}(\mathrm{MDR} \mathrm{Mtb})=140 \mathrm{nM}$

Template identified for lead optimisation

ABSTRACT: A high-throughput screen (HTS) was undertaken against the respiratory chain dehydrogenase component, $\mathrm{NADH}$ :menaquinone oxidoreductase ( $\mathrm{Ndh}$ ) of Mycobacterium tuberculosis (Mtb). The 11000 compounds were selected for the HTS based on the known phenothiazine Ndh inhibitors, trifluoperazine and thioridazine. Combined HTS (11000 compounds) and in-house screening of a limited number of quinolones (50 compounds) identified $\sim 100$ hits and four distinct chemotypes, the most promising of which contained the quinolone core. Subsequent Mtb screening of the complete in-house quinolone library (350 compounds) identified a further $\sim 90$ hits across three quinolone subtemplates. Quinolones containing the aminebased side chain were selected as the pharmacophore for further modification, resulting in metabolically stable quinolones effective against multi drug resistant (MDR) Mtb. The lead compound, 42a (MTC420), displays acceptable antituberculosis activity $\left(\mathrm{Mtb} \mathrm{IC}_{50}=525 \mathrm{nM}\right.$, Mtb Wayne $\mathrm{IC}_{50}=76 \mathrm{nM}$, and $\mathrm{MDR}$ Mtb patient isolates $\left.\mathrm{IC}_{50}=140 \mathrm{nM}\right)$ and favorable pharmacokinetic and toxicological profiles.

\section{INTRODUCTION}

In 2014, tuberculosis (TB) globally infected 9.6 million people, resulting in an estimated 1.5 million deaths. ${ }^{1}$ With the emergence of multidrug resistant (MDR) and extensively drug resistant (XDR) $\mathrm{TB}$, the need for new drug treatments targeting the disease has never been greater. ${ }^{2}$ Current first line drugs for TB were developed in 1952-1966 (Figure 1). Shortcomings of these drugs include: (i) long treatment regimens (6-9 months), leading to patient noncompliance, (ii) adverse drug-drug interactions with anti HIV drugs (HIV/AIDS is a common coinfection), and (iii) limited or no activity against MDR and XDR Mycobacterium tuberculosis (Mtb). ${ }^{3}$ Bedaquiline ${ }^{4,5}$ and delamanid $^{6,7}$ are the only recently FDA approved drugs for the treatment of $\mathrm{TB}$, and their approval is currently only for MDR in cases where established treatments have failed (Figure 1). To find an effective treatment for MDR and XDR, it is believed that a drug with a novel mode of action is required in order to circumvent resistance.

Targeting components of the Mtb respiratory chain (Figure 2) has been shown by us and other laboratories to be effective in sterilizing both replicating and dormant Mtb. ${ }^{9-18}$ The initial target within this program, $\mathrm{Ndh}$ ( $\mathrm{Rv1854c}$ ), is a single subunit $50 \mathrm{kDa}$ enzyme involved in the redox reaction of $\mathrm{NADH}$

Received: November 30, 2016

Published: March 17, 2017 
Current first line drugs used to treat TB:<smiles>NNC(=O)c1ccncc1</smiles>

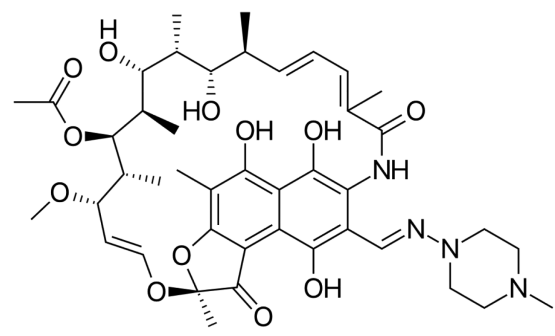<smiles>NC(=O)c1cnccn1</smiles>

Pyrazinamide<smiles>CC[C@H](CO)NCCN[C@H](CC)CO</smiles>

Rifampicin

Recently approved drugs to treat MDR TB:<smiles>COc1nc2ccc(Br)cc2cc1[C@H](c1ccccc1)[C@@](O)(CCN(C)C)c1cccc2ccccc12</smiles>

Bedaquiline<smiles>C[C@]1(COc2ccc(N3CCC(Oc4ccc(OC(F)(F)F)cc4)CC3)cc2)Cn2cc([N+](=O)[O-])nc2O1</smiles>

Delamanid

Figure 1. Current first line drugs used to treat tuberculosis and recently approved drugs for the treatment of MDR TB.

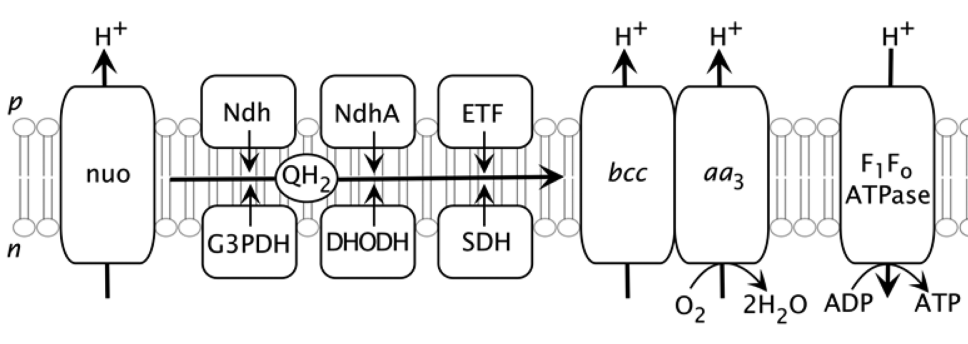

M. tuberculosis respiratory chain

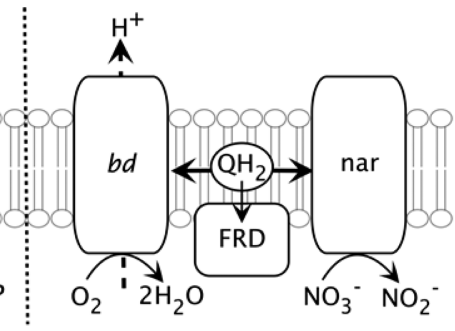

Alternative terminal oxidase pathway

Figure 2. Schematic representation of the respiratory chain of $M$. tuberculosis. The chain components are: Ndh/NdhA, type II NADH:(mena)quinone oxidoreductase (two isoforms); ETF, electron transferring flavoprotein (transfer of reducing equivalents from fatty acid $\beta$-oxidation into the Q-pool); nuo, protonmotive NADH dehydrogenase (complex I), $b c c$, cytochrome- $b c c$ complex (note that there is no evidence for soluble cytochrome $c$ in this organism); $a a_{3}$, cytochrome $b c c$ oxidase, postulated to form a supercomplex with $b c c$. An alternative terminal oxidase pathway is utilized in $M$. tuberculosis under conditions of low oxygen tension containing quinol oxidase (cytochrome $b d$ ), fumarate reductase (FRD), and nitrate reductase (nar) components. $P$ and $n$ correspond to the positive and negative sides of the respiratory membrane with respect to proton translocation. Proton movements are indicative only and do not represent $\mathrm{H}^{+} / \mathrm{e}^{-}$ratios for the respective complexes.

oxidation with subsequent menaquinol production. Ndh has been biochemically identified as a "choke point" and as such is essential for cell function and viability. ${ }^{19}$ Essentiality of $n d h$ has been shown by the inability of Mtb to tolerate insertion mutations in this gene ${ }^{20}$ and more recently in a study involving $n d h$ knockout with subsequent confirmation by complementation. $^{21}$ The other NADH-dependent electron donating dehydrogenases identified in the genome (complex I and ndhA) have been shown not to be lethal. ${ }^{18,22}$ These data are consistent with biochemical evidence that $\mathrm{Ndh}$ is a major source of electrons for the ETC.

Respiratory-chain inhibition-induced death represents a fundamental shift from traditional antitubercular drug design that have until recently relied on drugs that selectively target the replication machinery of Mtb. ${ }^{9,23-28}$ Antitubercular drugs developed to target the respiratory pathways should therefore have the potential to have sterilizing activity against current MDR and XDR Mtb strains.

Identification of hit compounds was achieved through a HTS screen of approximately 11000 compounds that were predicted to possess activity against the $\mathrm{Ndh}$ enzyme. $\mathrm{Ndh}$ was chosen for the HTS due to the critical role as an important dehydrogenase during growth and pathogenicity ${ }^{9,17}$ and due to its tractability for heterologous expression in Escherichia coli and HTS. ${ }^{29}$ The enzyme has been observed to be sensitive to phenothiazinebased inhibitors such as trifluoperazine and thioridazine. ${ }^{9}$ These inhibitors have been shown by a number of different laboratories to have sterilizing activity against replicating and slow growing 
MDR Mtb (grown anaerobically) in both in vitro and in vivo models. ${ }^{14,30,31}$ These two compounds were used as the basis to employ a range of ligand-based chemoinformatics methods ${ }^{32-35}$ in the rational selection of the $\sim 11000$ compounds for the HTS campaign (selected from a commercial library of $\sim 750000$ compounds (Biofocus DPI)). ${ }^{36-40}$ Selected compounds were subject to a sequential high throughput screening campaign using an in vitro assay against recombinant $\mathrm{Ndh}$ as described previously. $^{29}$

In addition to the HTS screen, a limited selection of 50 quinolones were also screened in-house against Mtb $\mathrm{Ndh}$. These compounds were selected for their structural diversity from a library of quinolones designed to target the NADH:ubiquinone oxidoreductase within the malaria parasite Plasmodium falciparum (PfNDH2) as described previously. ${ }^{41-44}$ The HTS screen and in-house screen in combination generated $\sim 100$ hits across four distinct templates, the most potent of which were also tested for whole cell replicating Mtb activity. Following analysis of the in vitro biological data, predicted DMPK properties and investigations into chemical tractability the quinolone template was selected as the most promising for further development.

In previous antimalarial discovery projects, ${ }^{41-48}$ the inhibitors based on the quinolone core displayed pharmacodynamics consistent of a privileged pharmacophore, with the ability to act on multiple electron transport chain (ETC) components. For example, quinolones with a dual mechanism of action against two respiratory enzymes, $P f \mathrm{NDH} 2$ and cytochrome $b c_{1}$, have recently been reported. ${ }^{43}$ To exploit this phenomenon in this antitubercular discovery project, further screening and SAR investigations was switched to whole cell replicating TB activity. To fully establish the structure-activity relationship (SAR) within the existing quinolone library with respect to whole cell Mtb activity, a further library of $\sim 350$ compounds were screened against replicating Mtb. There were $\sim 90$ compounds that were found to inhibit Mtb growth by $>50 \%$ at $5 \mu \mathrm{M}$. Four subtemplates were then identified as having moderate in vitro Mtb potency. The most promising of which only had a very limited number of examples (see Table S1, Supporting Information) within the existing library but demonstrated significantly more potency, as such, the template based on compounds $\mathbf{1}$ and $\mathbf{2}$ was chosen for lead optimization (Figure 3).

A comprehensive medicinal chemistry SAR study around this series was then undertaken to establish optimized leads for further development. Screening data analysis (see Table S1, Supporting Information) shows $\mathrm{NH}_{2}$ and $\mathrm{OAc}$ at the 4-position are inactive for this particular subtemplate (Table S1, entries 20, 23, and 24, Supporting Information) and show reduced activity for other quinolone subtemplates. Replacement of the phenyl ring with a pyridyl ring also rendered the subtemplate inactive (Table S1, entry 20, Supporting Information). Modification of ring $\mathrm{C}$ results in a loss of in vitro Mtb potency and is a general trend that was seen across most quinolone subtemplates screened. Modifications of particular interest were therefore optimization of the side chain to optimize potency and DMPK, the nature of the group at 3-position and the electronic/steric effect of substituents placed at the 5,6, and 7 positions (Figure 4).

\section{CHEMISTRY}

Following identification of quinolones $\mathbf{1}$ and $\mathbf{2}$ as the initial hits against Mtb, our initial efforts were focused on exploring the SAR of substituents placed in the A ring. The synthesis of these compounds was achieved in 3-5 steps from commercially available starting materials (Scheme 1). Oxazoline 4 was

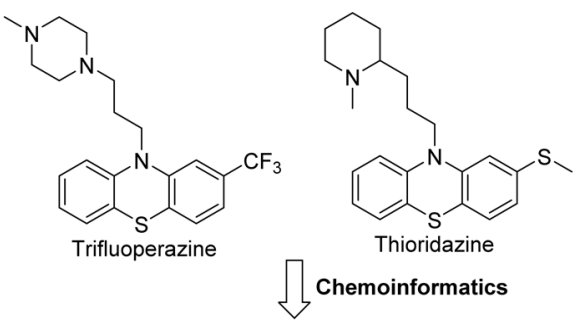

BIOFOCUS MtNDH HTS 11,000 Compounds LIMITED IN HOUSE MINDH QUINOLONE SCREEN $\sim 50$ compounds $\sim 100$ HITS - 4 TEMPLATES

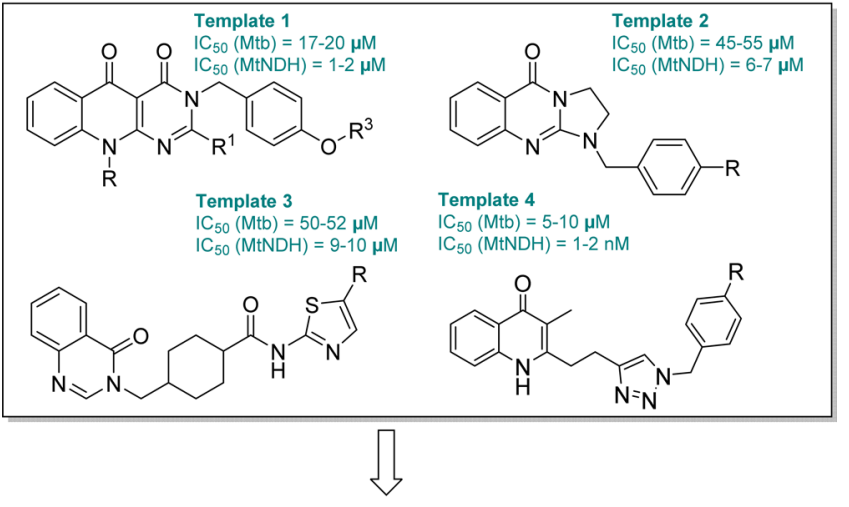

FULL Mtb SCREEN OF IN HOUSE QUINOLONE LIBRARY 350 compounds $\sim 90$ HITS - 4 SUB TEMPLATES

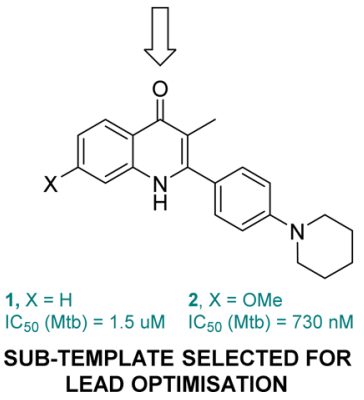

Figure 3. Identification of the quinolone template for lead optimization.

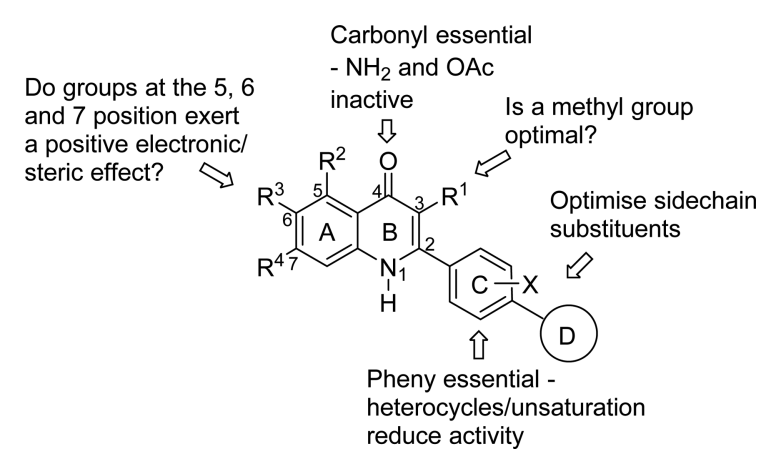

Figure 4. Known SAR and SAR to be investigated.

prepared from the corresponding isatoic anhydride 3 in yields of $34-75 \%$. Where the isatoic anhydride was not commercially available, the oxazolines were synthesized in-house (see Supporting Information). 4'-Fluoropropiophenone 5 was allowed to react with piperidine to give ketone 6 in $32-97 \%$ yields. 
Scheme 1. Synthesis of Quinolones 1, 2, and $7 \mathrm{a}-\mathrm{k}^{a}$

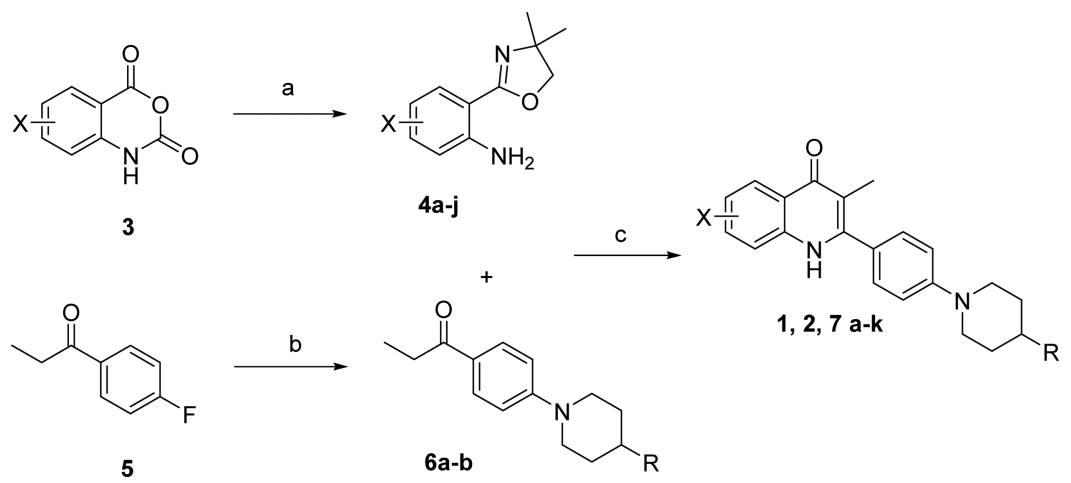

${ }^{a}$ Conditions and reagents: (a) 2-amino-2-methyl-propanol, $\mathrm{ZnCl}_{2}, \mathrm{PhCl}, 135{ }^{\circ} \mathrm{C}, 24 \mathrm{~h}$; (b) corresponding amine, $\mathrm{K}_{2} \mathrm{CO}_{3}, \mathrm{DMF} 120{ }^{\circ} \mathrm{C}$ to reflux, overnight; (c) $\mathrm{CF}_{3} \mathrm{SO}_{3} \mathrm{H}, n-\mathrm{BuOH}, \mathrm{N}_{2}, 130{ }^{\circ} \mathrm{C}, 24 \mathrm{~h}$.

Reaction of oxazoline 4 with ketone 6 in the presence of triflic acid gave the desired quinolones 1,2 , and $7 \mathbf{a}-\mathbf{k}$ in $23-45 \%$ yields (Table 1).

Table 1. Yields for the Synthesis of Compounds 1, 2, 7a-k

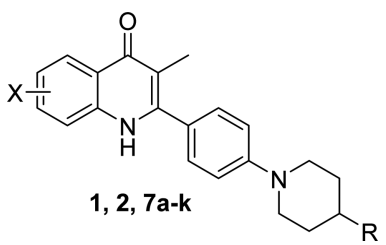

\begin{tabular}{clcccc} 
compd & \multicolumn{1}{c}{ X } & R & \% yield 4 & \% yield 6 & \% yield 7 \\
$\mathbf{1}$ & H & H & & 62 & 23 \\
$\mathbf{2}$ & 7-OMe & H & 75 & 62 & 36 \\
$7 \mathbf{a}$ & 6-F & H & 60 & 62 & 26 \\
$7 \mathbf{b}$ & 6-OMe, 7-OMe & H & 52 & 62 & 28 \\
$7 \mathbf{c}$ & 6-Cl, 7-OMe & H & 45 & 62 & 35 \\
$7 \mathbf{d}$ & 6-F, 7-OMe & H & 52 & 62 & 41 \\
$7 \mathbf{7 e}$ & 5-OMe, 7-OMe & $\mathrm{H}$ & 58 & 62 & 32 \\
$7 \mathbf{f}$ & 5-F,7-F & $\mathrm{H}$ & 68 & 62 & 45 \\
$7 \mathbf{g}$ & 7-F & $\mathrm{H}$ & & 62 & 35 \\
$7 \mathbf{h}$ & 7-Cl & $\mathrm{H}$ & 64 & 62 & 37 \\
$7 \mathbf{i}$ & H & $\mathrm{F}$ & & 55 & 36 \\
$7 \mathbf{j}$ & 7-OMe & $\mathrm{F}$ & 75 & 55 & 43 \\
$7 \mathbf{k}$ & 5-F, 7-F & $\mathrm{F}$ & 68 & 55 & 29 \\
\hline
\end{tabular}

The nature of the group at 3-position of the quinolone was also studied. A small set of analogues with a hydrogen at 3-position were synthesized (Scheme 2). Substituted 2-aminoacetophenone 9 was converted from the respective aminobenzoic acid 8 using methyl lithium in 36\% yield. 4-Fluorobenzoate 10 was reacted with piperidine in the presence of potassium carbonate to give the piperidinyl benzoate 11 in 37\% yield. Benzoate 11 was hydrolyzed to benzoic acid, which was then converted to acid chloride 12 by oxalyl chloride. Acylation of 2-aminoacetophenone 9 with acid chloride 12 provided the intermediate 13 in $30-51 \%$ yields. Cyclization of the intermediate 13 in the presence of $\mathrm{NaOH}$ or $\mathrm{KO}^{t} \mathrm{Bu}$ gave the $3-\mathrm{H}$ quinolones $14 a-c$ in 41-91\% yields (Table 2).

Literature precedent from the development of ETC inhibitors in the antimalarial field lead us then to look at the presence of a halide at the 3-position. GSK's pyridone series ${ }^{49}$ demonstrated tolerance of the presence of a chlorine at 3-position, and within our own group we have shown the combination of 3-chloro-7-methoxy enhances biological activity of the quinolone core. ${ }^{50}$ To achieve this, the $3-\mathrm{H}$ compounds were treated with sodium dichloroisocyanurate and sodium hydroxide to give $3-\mathrm{Cl}$ quinolones $\mathbf{1 5 a}-\mathbf{d}$ in $40-61 \%$ yields or NBS to give $3-\mathrm{Br}$ quinolones $15 \mathrm{e}-\mathrm{f}$ in $55-63 \%$ yields.

Having identified 3-methyl and 5,7-difluoro quinolone (followed by 6-fluoro-7-methoxy and 7-methoxy quinolone) to be optimal for Mtb activity (see Table 8), the focus of SAR explorations moved to the terminal ring of the side chain to further improve Mtb activity and optimize DMPK. Additional small groups, such as $\mathrm{Me}, \mathrm{F}$, and $\mathrm{CF}_{3}$, attached at different positions on the terminal piperidine ring were investigated. In addition, the effect of chirality was explored. ${ }^{51}$ Synthesis of compounds $17 \mathbf{a}-\mathbf{k}$ was achieved using chemistry described in Scheme 3 (Table 3).

Incorporation of different amino groups into the side chain as an alternative to the potentially metabolically labile piperidine ring was also investigated. To incorporate a diethylamine group, an alternative methodology was used to synthesize the side chain, commercially available 4-bromo- $N, N$-dimethylaniline 18 was treated with butyllithium for a lithium-halogen exchange and the intermediate was quenched with $\mathrm{N}, \mathrm{N}$-dimethylpropionamide to form the side chain 19 in $78 \%$ yield, reaction with oxazoline $4 \mathrm{~h}$ was then carried out to give quinolone $\mathbf{1 7 1}$ in $46 \%$ yield (Scheme 4 ).

Extension of the side chain with a phenyl or benzyl group at the 2-position was also investigated using the synthetic methodologies shown in Scheme 5 (Table 4). In addition, replacement of piperidine by piperazine was investigated. This was to further explore the length of side chain that could be tolerated and to improve the solubility.

In addition, the quinolone with a piperidine ring at the metaposition 24 was also synthesized by reacting the 3-bromopropiophenone 22 with piperidine using Buchwald coupling to yield the ketone intermediate 23 , which was coupled with oxazoline $\mathbf{4 h}$ to give the quinolone in $45 \%$ yield (Scheme 6).

A series of analogues with a pyrrole heterocycle in the side chain were also synthesized to further explore the side chain SAR and enhance the metabolic stability. The synthetic route to these compounds is illustrated in Scheme 7. Utilizing copper and trans$N, N^{\prime}$-dimethyl-1,2-cyclohexanediamine catalyzed $N$-arylation with 4-bromopropiophenone, the side chain ketone intermediate 31 was formed in $30-62 \%$ yields. ${ }^{52,53}$ Final cyclization with oxazoline gave quinolones $32 \mathbf{a}-\mathbf{g}$ in $35-57 \%$ yields (Table 5 ).

Using fluorine to block metabolism and improve oral absorptions was further explored. Research by Smith has shown that gem-difluorinated piperidine compounds exhibited a significant 
Journal of Medicinal Chemistry

Article

Scheme 2. Synthesis of Quinolones $14 a-c$ and $15 a-f^{a}$

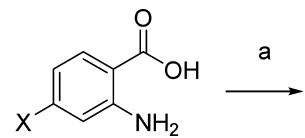

8

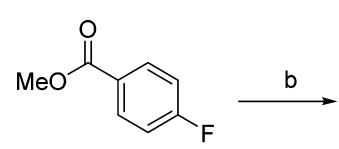

10<smiles>[X]c1ccc(C(C)=O)c(N)c1</smiles>

9a-b
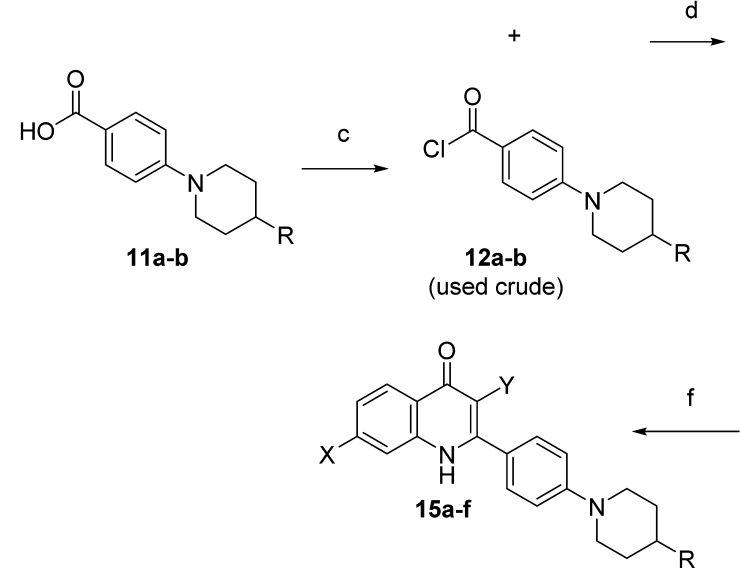

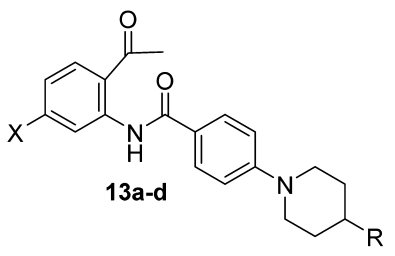

e

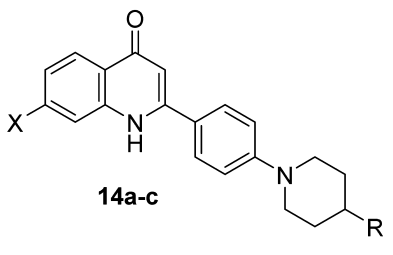

${ }^{a}$ Conditions and reagents: (a) MeLi, DME, $0{ }^{\circ} \mathrm{C}, 2 \mathrm{~h}$; (b) (i) $\mathrm{K}_{2} \mathrm{CO}_{3}$, DMF, reflux, overnight, (ii) $\mathrm{NaOH}$ (aq), MeOH, reflux, overnight; (c) oxalyl chloride, DCM, DMF (cat.), rt, 2 h; (d) $\mathrm{NEt}_{3}$, THF, rt, overnight; (e) $\mathrm{NaOH}$ (s), 1,4-dioxane, $110{ }^{\circ} \mathrm{C}, 5 \mathrm{~h}$ or $\mathrm{KO}^{t} \mathrm{Bu},{ }^{t} \mathrm{BuOH}, 75{ }^{\circ} \mathrm{C}, 16 \mathrm{~h}$; (f) sodium dichloroisocyanurate, $1 \mathrm{M} \mathrm{NaOH}$ (aq), $\mathrm{MeOH}$, rt, overnight (15a-d) or NBS, DCM, DMF, rt, overnight (15e-f).

Table 2. Yields for the Synthesis of Compounds $14 a-c$ and $15 a-f$

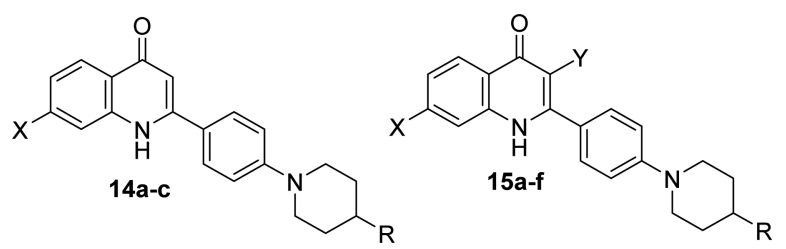

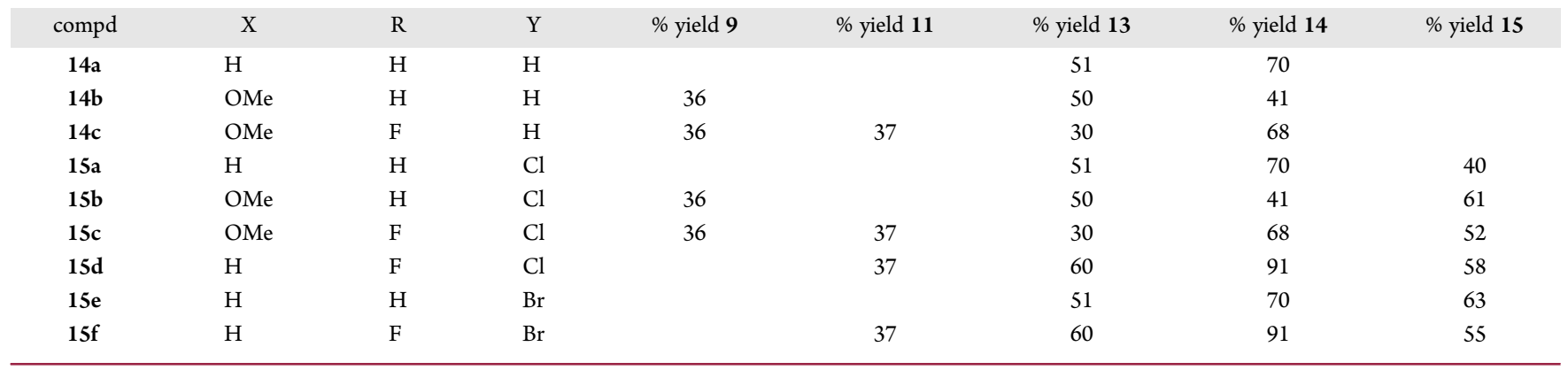

Scheme 3. Synthesis of Quinolones $17 \mathrm{a}-\mathrm{k}^{a}$

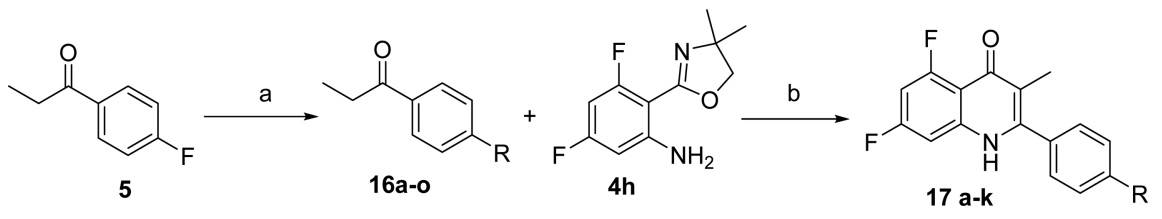

${ }^{a}$ Conditions and reagents: (a) corresponding amine, $\mathrm{K}_{2} \mathrm{CO}_{3}$, IMF, $120{ }^{\circ} \mathrm{C}$ to reflux, overnight; (b) $\mathrm{CF}_{3} \mathrm{SO}_{3} \mathrm{H}, n-\mathrm{BuOH}, \mathrm{N}_{2}, 130{ }^{\circ} \mathrm{C}, 24 \mathrm{~h}$.

improvement in metabolic stability. ${ }^{54}$ This led to the design and synthesis of fluorinate quinolones $\mathbf{3 8} \mathbf{a}-\mathbf{f}$ as well as the alcohol side chain quinolones $\mathbf{3 8 g}-\mathbf{i}$. The chemistry used in the synthesis of these compounds is shown in Scheme 8 (Table 6).

Removal of the benzyl group from the chiral proline derivatives $\mathbf{3 8 j - 1}$ was achieved using hydrogenation (Scheme 9 ) in good yields.

For the gem-difluoro analogues (42a (MTC420) and 42b), 4-bromopropiophenone was first converted to a more reactive 4-iodopropiophenone by an aromatic Finkelstein reaction catalyzed by copper(I) iodide in combination with $\mathrm{N}, \mathrm{N}$-dimethyl1,2-diaminoethane. ${ }^{55}$ A subsequent Buchwald-Hartwig aminotion using $\mathrm{Pd}_{2}(\mathrm{dba})_{3}$ and Xantphos with the gem-fluorinated amine gave the ketone side chain $41 \mathbf{a}-\mathbf{b}$ in $12-28 \%$ yields. ${ }^{56}$ Reaction with oxazoline gave quinolones $42 \mathbf{a}-\mathbf{b}$ in $47-56 \%$ yields (Scheme 10).

42a was identified as the lead compound in the series as it exhibited good potency and metabolic stability (See Table 11 and Table 12), and further investigation of the pyrrolidine side

3707

DOl: $10.1021 /$ acs.jmedchem.6b01718

J. Med. Chem. 2017, 60, 3703-3726 
Table 3. Yields for the Synthesis of Compounds 17a-k

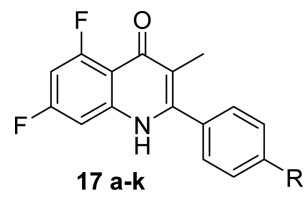

\begin{tabular}{|c|c|c|c|}
\hline Compound & $\mathrm{R}$ & $\%$ Yield 16 & $\%$ Yield 17 \\
\hline $17 \mathbf{a}$ & $-\mathrm{CF}_{3}$ & 48 & 32 \\
\hline $17 b$ & & 73 & 54 \\
\hline $17 \mathrm{c}$ & & 48 & 34 \\
\hline 17d & & 40 & 57 \\
\hline $17 \mathrm{e}$ & & 64 & 27 \\
\hline $17 f$ & & 84 & 45 \\
\hline $17 \mathrm{~g}$ & & 74 & 43 \\
\hline $17 \mathrm{~h}$ & & 75 & 40 \\
\hline $17 \mathbf{i}$ & & 72 & 39 \\
\hline $17 \mathbf{j}$ & & 69 & 41 \\
\hline $17 k$ & $-\mathrm{NHCH}_{2} \mathrm{Ph}$ & 28 & 51 \\
\hline
\end{tabular}

chain was undertaken to improve solubility and potency. Further modifications have included adding chirality and introducing amide functionality to rapidly ascertain if it is tolerated within the template. Quinolones $\mathbf{4 5 a}-\mathbf{h}$ were therefore synthesized using chemistry described in Scheme 11. To incorporate the amide group, Ullmann coupling of 4-bromopropiophenone with D-proline gave the carboxylic acid intermediate $43 \mathbf{a}-\mathbf{b}$. Crosslinking the carboxylic acid by EDC/NHS to the respective amine provided the ketone side chain 44 in $52-90 \%$ yields. This was subsequently coupled with oxazoline in $12-34 \%$ yields to afford quinolones $45 \mathbf{a}-\mathrm{g}$.

Incorporation of an amide moiety largely resulted in reduced antituberculosis activity (Table 7). As such, our attention returned to 42a and improving its pharmacokinetic profile. Use of a pro-drug strategy, previously used successfully within other quinolone development programs ${ }^{57}$ was investigated, leading to the synthesis of compound 46 (Scheme 12).
Compound 46 was synthesized by reacting $42 \mathrm{a}$ with potassium tert-butoxide and acetyl chloride to give the acetate pro-drug in high yield.

\section{RESULTS AND DISCUSSION}

Structure-Activity Relationships (SAR). Initial SAR investigations around the hit compounds $\mathbf{1}$ and $\mathbf{2}$ focused on establishing the optimal A-ring substituents (X). Compounds $\mathbf{1}$, 2 , and $7 \mathrm{a}-7 \mathrm{~h}$ demonstrate the most favorable $\mathrm{X}$ groups are $5-\mathrm{F}$, 7-F, closely followed by 6-F, 7-OMe, and 7-OMe. Compounds $7 \mathbf{i}-7 \mathbf{k}$ were synthesized with a view to reducing the potential metabolism of the piperidine ring. Pleasingly, a good level of potency was maintained. Concomitantly, the potential for replacing the methyl group at $\mathrm{Y}$ was also investigated. When $\mathrm{Y}=\mathrm{H}$, activity is lost, as demonstrated by compounds $14 \mathrm{a}-\mathrm{c}$. Halogenation was also investigated; again this largely resulted in reduced antituberculosis activity $(\mathbf{1 5 a}-\mathbf{f})$, the one exception to this being 15e possessing a $\mathrm{Br}$ at $\mathrm{Y}$. This affect appeared to be compound specific rather than a general trend across all brominated analogues, and as such it was decided that the methyl group was the optimal group at this position (Table 8).

With 5-F, 7-F and 3-methyl confirmed as optimal for antituberculosis activity, optimizing the side chain then became the focus of the SAR studies (Table 9). Initial investigations into piperidine ring substituents at the 4-position revealed that in addition to 4-F $7 \mathbf{k}$, a methyl group is also tolerated as demonstrated with compound $\mathbf{1 7} \mathbf{b}$. It rapidly became apparent that there was a size limitation to the group tolerated at the 4-position with larger groups such as $\mathrm{CF}_{3}$, cyclopropyl, and gemdifluoro, resulting in loss of potency. Movement of the $\mathrm{F}$ and Me groups to the 3-position resulted in improvements in antituberculosis activity as demonstrated by compounds $17 \mathbf{e}-\mathbf{h}$. Interestingly, racemic and enatiomerically pure analogues of the 3-methyl derivative $\mathbf{1 7 f}$ showed little variation in potency, which is in direct contrast to the pyrrolidine analogues discussed later. Replacement of the piperidine ring with a number of alternative amines was also investigated. Increasing ring size (17j) and use of dimethyl amine (17l) retained good potency. Incorporation of secondary amines (17k) and more polar groups such as $N$-methyl piperazine (17i) reduced antituberculosis activity. Moving the piperidine group from the para to the meta-position (24) also resulted in loss of activity.

The size limitation and unfavorable incorporation of piperazine was further confirmed by our concomitant investigation into extended side chain analogues (Table 10). The aim of this series was to explore the space available and to improve solubility with the incorporation of piperazine to facilitate salt-based formulation.

Scheme 4. Synthesis of Quinolone $171^{a}$

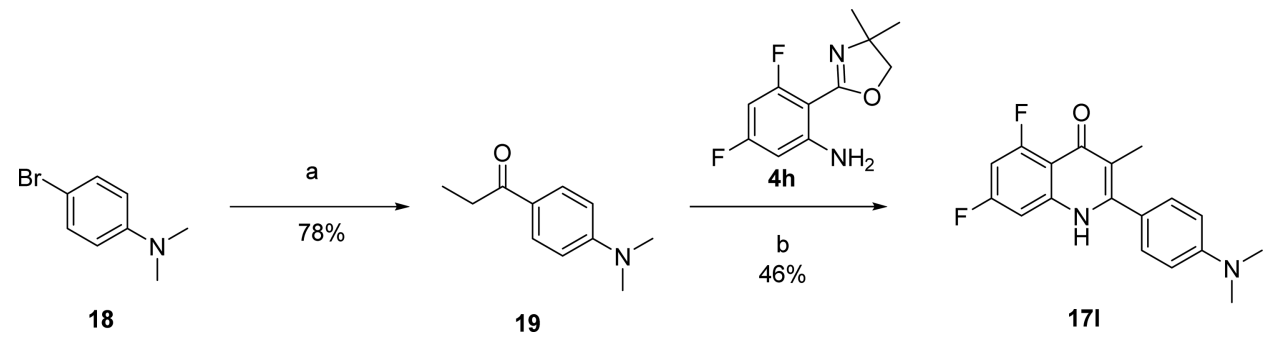

${ }^{a}$ Conditions and reagents: (a) (i) $n \mathrm{BuLi}, \mathrm{Et}_{2} \mathrm{O},-78^{\circ} \mathrm{C}, 30 \mathrm{~min}$, (ii) $\mathrm{N}, \mathrm{N}$-dimethylpropionamide, $-78{ }^{\circ} \mathrm{C}$ to rt, $2 \mathrm{~h}$; (b) $\mathrm{CF}_{3} \mathrm{SO}_{3} \mathrm{H}, n$ - $\mathrm{BuOH}, \mathrm{N}_{2}, 130$ ${ }^{\circ} \mathrm{C}, 24 \mathrm{~h}$. 
Scheme 5. Synthesis of Quinolones $21 \mathrm{a}-\mathrm{g}^{a}$

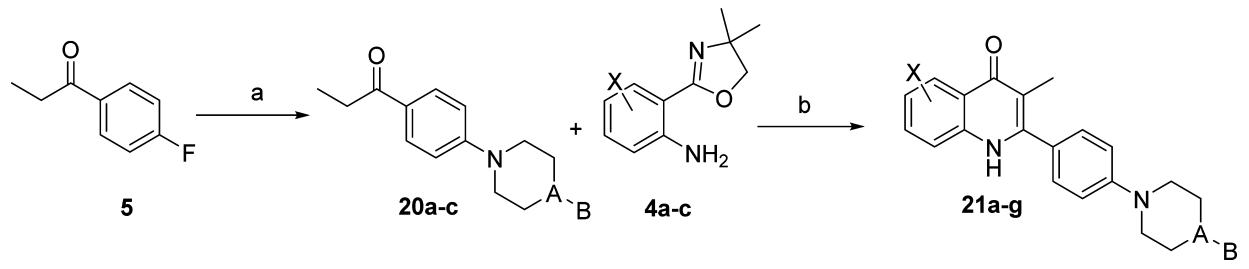

${ }^{a}$ Conditions and reagents: (a) corresponding amine, $\mathrm{K}_{2} \mathrm{CO}_{3}$, DMF, $120{ }^{\circ} \mathrm{C}$ to reflux, overnight; (b) $\mathrm{CF}_{3} \mathrm{SO}_{3} \mathrm{H}, n-\mathrm{BuOH}, \mathrm{N}_{2}, 130{ }^{\circ} \mathrm{C}, 24 \mathrm{~h}$.

Table 4. Yields for the Synthesis of Compounds $21 \mathrm{a}-\mathrm{g}$

\begin{tabular}{|c|c|c|c|c|c|}
\hline compd & $\mathrm{X}$ & A & B & $\%$ yield 20 & $\%$ yield 21 \\
\hline $21 a$ & $\mathrm{H}$ & $\mathrm{CH}$ & $\mathrm{CH}_{2} \mathrm{Ph}$ & 64 & 33 \\
\hline $21 b$ & $6-F$ & $\mathrm{CH}$ & $\mathrm{CH}_{2} \mathrm{Ph}$ & 64 & 40 \\
\hline $21 c$ & 7-OMe & $\mathrm{CH}$ & $\mathrm{CH}_{2} \mathrm{Ph}$ & 64 & 42 \\
\hline 21d & $\mathrm{H}$ & $\mathrm{N}$ & $\mathrm{CH}_{2} \mathrm{Ph}$ & 58 & 30 \\
\hline $21 e$ & $6-\mathrm{F}$ & $\mathrm{N}$ & $\mathrm{CH}_{2} \mathrm{Ph}$ & 58 & 28 \\
\hline $21 \mathrm{f}$ & 7-OMe & $\mathrm{N}$ & $\mathrm{Ph}$ & 64 & 30 \\
\hline $21 \mathrm{~g}$ & 7-OMe & $\mathrm{N}$ & $\mathrm{CH}_{2} \mathrm{Ph}$ & 58 & 38 \\
\hline
\end{tabular}

With this information in hand, several small heterocyclic, fluorinated, chiral, and amide analogues were synthesized to investigate SAR and improve DMPK (Table 11). Compounds $32 \mathbf{a}-\mathrm{g}$ are pyrrole derivatives. An unsubstituted pyrrole moiety is well tolerated in the 5-F (32d) and 5-F, 7-F (32e) analogues, however, increasing the size of the pyrrole group by addition of a fused benzene ring (32b) again results in loss of potency. Incorporation of a halogen on the aromatic ring was also investigated but reduced potency.

Fluorinated analogues were synthesized in order to improve metabolic stability (see Table 11). Both mono (38a and $38 \mathbf{b}$ ) and gem-difluoro (42a) substituted pyrrolidine derivatives exhibited good to excellent potency. The gem-difluoro azetidine (38c) and 3-substituted piperidine (42b) also demonstrated good potency. Incorporation of an alcohol group in the side chain to reduce lipophilicity and potentially facilitate pro-drug approaches provided mixed results. gem-Methyl, $\mathrm{OH}$ analogues $38 \mathrm{~g}-\mathbf{i}$ were not tolerated, whereas inclusion of prolinol $(39 \mathbf{a}-\mathbf{b})$ gave good antituberculosis activity. Benzylated analogue $\mathbf{3 8 j}$ and amide analogues $45 \mathbf{a}-\mathrm{g}$ largely resulted in loss of potency. For the pyrrolidine analogues, the effect of chirality on activity was marked with the $(R)$-3-fluoro analogue 38a $\left(\mathrm{Mtb} \mathrm{IC}_{50}=0.23 \mu \mathrm{M}\right)$, demonstrating significantly superior potency over the $(S)$-3fluoro analogue $38 \mathrm{~b}\left(\mathrm{Mtb} \mathrm{IC}_{50}=1.80 \mu \mathrm{M}\right)$. The effect of chirality was also observed with the prolinol analogues, $(S)$-prolinol analogue $39 \mathrm{~b}\left(\mathrm{Mtb} \mathrm{IC}_{50}=0.32 \mu \mathrm{M}\right)$ being more active than $(R)$-prolinol analogue 39a $\left(\mathrm{Mtb} \mathrm{IC}_{50}=1.52 \mu \mathrm{M}\right)$. The overall SAR trends for the series can be seen in Figure 5.

In Vitro DMPK and Toxicity. Analogues demonstrating good potency were then moved through our screening cascade and evaluated for microsomal turnover and HEPG2 cytotoxicity. None of the compounds were found to be cytotoxic, and all had good therapeutic indexes. From the earlier analogues tested (entries 1-6 in Table 12), it was apparent that the compounds were being metabolized quickly by liver microsomes. Resolving this issue was therefore the driving force for a large proportion of the medicinal chemistry manipulations described in Table 11 above.

Two strategies were employed to address the metabolic stability issues (Figure 6). The first was to replace the piperidine ring with an alternative heterocycle. Among those selected, pyrrole (32e) provided the most active compound with a modest improvement in metabolic stability. Fluorination of the pyrrole (38d) at the 3 and 4 positions resulted in complete resolution of metabolic instability; however, antituberculosis activity was also lost. From earlier SAR studies, we knew that replacing the piperidine ring (7f) with a pyrrolidine ring $(\mathbf{1 7 l})$ was tolerated in terms of activity and may provide us with more opportunity to modify the ring in what we believe to be a limited space. Monofluorination (38a) provided a very modest improvement in stability. Subsequent synthesis of the gem-difluoro analogue (42a), however, provided us with a compound with both good antituberculosis activity and excellent metabolic stability. The equivalent six-membered ring analogue $\mathbf{4 2 b}$ had good potency but comparatively decreased metabolic stability as expected (Table 12).

Selected analogues were also measured for Caco-2 permeability, stability in plasma, \% plasma protein binding (PPB), and solubility (Table 13). All compounds performed well in these assays with the exception of solubility, which is a common issue for the quinolone chemotype.

Scheme 6. Synthesis of Quinolone $24^{a}$
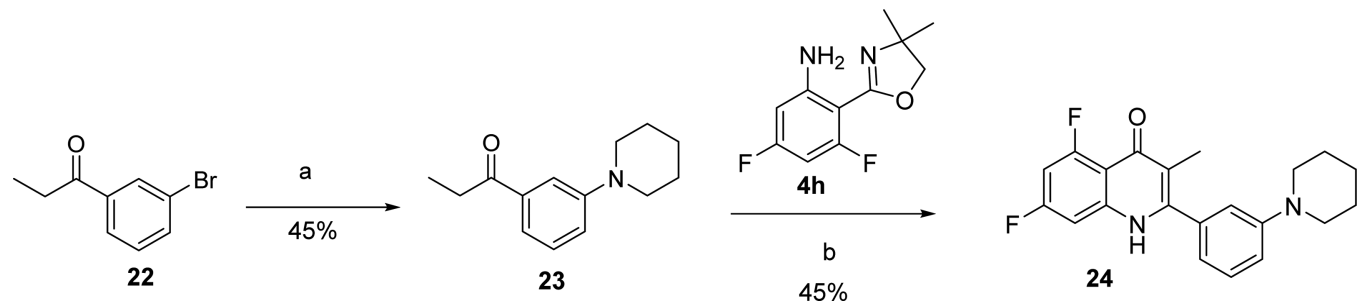

${ }^{a}$ Conditions and reagents: (a) piperidine, $\mathrm{Pd}(\mathrm{OAc})_{2}, \mathrm{XPhos}, \mathrm{NaO}{ }^{t} \mathrm{Bu}$, toluene, $110{ }^{\circ} \mathrm{C}, 24 \mathrm{~h}$; (b) $\mathrm{CF}_{3} \mathrm{SO}_{3} \mathrm{H}, n$ - $\mathrm{BuOH}, \mathrm{N}_{2}, 130{ }^{\circ} \mathrm{C}, 24 \mathrm{~h}$. 
Scheme 7. Synthesis of Quinolones 32a-g $\mathrm{g}^{a}$<smiles>O=Cc1ccc(Br)c(Cl)c1</smiles>

25

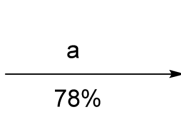

$$
\mathrm{Br}
$$<smiles>C[13CH3]</smiles>
28<smiles>O=Cc1ccc(Br)cc1F</smiles><smiles>[Y]c1ccc(C(=O)CC)cc1Br</smiles>
$\mathrm{RH}$<smiles>CCC(O)c1ccc(Br)c(Cl)c1</smiles>

26<smiles>CCCCCCC(=O)c1ccc(Br)c(Cl)c1</smiles>

27<smiles>CCC(=O)c1ccc(Br)cc1F</smiles>
29<smiles>CCC(O)c1ccc(Br)cc1F</smiles><smiles>[R]c1ccc(C(=O)CC)cc1[X]</smiles>
31a-f

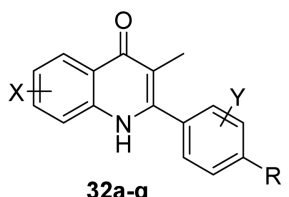

32a-g

${ }^{a}$ Conditions and reagents: (a) EtMgBr, THF, $0{ }^{\circ} \mathrm{C}, 1 \mathrm{~h}$; (b) PCC, DCM, rt, $2 \mathrm{~h}$; (c) 5 mol \% CuI, 20 mol \% trans-N,N'-dimethyl1,2 cyclohexanediamine, $\mathrm{K}_{3} \mathrm{PO}_{4}$, toluene, $110{ }^{\circ} \mathrm{C}, 24 \mathrm{~h}$; (d) $\mathrm{CF}_{3} \mathrm{SO}_{3} \mathrm{H}, n-\mathrm{BuOH}, \mathrm{N}_{2}, 130{ }^{\circ} \mathrm{C}, 24 \mathrm{~h}$.

Table 5. Yields for the Synthesis of Compounds 32a-g

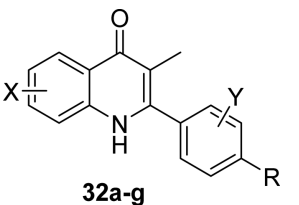

\begin{tabular}{|c|c|c|c|c|c|}
\hline Compound & $\mathrm{X}$ & $\mathrm{Y}$ & $\mathrm{R}$ & $\%$ yield $\mathbf{3 1}$ & $\%$ yield 32 \\
\hline $32 a$ & $5-\mathrm{F}, 7-\mathrm{F}$ & - & & 38 & 55 \\
\hline $32 \mathrm{~b}$ & $5-\mathrm{F}, 7-\mathrm{F}$ & - & & 30 & 57 \\
\hline $32 \mathrm{c}$ & $5-\mathrm{F}, 7-\mathrm{F}$ & - & & 46 & 35 \\
\hline 32d & $5-\mathrm{F}$ & - & & 62 & 32 \\
\hline $32 \mathrm{e}$ & $5-\mathrm{F}, 7-\mathrm{F}$ & - & & 62 & 30 \\
\hline $32 f$ & 5-F,7-F & $m-\mathrm{Cl}$ & & 49 & 39 \\
\hline $32 \mathrm{~g}$ & $5-\mathrm{F}, 7-\mathrm{F}$ & $o-\mathrm{F}$ & & 52 & 39 \\
\hline
\end{tabular}

Scheme 8. Synthesis of Quinolones 38a-1 ${ }^{a}$<smiles>[R]c1ccc(-c2[nH]c3ccccc3c(=O)c2C)cc1</smiles>

${ }^{a}$ Conditions and reagents: (a) corresponding amine, $\mathrm{K}_{2} \mathrm{CO}_{3}$, DMF, $120{ }^{\circ} \mathrm{C}$ to reflux, overnight; (b) $\mathrm{CF}_{3} \mathrm{SO}_{3} \mathrm{H}, n-\mathrm{BuOH}, \mathrm{N}_{2}, 130{ }^{\circ} \mathrm{C}, 24 \mathrm{~h}$.

A number of analogues also underwent additional in vitro DMPK (Table 14) experiments, further confirming the metabolism issues detailed above.

Biological Profile. Having selected 42a as the lead compound, full biological profiling was undertaken to establish its pharmacokinetic and toxicological profile in addition to its activity against slow-growing (Wayne assay) and MDR-resistant Mtb (Table 15). 42a demonstrated comparable activity against all tested strains of sensitive and MDR Mtb as well as having good potency against dormant, nonreplicating TB. It demonstrated a suitable in vitro DMPK and toxicity profile to undergo in vivo pharmacokinetic analysis.

Pharmacokinetics. The pharmacokinetic profile of $42 \mathrm{a}$ can be seen in Figure 7 and Table 16. Analysis of data from the parent 
Table 6. Yields for the Synthesis of Compounds 38a-1

\begin{tabular}{|c|c|c|c|c|}
\hline Compound & $\mathrm{X}$ & $\mathrm{R}$ & $\%$ Yield 37 & $\%$ Yield $\mathbf{3 8}$ \\
\hline $38 a$ & 5-F,7-F & & 38 & 45 \\
\hline $38 \mathrm{~b}$ & $5-\mathrm{F}, 7-\mathrm{F}$ & & 37 & 47 \\
\hline $38 \mathrm{c}$ & $5-\mathrm{F}, 7-\mathrm{F}$ & & 25 & 33 \\
\hline 38d & 5-F,7-F & & 32 & 30 \\
\hline $38 \mathrm{e}$ & 7-OMe & & 32 & 32 \\
\hline $38 \mathrm{f}$ & 6-Cl,7-OMe & & 32 & 30 \\
\hline $38 \mathrm{~g}$ & 5-F,7-F & & 69 & 48 \\
\hline $38 \mathrm{~h}$ & 5-F,7-F & & 54 & 50 \\
\hline $38 \mathrm{i}$ & 5-F,7-F & & 32 & 43 \\
\hline $38 \mathrm{j}$ & 5-F,7-F & & 41 & 20 \\
\hline $38 k$ & 5-F,7-F & & 43 & 25 \\
\hline 381 & $5-\mathrm{F}, 7-\mathrm{F}$ & & 41 & 37 \\
\hline
\end{tabular}

Scheme 9. Synthesis of Compounds 39a-c

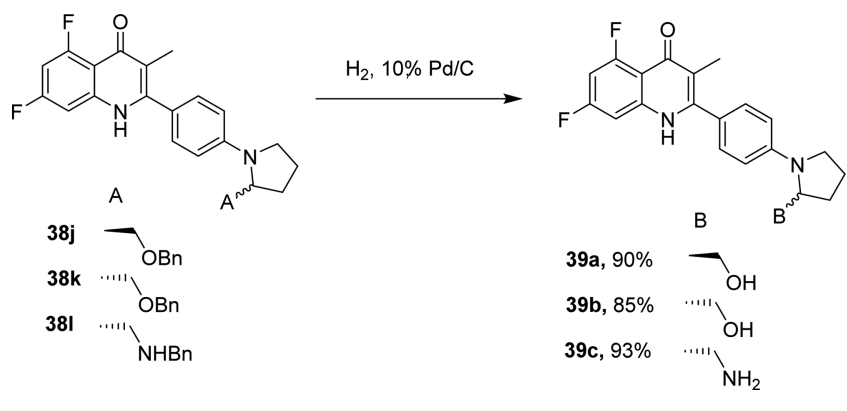

compound indicated solubility limited absorption as the PK did not increase linearly with dose from 10 to $50 \mathrm{mg} / \mathrm{kg}$. At this point, the acetate pro-drug strategy was deployed in an attempt to improve exposure.
Initial findings with both the 10 and $50 \mathrm{mg} / \mathrm{kg}$ dose of prodrug demonstrated a significant increase in overall exposure as indicated by a significantly increased AUC, $C_{\max }$ accompanied by increased bioavailability.

Metabolite ID work was undertaken to establish the metabolic activity exerted upon 46 (Figure 8 and Table 17).

In the study, five metabolites were detected in the urine and bile of SD rats dosed with 46 . These metabolites were named as M1 through to M5 based on their eluting time under HPLC conditions. Among the five metabolites, M1, M2, and M3 were identified as dihydroxy 42a, M4 was identified as hydroxylated 42a, and M5 was identified as active drug 42a. Location of the hydroxyl groups was established through mass spectrometry fragmentation patterns (see Supporting Information). M3 to M5 were detected both in urine and bile samples, and M1 and M2 were only detected in the bile sample.

The presence of the pro-drug in the rat urine indicates that the pro-drug does not completely break down to its active metabolites as predicted. As the plasma levels obtained are a measure of parent drug only, they are not a true representation of the drug levels present. Studies are currently underway to establish if a more suitable pro-drug can be synthesized that will resolve the issue and provide a compound suitable for in vivo efficacy testing.

\section{CONCLUSIONS}

To conclude, a 3-6 step synthesis of a range of 2-mono aryl amine 3-methyl quinolones with potent antituberculosis activity has been reported. Compounds have been developed that are metabolically stable and have a good pharmacokinetic and toxicological profile. Importantly, the lead compound 42a demonstrates equipotent activity against all drug sensitive and multidrug resistant strains of Mtb tested. Work continues to develop a suitable pro-drug to embark on in vivo efficacy studies.

\section{EXPERIMENTAL SECTION}

Chemistry. All reactions that employed moisture sensitive reagents were performed in dry solvent under an atmosphere of nitrogen in ovendried glassware. All reagents were purchased from Sigma-Aldrich or Alfa Aesar chemical companies and were used without purification. Thin layer chromatography (TLC) was carried out on Merck silica gel 60 F-254 plates, and UV inactive compounds were visualized using iodine or anisaldehyde solution. Flash column chromatography was performed on ICN Ecochrom 60 (32-63 mesh) silica gel eluting with various solvent mixtures and using an air line to apply pressure. NMR spectra were recorded on a Bruker AMX $400\left({ }^{1} \mathrm{H}, 400 \mathrm{MHz} ;{ }^{13} \mathrm{C}\right.$, $100 \mathrm{MHz})$ spectrometer. Chemical shifts are described on parts per million $(\delta)$ downfield from an internal standard of trimethylsilane. Mass spectra were recorded on a VG analytical 7070E machine and Fisons TRIO spectrometers using electron ionization (EI) and chemical

\section{Scheme 10. Synthesis of Quinolones $42 a-b^{a}$}

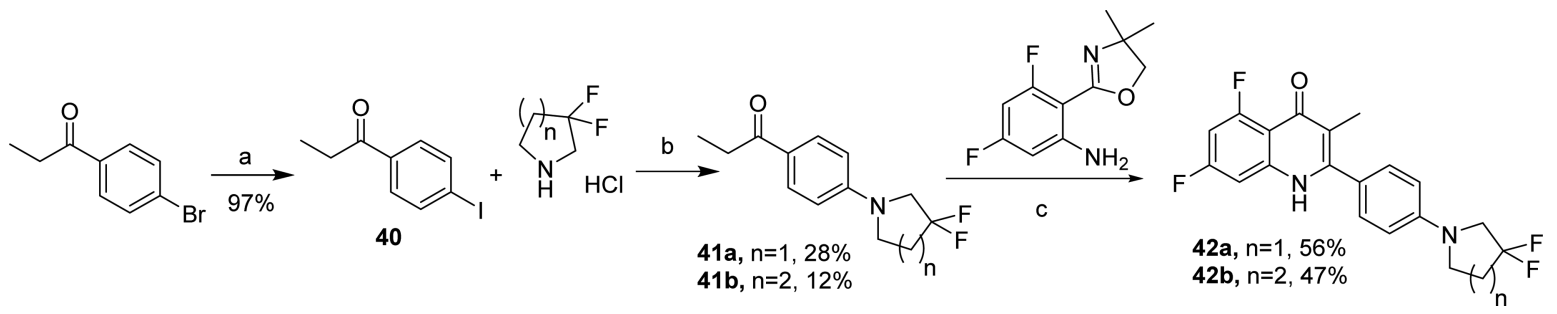

${ }^{a}$ Conditions and reagents: (a) CuI, N,N-dimethyl-1,2-diaminoethane, NaI, 1,4-dioxane, $110{ }^{\circ} \mathrm{C}, 24 \mathrm{~h}$; (b) $\mathrm{Pd}_{2}(\mathrm{dba})_{3}, \mathrm{Xantphos}, \mathrm{NaO}{ }^{t} \mathrm{Bu}, 1,4$-dioxane, $110{ }^{\circ} \mathrm{C}, 24 \mathrm{~h}$; (c) $\mathrm{CF}_{3} \mathrm{SO}_{3} \mathrm{H}, n-\mathrm{BuOH}, \mathrm{N}_{2}, 130{ }^{\circ} \mathrm{C}, 24 \mathrm{~h}$. 
Scheme 11. Synthesis of Quinolones 45a-g ${ }^{a}$

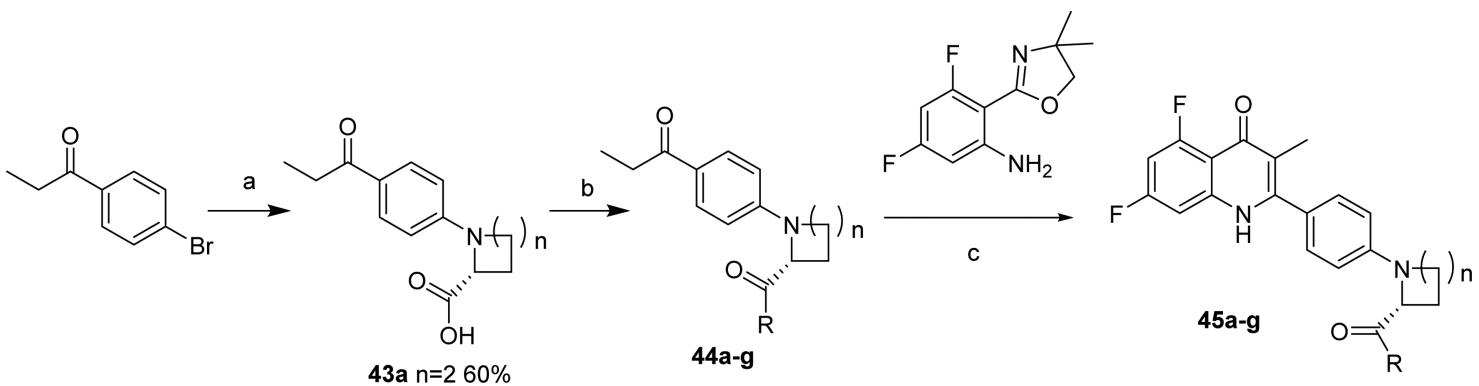

${ }^{a}$ Conditions and reagents: (a) D-proline, $\mathrm{CuI}, \mathrm{K}_{2} \mathrm{CO}_{3}, \mathrm{DMF}, 140{ }^{\circ} \mathrm{C}, 24 \mathrm{~h}$; (b) (i) EDC, N-hydroxysuccinamide, $\mathrm{CHCl}_{3}, \mathrm{NEt}_{3}$, amine, rt, $6 \mathrm{~h}$, (ii) amine, $\mathrm{NEt}_{3}, \mathrm{rt}, 2 \mathrm{~h}$; (c) $\mathrm{CF}_{3} \mathrm{SO}_{3} \mathrm{H}, n-\mathrm{BuOH}, \mathrm{N}_{2}, 130{ }^{\circ} \mathrm{C}, 24 \mathrm{~h}$.

Table 7. Yields for the Synthesis of Compounds $45 a-g$<smiles></smiles>

\begin{tabular}{ccccc}
\hline Compound & $\mathrm{R}$ & $\mathrm{n}$ & \% yield 44 & \% yield 45 \\
\hline $\mathbf{4 5 a}$ & $-\mathrm{NH}^{\mathrm{t}} \mathrm{Bu}$ & 2 & 52 & 20 \\
$\mathbf{4 5 b}$ & $-\mathrm{NMe}_{2}$ & 2 & 80 & 34 \\
$\mathbf{4 5 c}$ & 2 & 90 & 25 \\
$\mathbf{4 5 d}$ & 2 & 70 & 18 \\
$\mathbf{4 5 e}$ & $-\mathrm{NMe}_{2}$ & 1 & 65 & 24 \\
$\mathbf{4 5 f}$ & $-\mathrm{NHu}^{\mathrm{t}} \mathrm{Bu}$ & 1 & $45^{a}$ & 15 \\
$\mathbf{4 5 g}$ & & $-b$ & - & 12 \\
\hline
\end{tabular}

${ }^{a}$ Alternative methodology used please see Supporting Information. ${ }^{b}$ Used crude.

Scheme 12. Synthesis of Pro-drug $46^{a}$
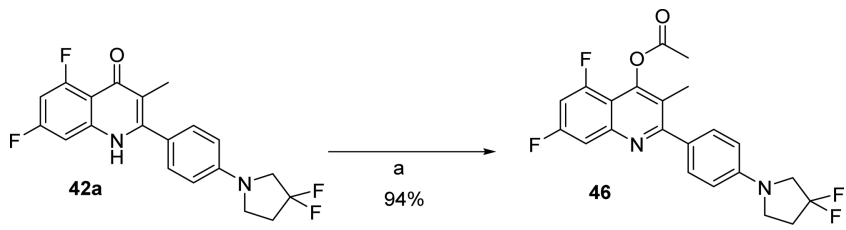

${ }^{a}$ (a) (i) ${ }^{t} \mathrm{BuOK}, \mathrm{THF}, \mathrm{rt}, 1 \mathrm{~h}$, (ii) acetyl chloride, rt, $3 \mathrm{~h}$.

ionization (CI). The optical rotation of the products were determined on PerkinElmer Polarimeter (model 343Plus), and data was collected and processed by Expert Read 1.00.02 software. All compounds were found to be $>95 \%$ pure by HPLC unless specified below. See Supporting Information for experimental methods and data relating to all intermediates.

Purity determination was performed by HPLC analysis using Agilent 1200 solvent delivery system. The HPLC methods used the following conditions: Knauer Eurospher 100-5 C18 $(250 \mathrm{~mm} \times 4.6 \mathrm{~mm})$ at $25^{\circ} \mathrm{C}$ with $1.5 \mathrm{~mL} / \mathrm{min}$ flow rate. Method A: $90 \%$ acetonitrile containing $0.05 \%$ trifluoroacetic acid and $10 \%$ water containing $0.05 \%$ trifluoroacetic acid. Method B: $80 \%$ methanol and 20\% acetonitrile.

General Procedure for the Preparation Ouinolones 1, 2, 7a-k, $17 a-l, 21 a-g, 24,32 a-g, 38 a-j, 42 a-b$, and 45a-g. Trifluoromethanesulfonic acid $(26 \mu \mathrm{L}, 0.31 \mathrm{mmol}, 0.2$ equiv) was added to oxazoline 4 ( $1.54 \mathrm{mmol})$ and the respective ketone $(1.54 \mathrm{mmol}, 1 \mathrm{eq})$ in anhydrous $n$-butanol $(10 \mathrm{~mL})$. The mixture was heated to $130{ }^{\circ} \mathrm{C}$ for
$24 \mathrm{~h}$ (followed by TLC). The reaction was cooled and the solvent removed under reduced pressure. Satd $\mathrm{NaHCO}_{3}(\mathrm{aq})$ was added and the resulting aqueous solution was extracted with ethyl acetate $(\times 3)$, the combined organic layers were washed with water and brine, dried over $\mathrm{MgSO}_{4}$, filtered, and concentrated to a yellow solid. The crude product was triturated with diethyl ether to give the desired quinolone. In cases where trituration was not possible, compounds were purified by flash column chromatography.

Preparation of 3-Methyl-2-(4-(piperidin-1-yl)phenyl)quinolin4(1H)-one 1. Light-yellow powder (yield 23\%); mp 290-292 ${ }^{\circ} \mathrm{C}$. ${ }^{1} \mathrm{H}$ NMR $\left(400 \mathrm{MHz}, \mathrm{CDCl}_{3}\right) \delta_{\mathrm{H}} 8.46(\mathrm{~s}, 1 \mathrm{H}, \mathrm{NH}), 8.35$ (d, $1 \mathrm{H}, J=$ $8.1 \mathrm{~Hz}, \mathrm{Ar}$ ), 7.59-7.52 (m, 1H, Ar), 7.36 (d, $2 \mathrm{H}, J=8.7 \mathrm{~Hz}, \mathrm{Ar}$ ), 7.30 (dd, $2 \mathrm{H}, J=15.1 \mathrm{H}, 7.2 \mathrm{~Hz}, \mathrm{Ar}), 6.96(\mathrm{~d}, 2 \mathrm{H}, J=8.7 \mathrm{~Hz}, \mathrm{Ar}), 2.10(3 \mathrm{H} \cdot$ $\left.\mathrm{CH}_{3}\right), 1.78-1.61\left(\mathrm{~m}, 10 \mathrm{H}, \mathrm{CH}_{2}\right) .{ }^{13} \mathrm{C} \mathrm{NMR}\left(100 \mathrm{MHz}, \mathrm{CDCl}_{3}\right) \delta_{\mathrm{C}}$ $179.1,152.9,148.0,139.4,131.8,129.9,126.7,125.5,124.0,123.5,117.4$, 116.5, 115.6, 50.0, 26.0, 13.0. MS (ES+), $[\mathrm{M}+\mathrm{H}]^{+}(100), 319.2$. HRMS calculated for 319.1810 $\mathrm{C}_{21} \mathrm{H}_{23} \mathrm{~N}_{2} \mathrm{O}$, found 319.1808. Anal.: $\mathrm{C}_{21} \mathrm{H}_{22} \mathrm{~N}_{2} \mathrm{O}$ requires C $79.21 \%$, H 6.96\%, N 8.80\%. Found: C 78.83\%, H 6.85\%, $\mathrm{N} 8.42 \%$.

Preparation of 7-Methoxy-3-methyl-2-(4-(piperidin-1-yl)phenyl)quinolin-4(1H)-one 2. Orange powder (yield 36\%); mp 278-280 ${ }^{\circ} \mathrm{C}$. ${ }^{1} \mathrm{H} \mathrm{NMR}\left(400 \mathrm{MHz}, \mathrm{CDCl}_{3}\right) \delta_{\mathrm{H}} 10.09(\mathrm{~s}, 1 \mathrm{H}, \mathrm{NH}), 8.16(\mathrm{~d}, 1 \mathrm{H}, J=$ $8.5 \mathrm{~Hz}, \mathrm{Ar}$ ), 7.39 (d, 2H, J $08.9 \mathrm{~Hz}, \mathrm{Ar}$ ), 7.10 (d, $2 \mathrm{H}, J=8.9 \mathrm{~Hz}, \mathrm{Ar}$ ), 6.92 $(\mathrm{dd}, 2 \mathrm{H}, J=8.5 \mathrm{~Hz}, 2.6 \mathrm{~Hz}, \mathrm{Ar}), 3.89\left(\mathrm{~s}, 3 \mathrm{H}, \mathrm{OCH}_{3}\right), 3.33-3.28(\mathrm{~m}, 2 \mathrm{H}$, $\left.\mathrm{CH}_{2}\right), 2.06\left(\mathrm{~s}, 3 \mathrm{H}, \mathrm{CH}_{3}\right), 1.80-1.61\left(\mathrm{~m}, 6 \mathrm{H}, \mathrm{CH}_{2}\right) .{ }^{13} \mathrm{C} \mathrm{NMR}$ $\left(100 \mathrm{MHz}, \mathrm{CDCl}_{3}\right) \delta_{\mathrm{C}} 176.4,161.8,152.8,129.5,126.5,124.7,115.3$, $114.7,114.3,97.7,54.7,25.3,24.1$ 11.4. MS (ES+), $[\mathrm{M}+\mathrm{H}]^{+}(100)$, 348.2. HRMS calculated for $348.1916 \mathrm{C}_{22} \mathrm{H}_{25} \mathrm{~N}_{3} \mathrm{O}$, found 348.2002. 
Table 8. Mtb IC $_{50}$ Values for Compounds 1, 2, 7a-k, 14a-c, and $15 \mathrm{a}-\mathrm{f}$

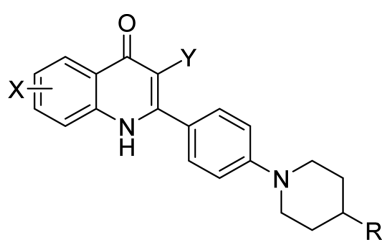

\begin{tabular}{|c|c|c|c|c|}
\hline compd & $\mathrm{X}$ & $\mathrm{Y}$ & $\mathrm{R}$ & Mtb $\mathrm{IC}_{50}(\mu \mathrm{M})$ \\
\hline 1 & $\mathrm{H}$ & $\mathrm{Me}$ & $\mathrm{H}$ & $1.50 \pm 0.19$ \\
\hline 2 & 7-OMe & $\mathrm{Me}$ & $\mathrm{H}$ & $0.73 \pm 0.01$ \\
\hline $7 a$ & $6-\mathrm{F}$ & $\mathrm{Me}$ & $\mathrm{H}$ & $1.83 \pm 0.22$ \\
\hline $7 \mathbf{b}$ & 6-OMe, 7-OMe & $\mathrm{Me}$ & $\mathrm{H}$ & $>10$ \\
\hline $7 \mathrm{c}$ & 6-Cl, 7-OMe & $\mathrm{Me}$ & $\mathrm{H}$ & $>10$ \\
\hline $7 \mathrm{~d}$ & 6-F, 7-OMe & $\mathrm{Me}$ & $\mathrm{H}$ & $0.52 \pm 0.06$ \\
\hline $7 \mathrm{e}$ & 5-OMe, 7-OMe & $\mathrm{Me}$ & $\mathrm{H}$ & $>10$ \\
\hline $7 f$ & 5-F, 7-F & $\mathrm{Me}$ & $\mathrm{H}$ & $0.27 \pm 0.08$ \\
\hline $7 \mathrm{~g}$ & $7-\mathrm{F}$ & $\mathrm{Me}$ & $\mathrm{H}$ & $>10$ \\
\hline $7 \mathrm{~h}$ & $7-\mathrm{Cl}$ & $\mathrm{Me}$ & $\mathrm{H}$ & $>10$ \\
\hline $7 \mathbf{i}$ & $\mathrm{H}$ & $\mathrm{Me}$ & $\mathrm{F}$ & $>10$ \\
\hline $7 \mathbf{j}$ & 7-OMe & $\mathrm{Me}$ & $\mathrm{F}$ & $1.32 \pm 0.10$ \\
\hline $7 \mathrm{k}$ & $5-F, 7-F$ & $\mathrm{Me}$ & $\mathrm{F}$ & $0.94 \pm 0.12$ \\
\hline $14 a$ & $\mathrm{H}$ & $\mathrm{H}$ & $\mathrm{H}$ & $>10$ \\
\hline $14 \mathrm{~b}$ & 7-OMe & $\mathrm{H}$ & $\mathrm{H}$ & $>10$ \\
\hline $14 \mathrm{c}$ & 7-OMe & $\mathrm{H}$ & $\mathrm{F}$ & $>10$ \\
\hline $15 a$ & $\mathrm{H}$ & $\mathrm{Cl}$ & $\mathrm{H}$ & $1.56 \pm 0.22$ \\
\hline $15 b$ & 7-OMe & $\mathrm{Cl}$ & $\mathrm{H}$ & $2.82 \pm 0.21$ \\
\hline $15 \mathrm{c}$ & 7-OMe & $\mathrm{Cl}$ & $\mathrm{F}$ & $>10$ \\
\hline $15 \mathrm{~d}$ & $\mathrm{H}$ & $\mathrm{Cl}$ & $\mathrm{F}$ & $>10$ \\
\hline $15 \mathrm{e}$ & $\mathrm{H}$ & $\mathrm{Br}$ & $\mathrm{H}$ & $0.60 \pm 0.09$ \\
\hline $15 f$ & $\mathrm{H}$ & $\mathrm{Br}$ & $\mathrm{F}$ & $>10$ \\
\hline
\end{tabular}

Anal.: $\mathrm{C}_{22} \mathrm{H}_{24} \mathrm{~N}_{2} \mathrm{O}_{2}$ requires C $75.83 \%, \mathrm{H}$ 6.94\%, N 8.04\%. Found: C $75.47 \%$, H $6.83 \%$, N $7.61 \%$.

Preparation of 6-Fluoro-3-methyl-2-(4-(piperidin-1-yl)phenyl)quinolin-4(1H)-one $7 a$. Orange powder (yield $26 \%$ ); mp 328$330{ }^{\circ} \mathrm{C} .{ }^{1} \mathrm{H}$ NMR $(400 \mathrm{MHz}, \mathrm{DMSO}) \delta_{\mathrm{H}} 11.53(\mathrm{~s}, 1 \mathrm{H}, \mathrm{NH}), 7.71$ (ddd, $1 \mathrm{H}, J=13.9 \mathrm{~Hz}, 9.3 \mathrm{~Hz}, 3.9 \mathrm{~Hz}, \mathrm{Ar}$ ), 7.51 (ddd, $1 \mathrm{H}, J=9.1 \mathrm{~Hz}$, $8.4 \mathrm{~Hz}, 3.0 \mathrm{~Hz}, \mathrm{Ar}), 7.38(\mathrm{~d}, 2 \mathrm{H}, J=8.9 \mathrm{~Hz}, \mathrm{Ar}), 7.07(\mathrm{~d}, 2 \mathrm{H}, J=8.9 \mathrm{~Hz}, \mathrm{Ar})$,
Table 10. Mtb $\mathrm{IC}_{50}$ Values for Compounds $21 \mathrm{a}-\mathrm{g}$

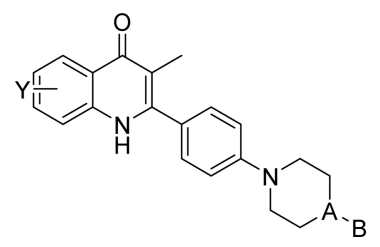

\begin{tabular}{cllcc} 
compd & \multicolumn{1}{c}{$\mathrm{X}$} & $\mathrm{A}$ & \multicolumn{1}{c}{$\mathrm{B}$} & $\mathrm{Mtb}_{50}(\mu \mathrm{M})$ \\
21a & $\mathrm{H}$ & $\mathrm{CH}$ & $\mathrm{CH}_{2} \mathrm{Ph}$ & $>10$ \\
21b & $6-\mathrm{F}$ & $\mathrm{CH}$ & $\mathrm{CH}_{2} \mathrm{Ph}$ & $>10$ \\
21c & $7-\mathrm{OMe}$ & $\mathrm{CH}$ & $\mathrm{CH}_{2} \mathrm{Ph}$ & $>10$ \\
21d & $\mathrm{H}$ & $\mathrm{N}$ & $\mathrm{CH}_{2} \mathrm{Ph}$ & $5.74 \pm 0.66$ \\
21e & $6-\mathrm{F}$ & $\mathrm{N}$ & $\mathrm{CH}_{2} \mathrm{Ph}$ & $>10$ \\
21f & $7-\mathrm{OMe}$ & $\mathrm{N}$ & $\mathrm{Ph}$ & $>10$ \\
21g & $7-\mathrm{OMe}$ & $\mathrm{N}$ & $\mathrm{CH}_{2} \mathrm{Ph}$ & $>10$ \\
\hline
\end{tabular}

3.30-3.26 (m, 4H, $\left.\mathrm{CH}_{2}\right), 1.95\left(\mathrm{~s}, 3 \mathrm{H}, \mathrm{CH}_{3}\right), 1.66-1.55\left(\mathrm{~m}, 6 \mathrm{H}, \mathrm{CH}_{2}\right)$. ${ }^{13} \mathrm{C}$ NMR $(100 \mathrm{MHz}, \mathrm{DMSO}) \delta_{\mathrm{C}} 176.2,157.1,152.2,148.6,136.6$, 130.2, 124.3, 121.2, 120.4, 115.0, 113.9,109.1, 49.1, 25.3, 24.3, 12.8. MS (ES+), $[\mathrm{M}+\mathrm{H}]^{+}(100)$, 337.2. HRMS calculated for 337.1716 $\mathrm{C}_{21} \mathrm{H}_{22} \mathrm{~N}_{2} \mathrm{OF}$, found 337.1728. Anal.: $\mathrm{C}_{21} \mathrm{H}_{21} \mathrm{~N}_{2} \mathrm{OF}$ requires $\mathrm{C} 74.98 \%$, H $6.29 \%$, N 8.33\%. Found: C 74.51\%, H 6.07\%, N 8.04\%.

Preparation of 6,7-Dimethoxy-3-methyl-2-(4-(piperidin-1-yl)phenyl)quinolin-4(1H)-one $7 b$. Very pale-yellow solid (yield $28 \%$ ). ${ }^{1} \mathrm{H}$ NMR $(400 \mathrm{MHz}, \mathrm{DMSO}) \delta_{\mathrm{H}} 11.24(\mathrm{~s}, 1 \mathrm{H}, \mathrm{NH}), 7.45$ (s, 1H, Ar), $7.36(\mathrm{~d}, J=8.8 \mathrm{~Hz}, 2 \mathrm{H}, \mathrm{Ar}), 7.16-6.98(\mathrm{~m}, 3 \mathrm{H}, \mathrm{Ar}), 3.83\left(\mathrm{~s}, 3 \mathrm{H}, \mathrm{OCH}_{3}\right)$, $3.82\left(\mathrm{~s}, 3 \mathrm{H}, \mathrm{OCH}_{3}\right), 3.29-3.25\left(\mathrm{~m}, 4 \mathrm{H}, \mathrm{CH}_{2}\right), 1.93\left(\mathrm{~s}, 3 \mathrm{H}, \mathrm{CH}_{3}\right), 1.69-$ $1.53\left(\mathrm{~m}, 6 \mathrm{H}, \mathrm{CH}_{2}\right) .{ }^{13} \mathrm{C}$ NMR $(101 \mathrm{MHz}, \mathrm{DMSO}) \delta_{\mathrm{C}} 175.90(\mathrm{C}=\mathrm{O})$, $152.89,152.05,146.82,146.54,135.51,130.19,124.73$, 117.34, 114.98, $113.15,104.50,99.38,55.86\left(\mathrm{OCH}_{3}\right), 55.79\left(\mathrm{OCH}_{3}\right), 49.20,25.35$, 24.32, $12.86\left(\mathrm{CH}_{3}\right)$. HRMS (ESI) $\mathrm{C}_{23} \mathrm{H}_{27} \mathrm{~N}_{2} \mathrm{O}_{3}[\mathrm{M}+\mathrm{H}]^{+}$requires 379.2022, found 379.2012 (100\%). Anal.: $\mathrm{C}_{23} \mathrm{H}_{26} \mathrm{~N}_{2} \mathrm{O}_{3}$ requires $\mathrm{C}$ $72.99 \%$, H 6.92\%, N 7.40\%. Found: C 71.98\%, H 6.96\%, N 6.96\%.

Preparation of 6-Chloro-7-methoxy-3-methyl-2-(4-(piperidin-1yl)phenyl)quinolin-4(1H)-one 7c. White solid (yield 35\%); mp $>300{ }^{\circ} \mathrm{C}$. ${ }^{1} \mathrm{H}$ NMR $(400 \mathrm{MHz}, \mathrm{DMSO}) \delta_{\mathrm{H}} 11.42(\mathrm{~s}, 1 \mathrm{H}, \mathrm{NH}), 8.02$ (s, $1 \mathrm{H}, \mathrm{Ar}), 7.38$ (d, $J=8.8 \mathrm{~Hz}, 2 \mathrm{H}, \mathrm{Ar}), 7.21(\mathrm{~s}, 1 \mathrm{H}, \mathrm{Ar}), 7.07$ (d, $J=$ $8.9 \mathrm{~Hz}, 2 \mathrm{H}, \mathrm{Ar}), 3.91\left(\mathrm{~s}, 3 \mathrm{H}, \mathrm{OCH}_{3}\right), 3.31-3.22\left(\mathrm{~m}, 4 \mathrm{H}, \mathrm{CH}_{2}\right), 1.93$ $\left(\mathrm{s}, 3 \mathrm{H}, \mathrm{CH}_{3}\right), 1.71-1.52\left(\mathrm{~m}, 6 \mathrm{H}, \mathrm{CH}_{2}\right) .{ }^{13} \mathrm{C}$ NMR $(101 \mathrm{MHz}, \mathrm{DMSO})$ $\delta_{\mathrm{C}} 175.63(\mathrm{C}=\mathrm{O}), 156.74,152.17,148.16,140.13,130.21,126.09$,

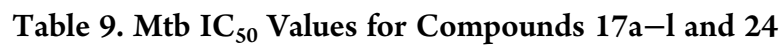

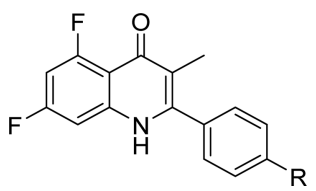

\begin{tabular}{|c|c|c|c|c|c|}
\hline Compound & $\mathrm{R}$ & $\mathrm{Mtb} \mathrm{IC}_{50}(\mu \mathrm{M})$ & Compound & $\mathrm{R}$ & Mtb $\mathrm{IC}_{50}(\mu \mathrm{M})$ \\
\hline $17 \mathbf{a}$ & & $>10$ & $17 \mathrm{~h}$ & & $0.47 \pm 0.02$ \\
\hline $17 \mathrm{~b}$ & & $0.61 \pm 0.05$ & $17 \mathbf{i}$ & & $>10$ \\
\hline $17 \mathrm{c}$ & & $>10$ & $17 \mathbf{j}$ & & $0.49 \pm 0-07$ \\
\hline $17 d$ & & $>10$ & $17 k$ & $-\mathrm{NHCH}_{2} \mathrm{Ph}$ & $>10$ \\
\hline $17 \mathrm{e}$ & & $0.31 \pm 0.03$ & 171 & $-N^{\prime}$ & $0.41 \pm 0.002$ \\
\hline $17 f$ & & $0.37 \pm 0.04$ & 24 & meta & $>10$ \\
\hline $17 \mathrm{~g}$ & & $0.47 \pm 0.03$ & & & \\
\hline
\end{tabular}


Table 11. Mtb $\mathrm{IC}_{50}$ Values for Compounds 32a-g, 38a-j, 39a-c, 42a-b, and 45a-g

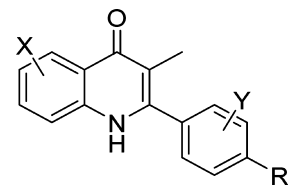

\begin{tabular}{|c|c|c|c|c|c|c|c|}
\hline Compound & $\bar{X}$ & $\overline{\mathrm{R}}$ & $\begin{array}{l}\mathrm{Mtb} \\
\mathrm{IC}_{50} \\
(\mu \mathrm{M})\end{array}$ & Compound & $\bar{X}$ & $\bar{R}$ & $\begin{array}{c}\mathrm{Mtb} \\
\mathrm{IC}_{50} \\
(\mu \mathrm{M})\end{array}$ \\
\hline $32 a$ & 5-F,7-F & $\mathrm{NC}$ & $>10$ & $38 \mathrm{i}$ & 5-F,7-F & & $>10$ \\
\hline 32b & $5-F, 7-F$ & & $>10$ & $38 \mathbf{j}$ & $5-\mathrm{F}, 7-\mathrm{F}$ & & $\begin{array}{c}0.96 \pm \\
0.06\end{array}$ \\
\hline $32 \mathrm{c}$ & $5-F, 7-F$ & & $>10$ & 39a & $5-\mathrm{F}, 7-\mathrm{F}$ & & $\begin{array}{c}1.59 \pm \\
0.05\end{array}$ \\
\hline 32d & $5-\mathrm{F}$ & & $\begin{array}{c}0.71 \pm \\
0.05\end{array}$ & 39b & 5-F,7-F & & $\begin{array}{c}0.32 \pm \\
0.04\end{array}$ \\
\hline $32 \mathrm{e}$ & $5-\mathrm{F}, 7-\mathrm{F}$ & & $\begin{array}{c}0.44 \pm \\
0.02\end{array}$ & $39 c$ & $5-\mathrm{F}, 7-\mathrm{F}$ & & $>10$ \\
\hline $32 f$ & $\begin{array}{c}5-\mathrm{F}, 7-\mathrm{F} \\
\mathrm{Y}=m-\mathrm{Cl}\end{array}$ & & $>10$ & $42 a$ & $5-\mathrm{F}, 7-\mathrm{F}$ & & $\begin{array}{c}0.53 \pm \\
0.08\end{array}$ \\
\hline $32 \mathrm{~g}$ & $\begin{array}{l}5-\mathrm{F}, 7-\mathrm{F} \\
\mathrm{Y}=o-\mathrm{F}\end{array}$ & & $>10$ & $42 b$ & 5-F,7-F & & $\begin{array}{c}0.36 \pm \\
0.04\end{array}$ \\
\hline 38a & $5-F, 7-F$ & & $\begin{array}{l}0.23 \pm \\
0.003\end{array}$ & $45 \mathbf{a}$ & $5-\mathrm{F}, 7-\mathrm{F}$ & & $\begin{array}{c}0.96 \pm \\
0.05\end{array}$ \\
\hline $38 b$ & $5-F, 7-F$ & & $\begin{array}{c}1.80 \pm \\
0.09\end{array}$ & $45 b$ & $5-\mathrm{F}, 7-\mathrm{F}$ & & $>10$ \\
\hline $38 c$ & $5-F, 7-F$ & & $\begin{array}{c}1.53 \pm \\
0.04\end{array}$ & $45 c$ & $5-\mathrm{F}, 7-\mathrm{F}$ & & $>10$ \\
\hline 38d & $5-F, 7-F$ & & $>10$ & $45 d$ & $5-\mathrm{F}, 7-\mathrm{F}$ & & $>10$ \\
\hline $38 \mathrm{e}$ & 7-OMe & & $>10$ & $45 e$ & $5-F, 7-F$ & & $>10$ \\
\hline $38 f$ & 6-Cl,7-OMe & & $>10$ & $45 f$ & $5-F, 7-F$ & & $>10$ \\
\hline $38 \mathrm{~g}$ & $5-F, 7-F$ & & $\begin{array}{c}5.01 \pm \\
0.03\end{array}$ & 45g & $5-\mathrm{F}, 7-\mathrm{F}$ & & $>10$ \\
\hline $38 \mathrm{~h}$ & $5-\mathrm{F}, 7-\mathrm{F}$ & & $>10$ & & & & \\
\hline
\end{tabular}

$124.18,118.08,117.91,114.89,114.25,100.13,56.59\left(\mathrm{OCH}_{3}\right), 49.10$, 25.32, 24.32, $12.70\left(\mathrm{CH}_{3}\right)$. HRMS (ESI) $\mathrm{C}_{22} \mathrm{H}_{24} \mathrm{~N}_{2} \mathrm{O}_{2}{ }^{35} \mathrm{Cl}[\mathrm{M}+\mathrm{H}]^{+}$ requires 383.1526, found $383.1513(100 \%), \mathrm{C}_{22} \mathrm{H}_{24} \mathrm{~N}_{2} \mathrm{O}_{2}{ }^{37} \mathrm{Cl}[\mathrm{M}+\mathrm{H}]^{+}$ requires 385.1497, found 385.1501 (34\%). Anal.: $\mathrm{C}_{22} \mathrm{H}_{23} \mathrm{~N}_{2} \mathrm{O}_{2} \mathrm{Cl}$ 


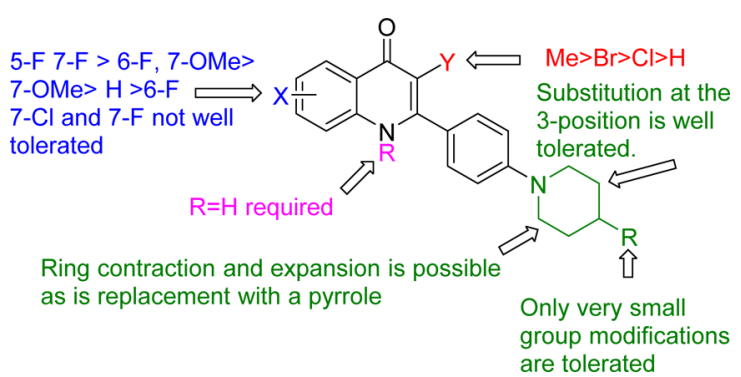

Figure 5. Overall SAR trends for the heterocyclic quinolone series.

Table 12. HEPG2 and Microsomal Turnover $t_{1 / 2}$ for Selected Analogues

\begin{tabular}{|c|c|c|c|c|c|}
\hline compd & Mtb $\mathrm{IC}_{50}(\mu \mathrm{M})$ & $\begin{array}{l}\mathrm{Mtb} \\
\mathrm{IC}_{90} \\
(\mu \mathrm{M})\end{array}$ & $\begin{array}{c}\text { HEPG2 } \\
\text { GLU } \\
(\mu \mathrm{M})\end{array}$ & $\begin{array}{l}\text { therapeutic } \\
\text { index }\end{array}$ & $\begin{array}{l}\text { microsomal } \\
\text { turnover }(\mathrm{h}, \mathrm{m} \text {, } \\
\mathrm{r}) t_{1 / 2}(\mathrm{~min})\end{array}$ \\
\hline $7 \mathrm{f}$ & $0.270 \pm 0.080$ & 0.78 & $>100$ & $>370$ & $\begin{array}{c}\text { h, } 7.31 \\
\text { m, } 8.27 \\
\text { r, } 8.30\end{array}$ \\
\hline $7 \mathrm{k}$ & $0.950 \pm 0.120$ & 1.83 & 102.2 & 108 & $\begin{array}{c}\text { h, } 5.7 \\
\text { m, } 4.4 \\
\text { r, } 8.4\end{array}$ \\
\hline $17 b$ & $0.611 \pm 0.048$ & 1.93 & $>100$ & $>164$ & $\begin{array}{c}\mathrm{h},<10 \\
\mathrm{~m},<10 \\
\mathrm{r},<10\end{array}$ \\
\hline $17 \mathrm{e}$ & $0.300 \pm 0.025$ & 0.56 & 188.1 & 627 & $\begin{array}{l}\text { h, } 7.8 \\
\text { m, } 6.8 \\
\text { r, } 10.1\end{array}$ \\
\hline $17 f$ & $0.367 \pm 0.040$ & 0.63 & $>100$ & $>272$ & $\begin{array}{c}\text { h, } 7.9 \\
\text { m, } 22.3 \\
\text { r, } 10.8\end{array}$ \\
\hline $17 \mathrm{~h}$ & $0.400 \pm 0.023$ & 0.66 & 85.54 & 223 & $\begin{array}{c}\text { h, } 8.54 \\
\text { m, } 7.65 \\
\text { r, } 5.72\end{array}$ \\
\hline $32 \mathrm{e}$ & $0.432 \pm 0.020$ & 0.69 & 141 & 342 & $\begin{array}{c}\text { h, } 10.2 \\
\text { m, } 20.7 \\
\text { r, } 30.1\end{array}$ \\
\hline $38 a$ & $0.231 \pm 0.036$ & 0.50 & 150.6 & 649 & $\begin{array}{l}\mathrm{h}, 10.2 \\
\mathrm{~m}, 4.4 \\
\mathrm{r}, 10.6\end{array}$ \\
\hline $38 d$ & $>10$ & $>10$ & ND & ND & $\begin{array}{c}\mathrm{h}, 60 \\
\mathrm{~m}, 60 \\
\mathrm{r}, 60\end{array}$ \\
\hline $42 a$ & $0.525 \pm 0.080$ & 1.10 & $>100$ & $>190$ & $\begin{array}{c}\text { h, } 72.8 \\
\text { m, } 114.9 \\
\text { r, } 61.6\end{array}$ \\
\hline $42 b$ & $0.361 \pm 0.041$ & 0.83 & ND & $\mathrm{ND}$ & $\begin{array}{c}\text { h, } 17.4 \\
\text { m, } 16.2 \\
\text { r, } 13.7\end{array}$ \\
\hline
\end{tabular}

requires C 69.01\%, H 6.05\%, N 7.32\%. Found: C 68.98\%, H 6.04\%, N 7.23\%.

Preparation of 6-Fluoro-7-methoxy-3-methyl-2-(4-(piperidin-1yl)phenyl)quinolin-4(1H)-one $7 d$. White solid (yield $41 \%) .{ }^{1} \mathrm{H}$ NMR $(400 \mathrm{MHz}, \mathrm{DMSO}) \delta_{\mathrm{H}} 11.39(\mathrm{~s}, 1 \mathrm{H}, \mathrm{NH}), 7.71(\mathrm{~d}, J=11.9 \mathrm{~Hz}, 1 \mathrm{H}, \mathrm{Ar})$, 7.37 (d, $J=8.7 \mathrm{~Hz}, 2 \mathrm{H}, \mathrm{Ar}$ ), 7.24 (d, $J=7.5 \mathrm{~Hz}, 1 \mathrm{H}, \mathrm{Ar}$ ), 7.07 (d, $J=$ $8.8 \mathrm{~Hz}, 2 \mathrm{H}, \mathrm{Ar}), 3.90\left(\mathrm{~s}, 3 \mathrm{H}, \mathrm{OCH}_{3}\right), 3.30-3.19\left(\mathrm{~m}, 4 \mathrm{H}, \mathrm{CH}_{2}\right), 1.92$ $\left(\mathrm{s}, 3 \mathrm{H}, \mathrm{CH}_{3}\right), 1.74-1.48\left(\mathrm{~m}, 6 \mathrm{H}, \mathrm{CH}_{2}\right) \cdot{ }^{13} \mathrm{C}$ NMR $(101 \mathrm{MHz}, \mathrm{DMSO})$ $\delta_{\mathrm{C}} 175.94(\mathrm{C}=\mathrm{O}), 152.15,151.00,150.87,150.35,147.88,137.55$, $130.20,124.30,114.93,113.57,110.03,101.12,56.36\left(\mathrm{OCH}_{3}\right)$, $49.13,25.33,24.32,12.70\left(\mathrm{CH}_{3}\right)$. HRMS (ESI) $\mathrm{C}_{22} \mathrm{H}_{24} \mathrm{~N}_{2} \mathrm{O}_{2} \mathrm{~F}$ $[\mathrm{M}+\mathrm{H}]^{+}$requires 367.1822, found 367.1818. Anal.: $\mathrm{C}_{22} \mathrm{H}_{23} \mathrm{~N}_{2} \mathrm{O}_{2} \mathrm{~F}$ requires C $72.11 \%$, H 6.33\%, N 7.64\%. Found: C 71.95\%, H 6.45\%, N 7.37\%.

Preparation of 5,7-Dimethoxy-3-methyl-2-(4-(piperidin-1-yl)phenyl)quinolin-4(1H)-one 7e. White solid (yield 32\%); mp 264$265{ }^{\circ} \mathrm{C} .{ }^{1} \mathrm{H}$ NMR $(400 \mathrm{MHz}, \mathrm{DMSO}) \delta_{\mathrm{H}} 10.93(\mathrm{~s}, 1 \mathrm{H}, \mathrm{NH}), 7.33(\mathrm{~d}, J=$ $8.7 \mathrm{~Hz}, 2 \mathrm{H}, \mathrm{Ar}), 7.05(\mathrm{~d}, J=8.7 \mathrm{~Hz}, 2 \mathrm{H}, \mathrm{Ar}), 6.64(\mathrm{~d}, J=2.2 \mathrm{~Hz}, 1 \mathrm{H}, \mathrm{Ar})$, $6.25(\mathrm{~d}, J=2.1 \mathrm{~Hz}, 1 \mathrm{H}, \mathrm{Ar}), 3.78\left(\mathrm{~s}, 3 \mathrm{H}, \mathrm{OCH}_{3}\right), 3.77\left(\mathrm{~s}, 3 \mathrm{H}, \mathrm{OCH}_{3}\right)$, 3.32-3.11 (m, 4H, $\left.\mathrm{CH}_{2}\right), 1.82\left(\mathrm{~s}, 3 \mathrm{H}, \mathrm{CH}_{3}\right), 1.70-1.48\left(\mathrm{~m}, 6 \mathrm{H}, \mathrm{CH}_{2}\right)$. ${ }^{13} \mathrm{C}$ NMR $(101 \mathrm{MHz}, \mathrm{DMSO}) \delta_{\mathrm{C}} 176.49(\mathrm{C}=\mathrm{O}), 161.75,161.03$, 152.02 , 145.53, 143.94, 130.15, 124.47, 115.49, 114.98, 109.24, 94.23, 91.57, $55.97\left(\mathrm{OCH}_{3}\right), 55.48\left(\mathrm{OCH}_{3}\right), 49.22,25.35,24.32,12.82\left(\mathrm{CH}_{3}\right)$. HRMS (ESI) $\mathrm{C}_{23} \mathrm{H}_{27} \mathrm{~N}_{2} \mathrm{O}_{2}[\mathrm{M}+\mathrm{H}]^{+}$requires 379.2022, found 379.2007. Anal.: $\mathrm{C}_{23} \mathrm{H}_{26} \mathrm{~N}_{2} \mathrm{O}_{2}$ requires $\mathrm{C} 72.99 \%, \mathrm{H} 6.92 \%$, N 7.40\%. Found: C $72.13 \%$, H 6.88\%, N 7.03\%.

Preparation of 5,7-Difluoro-3-methyl-2-(4-(piperidin-1-yl)phenyl)quinolin-4(1H)-one $7 f$. Off-white solid (0.25 g, 35\%); mp 305-306 ${ }^{\circ} \mathrm{C}$. ${ }^{1} \mathrm{H}$ NMR (400 MHz, DMSO) $\delta 11.50(\mathrm{bs}, 1 \mathrm{H}), 7.37$ (d, $J=8.8 \mathrm{~Hz}, 2 \mathrm{H}), 7.15$ (d, $J=9.2 \mathrm{~Hz}, 1 \mathrm{H}), 7.08(\mathrm{~d}, J=8.9 \mathrm{~Hz}, 2 \mathrm{H})$, $6.98(\mathrm{t}, J=9.6 \mathrm{~Hz}, 1 \mathrm{H}), 3.30(\mathrm{~m}, 4 \mathrm{H}), 1.88(\mathrm{~s}, 3 \mathrm{H}), 1.61(\mathrm{~m}, 6 \mathrm{H}) .{ }^{13} \mathrm{C}$ NMR $\left(100 \mathrm{MHz}, \mathrm{CDCl}_{3}\right) \delta_{\mathrm{C}} 175.2,152.1,148.6,130.2,116.1,114.9$, $100.2,49.2,25.3,24.3,12.6$. MS $\left(\mathrm{ES}^{+}\right) \mathrm{m} / z 355(\mathrm{M}+\mathrm{H})^{+}$. HRMS calculated for $355.1622 \mathrm{C}_{21} \mathrm{H}_{21} \mathrm{~N}_{2} \mathrm{OF}_{2}$, found 355.1625 . Purity HPLC 95\% (method A) $R_{\mathrm{t}}=2.34 \mathrm{~min}$.

Preparation of 7-Fluoro-3-methyl-2-(4-(piperidin-1-yl)phenyl)quinolin-4(1H)-one $7 \mathrm{~g}$. Off-white solid (0.15 g, 35\%); mp 343$345^{\circ} \mathrm{C} .{ }^{1} \mathrm{H}$ NMR $(400 \mathrm{MHz}, \mathrm{DMSO}) \delta 8.14(\mathrm{dd}, J=9.0,6.6 \mathrm{~Hz}, 1 \mathrm{H})$, $7.38(\mathrm{~d}, J=8.8 \mathrm{~Hz}, 2 \mathrm{H}), 7.30(\mathrm{dd}, J=10.5,2.3 \mathrm{~Hz}, 1 \mathrm{H}), 7.10(\mathrm{~m}, 1 \mathrm{H})$, $7.05(\mathrm{~d}, J=8.8 \mathrm{~Hz}, 2 \mathrm{H}), 3.28(\mathrm{~m}, 4 \mathrm{H}), 1.94(\mathrm{~s}, 3 \mathrm{H}), 1.62(\mathrm{~m}, 6 \mathrm{H}) .{ }^{13} \mathrm{C}$ NMR $(100 \mathrm{MHz}, \mathrm{DMSO}) \delta_{\mathrm{C}}$ not soluble in DMSO. MS $\left(\mathrm{ES}^{+}\right) \mathrm{m} / z 337$ $(\mathrm{M}+\mathrm{H})^{+}$. HRMS calculated for $337.1716 \mathrm{C}_{21} \mathrm{H}_{22} \mathrm{~N}_{2} \mathrm{OF}$, found 337.1722. Purity HPLC 97\% (method B) $R_{\mathrm{t}}=2.44$ min.

Preparation of 7-Chloro-3-methyl-2-(4-(piperidin-1-yl)phenyl)quinolin-4(1H)-one $7 h$. Off-white solid $(0.17 \mathrm{~g}, 37 \%) ; \mathrm{mp} 342-$ $343^{\circ} \mathrm{C} .{ }^{1} \mathrm{H}$ NMR $(400 \mathrm{MHz}, \mathrm{DMSO}) \delta 8.08(\mathrm{~d}, J=8.7 \mathrm{~Hz}, 1 \mathrm{H}), 7.59(\mathrm{~s}$ $1 \mathrm{H}), 7.40(\mathrm{~d}, J=8.8 \mathrm{~Hz}, 2 \mathrm{H}), 7.18(\mathrm{dd}, J=8.7,2.0 \mathrm{~Hz}, 1 \mathrm{H}), 7.04(\mathrm{~d}, J=$ $8.8 \mathrm{~Hz}, 2 \mathrm{H}), 3.08(\mathrm{~m}, 4 \mathrm{H}), 1.95(\mathrm{~s}, 3 \mathrm{H}), 1.61(\mathrm{~m}, 6 \mathrm{H}) .{ }^{13} \mathrm{C}$ NMR $\left(100 \mathrm{MHz}, \mathrm{CDCl}_{3}\right) \delta_{\mathrm{C}}$ not soluble in DMSO. MS $\left(\mathrm{ES}^{+}\right) \mathrm{m} / z 353$ $(\mathrm{M}+\mathrm{H})^{+}$. HRMS calculated for $353.1425 \mathrm{C}_{21} \mathrm{H}_{22} \mathrm{~N}_{2} \mathrm{O}^{35} \mathrm{Cl}$, found 353.1421. Purity HPLC 97\% (method A) $R_{\mathrm{t}}=2.07 \mathrm{~min}$.

Preparation of 2-(4-(4-Fluoropiperidin-1-yl)phenyl)-3-methylquinolin-4(1H)-one 7i. White solid $(0.18 \mathrm{~g}, 36 \%) .{ }^{1} \mathrm{H}$ NMR $(400 \mathrm{MHz}$, DMSO) $8.10(\mathrm{~d}, J=8.8 \mathrm{~Hz}, 1 \mathrm{H}), 7.57(\mathrm{~m}, 2 \mathrm{H}), 7.40(\mathrm{~d}, J=8.8 \mathrm{~Hz}, 2 \mathrm{H})$, $7.24(\mathrm{dd}, J=7.2,6.8 \mathrm{~Hz}, 1 \mathrm{H}), 7.11(\mathrm{~d}, J=8.8 \mathrm{~Hz}, 2 \mathrm{H}), 4.88(\mathrm{~d}, J=$ $48.8 \mathrm{~Hz}, 1 \mathrm{H}), 3.24(\mathrm{~m}, 4 \mathrm{H}), 2.03(\mathrm{~m}, 2 \mathrm{H}), 1.95(\mathrm{~s}, 3 \mathrm{H}), 1.80(\mathrm{~m}, 2 \mathrm{H})$. ${ }^{13} \mathrm{C}$ NMR (100 MHz, DMSO) $\delta_{\mathrm{C}} 176.4,150.7,130.6,130.0,124.9$, $123.3,122.1,119.0,114.8,113.8,89.4,87.8,44.6,44.5,30.5,30.3$, 12.6. MS $\left(\mathrm{ES}^{+}\right) m / z 337(\mathrm{M}+\mathrm{H})^{+}$. HRMS calculated for 337.1716 $\mathrm{C}_{21} \mathrm{H}_{22} \mathrm{~N}_{2} \mathrm{OF}$, found 337.1720. Purity HPLC 96\% (method A) $R_{\mathrm{t}}=$ $2.21 \mathrm{~min}$.

Preparation of 2-(4-(4-Fluoropiperidin-1-yl)phenyl)-7-methoxy-3methylquinolin-4(1H)-one 7j. Yellow solid (yield $43 \%$ ). ${ }^{1} \mathrm{H}$ NMR $(400 \mathrm{MHz}, \mathrm{DMSO}) \delta 11.26(\mathrm{~s}, 1 \mathrm{H}, \mathrm{NH}), 8.00(\mathrm{~d}, J=8.9 \mathrm{~Hz}, 1 \mathrm{H}, \mathrm{Ar})$, $7.39(\mathrm{~d}, J=8.6 \mathrm{~Hz}, 2 \mathrm{H}, \mathrm{Ar}), 7.12(\mathrm{~d}, J=8.6 \mathrm{~Hz}, 2 \mathrm{H}, \mathrm{Ar}), 7.05(\mathrm{~d}, J=$ $2.1 \mathrm{~Hz}, 1 \mathrm{H}, \mathrm{Ar}), 6.88(\mathrm{dd}, J=8.9,2.2 \mathrm{~Hz}, 1 \mathrm{H}, \mathrm{Ar}), 5.02-4.77(\mathrm{~m}, 1 \mathrm{H}$, $\mathrm{CH}), 3.82\left(\mathrm{~s}, 3 \mathrm{H}, \mathrm{OCH}_{3}\right), 3.57-3.44\left(\mathrm{~m}, 2 \mathrm{H}, \mathrm{CH}_{2}\right), 3.32-3.20(\mathrm{~m}, 2 \mathrm{H}$, $\left.\mathrm{CH}_{2}\right), 2.13-1.95\left(\mathrm{~m}, 2 \mathrm{H}, \mathrm{CH}_{2}\right), 1.91\left(\mathrm{~s}, 3 \mathrm{H}, \mathrm{CH}_{3}\right), 1.86-1.71(\mathrm{~m}, 2 \mathrm{H}$, $\left.\mathrm{CH}_{2}\right) \cdot{ }^{13} \mathrm{C}$ NMR (101 MHz, DMSO) $\delta 176.78(\mathrm{C}=\mathrm{O}), 161.89,151.28$, 147.80, 141.66, 130.39, 127.22, 125.12, 117.98, 115.22, 114.02, 113.14, 99.23, $89.01(\mathrm{~d}, J=169.4 \mathrm{~Hz}, \mathrm{C}-\mathrm{F}), 55.74,44.87(\mathrm{~d}, J=6.8 \mathrm{~Hz}), 30.84$ $(\mathrm{d}, J=19.0 \mathrm{~Hz}), 12.78\left(\mathrm{CH}_{3}\right)$. HRMS (ESI) $\mathrm{C}_{22} \mathrm{H}_{24} \mathrm{~N}_{2} \mathrm{O}_{2} \mathrm{~F}[\mathrm{M}+\mathrm{H}]^{+}$ requires 367.1822, found 367.1836. Anal.: $\mathrm{C}_{22} \mathrm{H}_{23} \mathrm{~N}_{2} \mathrm{O}_{2} \mathrm{~F}$ requires $\mathrm{C}$ $72.11 \%$, H 6.33\%, N 7.64\%. Found: C 71.32\%, H 6.34\%, N 7.46\%.

Preparation of 5,7-Difluoro-2-(4-(4-fluoropiperidin-1-yl)phenyl)3-methylquinolin-4(1H)-one $7 \boldsymbol{k}$. White solid $(29 \%) ; \mathrm{mp}>320{ }^{\circ} \mathrm{C} .{ }^{1} \mathrm{H}$ NMR (400 MHz, DMSO) $11.51(\mathrm{~s}, 1 \mathrm{H}), 7.40(\mathrm{~m}, 2 \mathrm{H}), 7.15(\mathrm{~m}, 3 \mathrm{H})$, $7.00(\mathrm{~m}, 1 \mathrm{H}), 3.49(\mathrm{~m}, 2 \mathrm{H}), 3.24(\mathrm{~m}, 2 \mathrm{H}), 2.0(\mathrm{~m}, 2 \mathrm{H}), 1.89(\mathrm{~s}, 3 \mathrm{H})$, $1.75(\mathrm{~m}, 2 \mathrm{H}) .{ }^{13} \mathrm{C}$ NMR $(100 \mathrm{MHz}, \mathrm{DMSO}) \delta_{\mathrm{C}}$ not soluble in DMSO. MS $\left(\mathrm{ES}^{+}\right) \mathrm{m} / z 373(\mathrm{M}+\mathrm{H})^{+}$HRMS calculated for 373.1519 $\mathrm{C}_{21} \mathrm{H}_{20} \mathrm{~N}_{2} \mathrm{OF}_{3}$, found 373.7528. Purity HPLC 97\% (method A) $R_{\mathrm{t}}=$ $2.18 \mathrm{~min}$. 


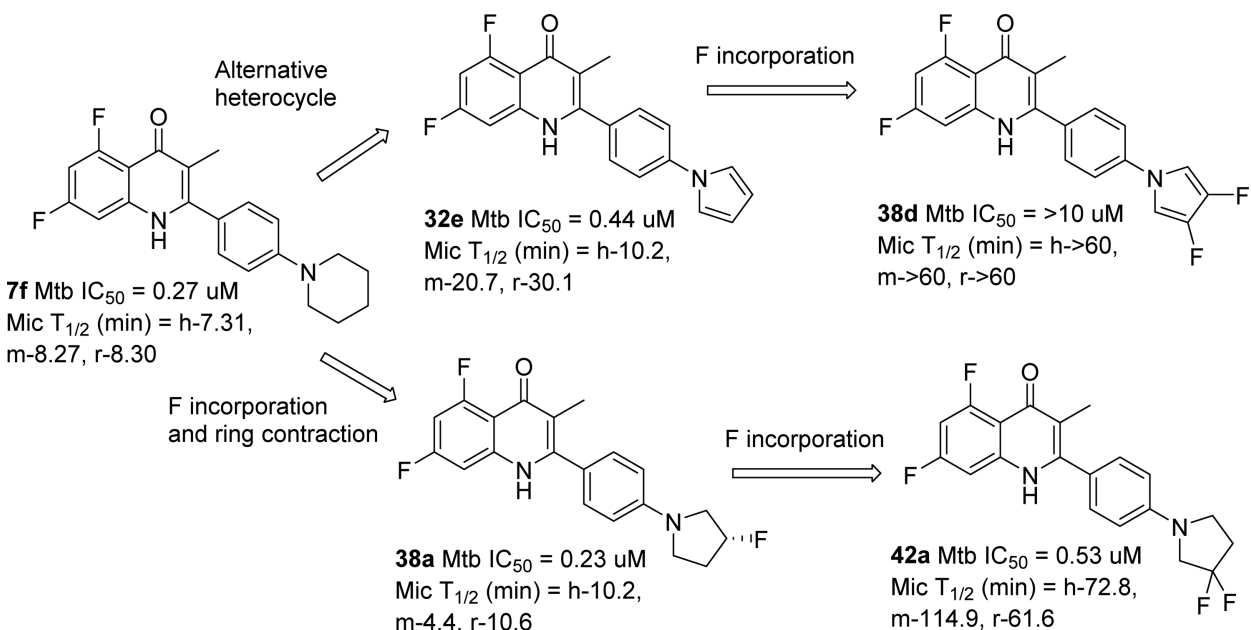

Figure 6. Resolution of metabolic stability problems.

Table 13. Caco-2 Permeability, Stability in Plasma, \% PPB, and Solubility Values for Selected Analogues

\begin{tabular}{|c|c|c|c|c|c|c|}
\hline \multirow[b]{2}{*}{ compd } & \multirow[b]{2}{*}{$\begin{array}{c}\text { Caco-2 } \\
\text { permeability } \\
\left(\mathrm{cm}^{-1} / \mathrm{s}\right)\end{array}$} & \multirow[b]{2}{*}{$\begin{array}{c}\text { stability in } \\
\text { plasma }(\mathrm{r}, \mathrm{h}) \\
T 1 / 2(\mathrm{~min})\end{array}$} & \multirow[b]{2}{*}{$\begin{array}{l}\text { human } \\
\text { PPB } \\
(\%)\end{array}$} & \multicolumn{3}{|c|}{ solubility $(\mu \mathrm{g} / \mathrm{mL})$} \\
\hline & & & & $\mathrm{pH} 1$ & $\mathrm{pH} 7.4$ & $\mathrm{CM}^{a}$ \\
\hline $5 \mathbf{k}$ & ND & $\begin{array}{l}\mathrm{r},>180 \\
\mathrm{~h},>180\end{array}$ & 95.82 & $>150$ & $<1$ & 12 \\
\hline $17 \mathrm{e}$ & $22.86 \times 10^{-6}$ & $\begin{array}{l}\mathrm{r},>180 \\
\mathrm{~h},>180\end{array}$ & 98.45 & $>150$ & $<1$ & 10 \\
\hline $32 \mathrm{e}$ & $30.97 \times 10^{-6}$ & $\begin{array}{l}\mathrm{r},>180 \\
\mathrm{~h},>180\end{array}$ & 96.1 & 5.1 & 3.6 & 61 \\
\hline $38 b$ & $15.51 \times 10^{-6}$ & $\begin{array}{l}\mathrm{r},>180 \\
\mathrm{~h},>180\end{array}$ & 98.97 & $<1$ & $<1$ & 2.5 \\
\hline $42 a$ & $10.00 \times 10^{-6}$ & $\begin{array}{l}\mathrm{r},>180 \\
\mathrm{~h},>180\end{array}$ & 97.30 & $<1$ & $<1$ & 55 \\
\hline
\end{tabular}

${ }^{a} \mathrm{CM}$, culture media: Middlebrook $7 \mathrm{H} 9$ broth with addition of $10 \%$ albumin-dextrose-catalase solution (Becton Dickinson), $0.2 \%$ [vol/ vol] glycerol, and $0.05 \%$ [vol/vol] Tween 80 .

Table 14. In Vitro DMPK Measurements for Selected Analogues

\begin{tabular}{|c|c|c|c|c|c|}
\hline compd & $\begin{array}{c}\text { aq } \\
\text { solubility } \\
(\mu \mathrm{M})\end{array}$ & $\begin{array}{l}\text { human } \\
\text { \% PPB }\end{array}$ & $\operatorname{LogD7.4}$ & $\begin{array}{c}\text { human } \\
\text { microsomes } \\
\mathrm{CL}_{\text {int }} \\
(\mu \mathrm{L} / \mathrm{min} / \mathrm{mg})\end{array}$ & $\begin{array}{l}\text { rat hepatocytes } \\
\mathrm{CL}_{\text {int }} \\
\left(\mu \mathrm{L} / \mathrm{min} / 10^{6}\right. \\
\text { cells })\end{array}$ \\
\hline $7 d$ & 2 & 98.8 & 3.9 & $>300.0$ & 231.3 \\
\hline $15 b$ & 0.5 & 98.8 & 3.6 & $>300.0$ & 48.9 \\
\hline $17 \mathrm{~g}$ & $<0.5$ & 99.5 & 4.7 & $>300.0$ & 183.4 \\
\hline $17 \mathrm{~h}$ & $<0.3$ & 99.3 & $>3.2$ & $>300.0$ & 91.2 \\
\hline $17 j$ & $<0.1$ & 99.4 & 4.8 & $>300.0$ & 243.4 \\
\hline $38 a$ & 0.9 & 99.1 & 3.8 & 174.9 & 117.6 \\
\hline $38 b$ & 1 & 98.6 & 3.6 & 197.4 & 150.1 \\
\hline $39 a$ & 4 & 95.5 & $>3.4$ & $>300.0$ & 36.5 \\
\hline $39 b$ & 4 & 95.5 & $>3.4$ & $>300.0$ & 36.5 \\
\hline $42 a$ & 0.2 & 99.7 & 4 & 89.7 & 52.2 \\
\hline
\end{tabular}

General Procedure for the Preparation of Compounds $14 a-c$. To a solution of ketone $13(0.24 \mathrm{mmol})$ in anhydrous 1,4-dioxane $(8 \mathrm{~mL})$ was added ground sodium hydroxide ( $30 \mathrm{mg}, 0.75 \mathrm{mmol}, 3$ equiv). The mixture was allowed to reflux at $110^{\circ} \mathrm{C}$ for $5 \mathrm{~h}$. The solution was cooled to room temperature and acidified by addition of $2 \mathrm{~N}$ hydrochloric acid. The solid was filtered and washed with water, followed by ethyl acetate and dried.
Table 15. Biological Profile of 42a<smiles>Cc1c(-c2ccc(N3CCC(F)(F)C3)cc2)[nH]c2cc(F)cc(F)c2c1=O</smiles>

42a

In Vitro Antituberculosis Activity

replicating sensitive $\mathrm{Mtb}_{\mathrm{IC}}(\mu \mathrm{M}) \quad 0.525$

replicating sensitive $\mathrm{Mtb}_{90}(\mu \mathrm{M}) \quad 1.10$

dormant (Wayne model) $\mathrm{Mtb} \mathrm{IC}_{90}(\mu \mathrm{M}) \quad 0.076$

MDR Mtb (05TB42059) $\mathrm{IC}_{50}(\mu \mathrm{M}) \quad 0.140$

MDR Mtb (DQ707(S315N kat G)) $\mathrm{IC}_{50}(\mu \mathrm{M}) \quad 0.548$ In Vitro DMPK

microsomal turnover (h, m, r) $T_{1 / 2}(\mathrm{~min}) \quad \mathrm{h}, 72.8 ; \mathrm{m}, 114.9 ; \mathrm{r}, 61.6$ microsomal $\mathrm{Cl}_{\text {int }}(\mathrm{h}, \mathrm{m}, \mathrm{r})(\mu \mathrm{L} / \mathrm{min} / \mathrm{mg}) \quad \mathrm{h}, 9.52 ; \mathrm{m}, 6.03 ; \mathrm{r}, 11.25$ Caco-2 permeability $\left(\mathrm{cm}^{-1} / \mathrm{s}\right)$ A to B $\quad 10.00 \times 10^{-6}$ Caco-2 permeability $\left(\mathrm{cm}^{-1} / \mathrm{s}\right) \mathrm{B}$ to A $\quad 9.8 \times 10^{-6}$ stability in plasma $(\mathrm{r}, \mathrm{h}) T_{1 / 2}(\mathrm{~min}) \quad \mathrm{r},>180 ; \mathrm{h},>180$ human \% PPB

solubility $(\mu \mathrm{g} / \mathrm{mL}) \mathrm{pH} 1, \mathrm{pH} 7.4, \mathrm{CM}$

CYP2C8 inhibition (\% at $10 \mu \mathrm{M}$ )

CYP2C9 inhibition (\% at $10 \mu \mathrm{M})$

97.30

CYP2D6 inhibition (\% at $10 \mu \mathrm{M})$

CYP3A4 inhibition (\% at $10 \mu \mathrm{M})$

CYP3A5 inhibition (\% at $10 \mu \mathrm{M})$

In Vitro Toxicity

HEPG2 $\mathrm{IC}_{50}$ GLU $(\mu \mathrm{M}) \quad>100$

TI $>190$

$\mathrm{hERG} \mathrm{IC}_{50}(\mu \mathrm{M}) \quad>25$

Ames $\quad-\mathrm{ve}$

Preparation of 2-(4-(Piperidin-1-yl)phenyl)quinolin-4(1H)-one 14a. White solid $(0.25 \mathrm{~g}, 70 \%)$; mp $350{ }^{\circ} \mathrm{C} .{ }^{1} \mathrm{H}$ NMR $(400 \mathrm{MHz}$, DMSO) $\delta 11.42(\mathrm{bs}, 1 \mathrm{H}), 8.07(\mathrm{~d}, J=8.0 \mathrm{~Hz}, 1 \mathrm{H}), 7.76(\mathrm{~d}, J=$ $8.3 \mathrm{~Hz}, 1 \mathrm{H}), 7.71(\mathrm{~d}, J=8.6 \mathrm{~Hz}, 2 \mathrm{H}), 7.64(\mathrm{dd}, J=8.3,7.0 \mathrm{~Hz}, 1 \mathrm{H})$, $7.30(\mathrm{dd}, J=8.3,7.0 \mathrm{~Hz}, 1 \mathrm{H}), 7.07(\mathrm{~d}, J=8.8 \mathrm{~Hz}, 2 \mathrm{H}), 6.29(\mathrm{~s}, 1 \mathrm{H})$, $3.33(\mathrm{~m}, 4 \mathrm{H}), 1.19(\mathrm{~m}, 6 \mathrm{H}) .{ }^{13} \mathrm{C}$ NMR $(100 \mathrm{MHz}, \mathrm{DMSO}) \delta_{\mathrm{C}}$ not soluble in DMSO. MS $\left(\mathrm{ES}^{+}\right) \mathrm{m} / z 305(\mathrm{M}+\mathrm{H})^{+}$. HRMS calculated for 305.1654 $\mathrm{C}_{20} \mathrm{H}_{21} \mathrm{~N}_{2} \mathrm{O}$, found 305.1662. Anal.: $\mathrm{C}_{20} \mathrm{H}_{20} \mathrm{~N}_{2} \mathrm{O}$ requires C 78.92\%, H 6.62\%, N 9.20\%. Found: C 78.67\%, H 6.55\%, N 8.89\%. 

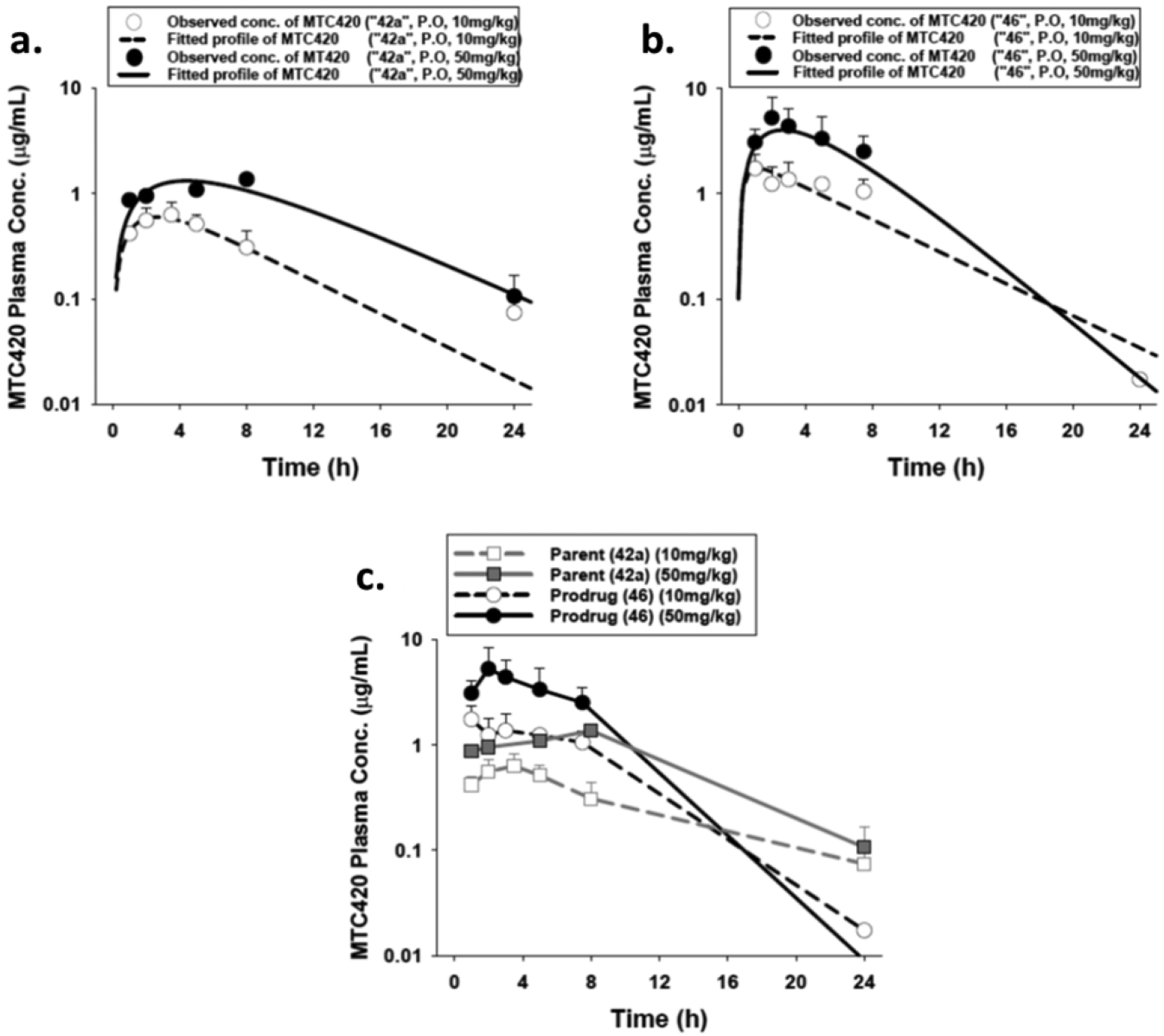

Figure 7. Pharmacokinetics after oral dosing of $42 a(a), 46$ (b), and an overlay of both (c).

Table 16. Pharmacokinetic Parameters for $42 \mathrm{a}$ and 46

\begin{tabular}{lcccccc} 
& \multicolumn{3}{c}{ parent 42a } & & \multicolumn{2}{c}{ pro-drug $\mathbf{4 6}^{\mathbf{a}}$} \\
\cline { 2 - 3 } \cline { 7 - 8 } \multicolumn{1}{c}{ dose $(\mathrm{mg} / \mathrm{kg})$} & $0.5(\mathrm{iv})$ & $10(\mathrm{po})$ & $50(\mathrm{po})$ & & $10(\mathrm{po})$ & $50(\mathrm{po})$ \\
$T_{1 / 2}(\mathrm{~h})$ & 1.48 & 3.8 & 4.2 & & 3.9 & 2.3 \\
$\mathrm{CL}(\mathrm{L} / \mathrm{h} / \mathrm{kg})$ & 0.524 & & & & \\
$V_{\mathrm{ss}}(\mathrm{L} / \mathrm{kg})$ & 0.291 & & & & \\
$C_{\max }(\mu \mathrm{g} / \mathrm{mL})$ & & 0.61 & 1.4 & & 1.7 & 4.0 \\
$\mathrm{AUC}(\mathrm{mg} \cdot \mathrm{h} / \mathrm{L})$ & 0.964 & 5.4 & 16.5 & & 12.3 & 29.6 \\
oral bioavailability $(\% \mathrm{~F})$ & $\mathrm{N} / \mathrm{A}$ & 28.0 & 17.1 & & 63.8 & 30.7
\end{tabular}

${ }^{a_{T}}$ These two studies were dosed with prodrug 46 orally, and measured for the parent 42a in plasma.

Preparation of 7-Methoxy-2-(4-(piperidin-1-yl)phenyl)quinolin4(1H)-one 14b. White solid (0.065 g, 41\%); mp $350{ }^{\circ} \mathrm{C} .{ }^{1} \mathrm{H}$ NMR $(400 \mathrm{MHz}, \mathrm{DMSO}) \delta 11.30$ (bs, $1 \mathrm{H}), 7.96(\mathrm{~d}, J=8.9 \mathrm{~Hz}, 1 \mathrm{H}), 7.69$ $(\mathrm{d}, J=8.7 \mathrm{~Hz}, 2 \mathrm{H}), 7.23(\mathrm{~d}, J=2.3 \mathrm{~Hz}, 1 \mathrm{H}), 7.07(\mathrm{~d}, J=8.9 \mathrm{~Hz}, 2 \mathrm{H})$, $6.89(\mathrm{dd}, J=8.0,4.0 \mathrm{~Hz}, 1 \mathrm{H}), 6.21(\mathrm{~s}, 1 \mathrm{H}), 3.86(\mathrm{~s}, 3 \mathrm{H}), 3.34(\mathrm{~m}, 4 \mathrm{H})$, $1.60(\mathrm{~m}, 6 \mathrm{H}) .{ }^{13} \mathrm{C}$ NMR $(100 \mathrm{MHz}, \mathrm{DMSO}) \delta_{\mathrm{C}}$ not soluble in DMSO. MS $\left(\mathrm{ES}^{+}\right) \mathrm{m} / z 335(\mathrm{M}+\mathrm{H})^{+}$. HRMS calculated for $335.1760 \mathrm{C}_{21} \mathrm{H}_{23} \mathrm{~N}_{2} \mathrm{O}_{2}$, found 335.1761 . Purity HPLC $96 \%\left(\operatorname{method}\right.$ A) $R_{\mathrm{t}}=1.81 \mathrm{~min}$.

Preparation of 2-(4-(4-Fluoropiperidin-1-yl)phenyl)-7-methoxyquinolin-4(1H)-one 14c. Yellow solid (yield $68 \%$ ). ${ }^{1} \mathrm{H}$ NMR $(400 \mathrm{MHz}, \mathrm{DMSO}) \delta_{\mathrm{H}} 13.70(\mathrm{~s}, 1 \mathrm{H}, \mathrm{NH}), 8.18(\mathrm{~d}, J=9.2 \mathrm{~Hz}, 1 \mathrm{H}$, Ar), 7.88 (d, $J=9.0 \mathrm{~Hz}, 2 \mathrm{H}, \mathrm{Ar}$ ), 7.58 (d, $J=2.3 \mathrm{~Hz}, 1 \mathrm{H}, \mathrm{Ar}$ ), 7.34 (dd, $J=9.2,2.4 \mathrm{~Hz}, 1 \mathrm{H}, \mathrm{Ar}), 7.31-7.19(\mathrm{~m}, 3 \mathrm{H}, \mathrm{Ar}), 4.93$ (dtt, $J=48.9$, 7.0, 3.4 Hz, $1 \mathrm{H}, \mathrm{CH}), 3.98\left(\mathrm{~s}, 3 \mathrm{H}, \mathrm{OCH}_{3}\right), 3.71-3.58\left(\mathrm{~m}, 2 \mathrm{H}, \mathrm{CH}_{2}\right)$, $3.51-3.37\left(\mathrm{~m}, 2 \mathrm{H}, \mathrm{CH}_{2}\right), 2.10-1.88\left(\mathrm{~m}, 2 \mathrm{H}, \mathrm{CH}_{2}\right), 1.87-1.68(\mathrm{~m}, 2 \mathrm{H}$, $\mathrm{CH}_{2}$ ). HRMS (ESI) $\mathrm{C}_{21} \mathrm{H}_{22} \mathrm{~N}_{2} \mathrm{O}_{2} \mathrm{~F}[\mathrm{M}+\mathrm{H}]^{+}$requires 353.1665 , found 353.1667. Anal.: $\mathrm{C}_{21} \mathrm{H}_{21} \mathrm{~N}_{2} \mathrm{O}_{2} \mathrm{~F}$ requires $\mathrm{C} 71.57 \%, \mathrm{H} 6.01 \%$, N 7.95\%. Found: C 71.12\%, H 5.93\%, N 7.71\%.
General Procedure for the Preparation of Compounds 15a-d. Quinolone $14(0.33 \mathrm{mmol})$ was added to $\mathrm{MeOH}(20 \mathrm{~mL}), 2 \mathrm{M} \mathrm{NaOH}$ $(4 \mathrm{~mL})$, and water $(4 \mathrm{~mL})$. Sodium dichloroisocyanurate $(36 \mathrm{mgs}, 0.17$ mmol, 0.5 equiv) was added at room temperature, and the resultant light-orange solution was allowed to stir overnight. The solvent was removed in vacuo and the residue was dissolved in EtOAc $(100 \mathrm{~mL})$, followed by washing with water $(50 \mathrm{~mL})$ and brine $(50 \mathrm{~mL})$. The crude product was purified by column chromatography (eluting with $100 \%$ EtOAc) to afford the desired product.

Preparation of 3-Chloro-2-(4-(piperidin-1-yl)phenyl)quinolin4(1H)-one 15a. White solid (40 mgs, 40\%). ${ }^{1} \mathrm{H}$ NMR (400 MHz, DMSO) $\delta 12.01(\mathrm{bs}, 1 \mathrm{H}), 8.15(\mathrm{~d}, J=7.9 \mathrm{~Hz}, 1 \mathrm{H}), 7.69(\mathrm{~m} \mathrm{2H}), 7.52$ $(\mathrm{d}, J=8.7 \mathrm{~Hz}, 2 \mathrm{H}), 7.38(\mathrm{~m}, 1 \mathrm{H}), 7.09(\mathrm{~d}, J=8.8 \mathrm{~Hz}, 2 \mathrm{H}), 3.33(\mathrm{~m}, 4 \mathrm{H})$, $1.61(\mathrm{~m}, 6 \mathrm{H}) .{ }^{13} \mathrm{C}$ NMR $(100 \mathrm{MHz}, \mathrm{DMSO}) \delta_{\mathrm{C}} 171.7,152.5,148.7$, 139.3, 132.2, 130.7, 125.4, 124.0, 123.8, 122.1, 118.9, 114.5, 113.2, 48.9, 25.3, 24.3. MS $\left(\mathrm{ES}^{+}\right) \mathrm{m} / z 339(\mathrm{M}+\mathrm{H})^{+}$HRMS calculated for 339.1264 $\mathrm{C}_{20} \mathrm{H}_{20} \mathrm{~N}_{2} \mathrm{O}^{35} \mathrm{Cl}$, found 339.1252 . Purity HPLC $98 \%(\operatorname{method} \mathrm{A}) R_{\mathrm{t}}=$ $2.13 \mathrm{~min}$.

Preparation of 3-Chloro-7-methoxy-2-(4-(piperidin-1-yl)phenyl)quinolin-4(1H)-one 15b. White solid (27 mgs, 61\%). ${ }^{1} \mathrm{H}$ NMR $(400 \mathrm{MHz}, \mathrm{DMSO}) \delta 11.82(\mathrm{bs}, 1 \mathrm{H}), 8.04(\mathrm{~d}, J=9.0 \mathrm{~Hz}, 1 \mathrm{H}), 7.52$ $(\mathrm{d}, J=8.8 \mathrm{~Hz}, 2 \mathrm{H}), 7.11(\mathrm{~m}, 3 \mathrm{H}), 6.99(\mathrm{dd}, J=9.2,2.4 \mathrm{~Hz}, 1 \mathrm{H}), 3.85$ $(\mathrm{s}, 3 \mathrm{H}), 3.33(\mathrm{~m}, 4 \mathrm{H}), 1.61(\mathrm{~m}, 6 \mathrm{H}) \cdot{ }^{13} \mathrm{C}$ NMR $(100 \mathrm{MHz}, \mathrm{DMSO}) \delta_{\mathrm{C}}$ 162.3 , 148.1, 141.1, 130.6, 127.3, 118.2, 114.7, 114.2, 112.9, 99.7, 55.8, 49.1, 25.2, 24.2. MS $\left(\mathrm{ES}^{+}\right) \mathrm{m} / z 369(\mathrm{M}+\mathrm{H})^{+} \mathrm{HRMS}$ calculated for $369.1370 \mathrm{C}_{21} \mathrm{H}_{22} \mathrm{~N}_{2} \mathrm{O}_{2}{ }^{35} \mathrm{Cl}$, found 369.1375 . Purity HPLC $99 \%$ (method A) $R_{\mathrm{t}}=1.83 \mathrm{~min}$.

Preparation of 3-Chloro-2-(4-(4-fluoropiperidin-1-yl)phenyl)-7methoxyquinolin-4(1H)-one 15c. Yellow solid (yield 52\%); mp 304-306 ${ }^{\circ} \mathrm{C} .{ }^{1} \mathrm{H}$ NMR $(400 \mathrm{MHz}, \mathrm{DMSO}) \delta_{\mathrm{H}} 11.86(\mathrm{~s}, 1 \mathrm{H}, \mathrm{NH})$, $8.03(\mathrm{~d}, J=9.0 \mathrm{~Hz}, 1 \mathrm{H}, \mathrm{Ar}), 7.52(\mathrm{~d}, J=8.8 \mathrm{~Hz}, 2 \mathrm{H}, \mathrm{Ar}), 7.14$ (d, $J=$ $8.9 \mathrm{~Hz}, 2 \mathrm{H}, \mathrm{Ar}$ ), 7.10 (d, $J=2.3 \mathrm{~Hz}, 1 \mathrm{H}, \mathrm{Ar}), 6.98$ (dd, $J=9.0,2.4 \mathrm{~Hz}$, 

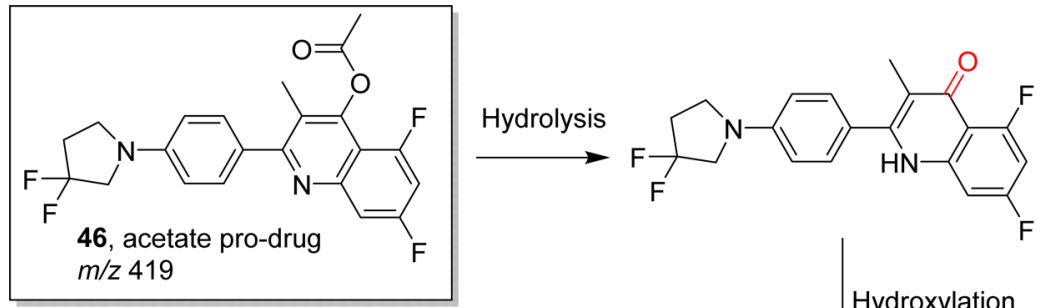

M5 - 42a, parent

$\mathrm{m} / \mathrm{z} 377$

urine and bile

Hydroxylation
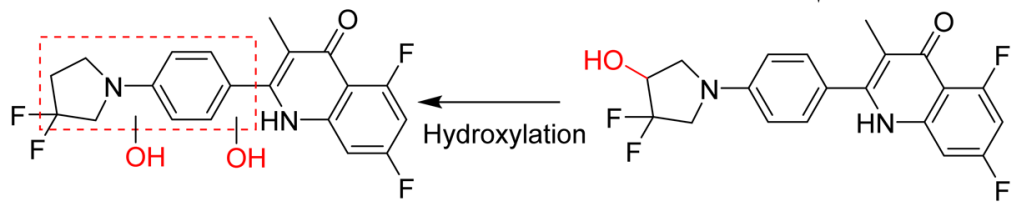

M4

$m / z 393$

urine and bile

M1 and M2, $m / z 409$ bile

M3, $m / z$ 409, urine and bile

Figure 8. Metabolic Pathways of Pro-drug 46 in SD Rat Urine and Bile.

Table 17. Identified Metabolites of Pro-drug 46 in SD Rat Urine and Bile (MS)

\begin{tabular}{|c|c|c|c|c|c|c|}
\hline \multirow[b]{2}{*}{ peak ID } & \multirow[b]{2}{*}{ mass shift } & \multirow[b]{2}{*}{ found $m / z$} & \multirow[b]{2}{*}{ biotransformation } & \multirow[b]{2}{*}{$\mathrm{RT}(\min )$} & \multicolumn{2}{|c|}{ relative MS abundance } \\
\hline & & & & & bile & urine \\
\hline 46 & 0 & 419 & parent & 14.3 & ND & $1.85 \times 10^{07}$ \\
\hline M1 & -10 & 409 & hydrolysis/hydroxylation & 8.6 & $5.89 \times 10^{6}$ & ND \\
\hline M2 & -10 & 409 & hydrolysis/hydroxylation & 9.2 & $4.21 \times 10^{6}$ & ND \\
\hline M3 & -10 & 409 & hydrolysis/hydroxylation & 9.9 & $5.92 \times 10^{7}$ & $2.61 \times 10^{7}$ \\
\hline M4 & -26 & 393 & hydrolysis/hydroxylation & 10.1 & $2.12 \times 10^{7}$ & $3.80 \times 10^{6}$ \\
\hline M5-42a & -42 & 377 & hydrolysis & 11.4 & $5.36 \times 10^{6}$ & $6.12 \times 10^{6}$ \\
\hline
\end{tabular}

$1 \mathrm{H}, \mathrm{Ar}), 4.90(\mathrm{dtt}, J=21.4,7.3,3.6 \mathrm{~Hz}, 1 \mathrm{H}, \mathrm{CH}), 3.84\left(\mathrm{~s}, 3 \mathrm{H}, \mathrm{OCH}_{3}\right)$, $3.63-3.46(\mathrm{~m}, 2 \mathrm{H}), 3.34-3.19(\mathrm{~m}, 2 \mathrm{H}), 2.13-1.90(\mathrm{~m}, 2 \mathrm{H}), 1.85-1.58$ (m, 2H). ${ }^{13} \mathrm{C}$ NMR (101 MHz, DMSO) $\delta_{\mathrm{C}} 171.31(\mathrm{C}=\mathrm{O}), 162.33$ (C-O), 151.61, 148.08, 141.06, 130.67, 127.30, 122.71, 118.20, 114.66, $114.20,112.89,99.63,88.89$ (d, $J=169.5 \mathrm{~Hz}, \mathrm{C}-\mathrm{F}), 55.81,44.53$ (d, $J=$ $6.8 \mathrm{~Hz}$ ), $30.69(\mathrm{~d}, J=19.1 \mathrm{~Hz})$. HRMS (ESI) $\mathrm{C}_{21} \mathrm{H}_{21} \mathrm{~N}_{2} \mathrm{O}_{2} \mathrm{~F}^{35} \mathrm{Cl}$ $[\mathrm{M}+\mathrm{H}]^{+}$requires 387.1276, found 387.1287. Anal.: $\mathrm{C}_{21} \mathrm{H}_{20} \mathrm{~N}_{2} \mathrm{O}_{2} \mathrm{FCl}$ requires C 65.20\%, H 5.21\%, N 7.24\%. Found: C 64.90\%, H 5.35\%, N 6.95\%.

Preparation of 3-Chloro-2-(4-(4-fluoropiperidin-1-yl)phenyl)quinolin-4(1H)-one 15d. Light-yellow solid (0.19 g, 58\%). ${ }^{1} \mathrm{H}$ NMR $(400 \mathrm{MHz}, \mathrm{DMSO}) 12.05(\mathrm{bs}, 1 \mathrm{H}), 8.15(\mathrm{~d}, J=8.0 \mathrm{~Hz}, 1 \mathrm{H}), 7.70(\mathrm{~d}, J=$ $4.0 \mathrm{~Hz}, 2 \mathrm{H}), 7.54(\mathrm{~d}, J=8.8 \mathrm{~Hz}, 2 \mathrm{H}), 7.38(\mathrm{~m}, 1 \mathrm{H}), 7.15(\mathrm{~d}, J=8.8 \mathrm{~Hz}$, $2 \mathrm{H}), 4.89(\mathrm{~d}, J=48.0 \mathrm{~Hz}, 1 \mathrm{H}), 3.53(\mathrm{~m}, 2 \mathrm{H}), 3.30(\mathrm{~m}, 2 \mathrm{H}), 1.97(\mathrm{~m}$, $2 \mathrm{H}), 1.79(\mathrm{~m}, 2 \mathrm{H}) .{ }^{13} \mathrm{C}$ NMR (100 MHz, DMSO) $\delta_{\mathrm{C}} 175.2,150.8$, 128.5, 127.9, 127.3, 124.6, 115.4, 103.9, 89.9, 88.2, 79.6, 66.7, 45.2, 45.1, 31.0, 30.8, 15.5. MS $\left(\mathrm{ES}^{+}\right) \mathrm{m} / z 357(\mathrm{M}+\mathrm{H})^{+}$. HRMS calculated for $357.1170 \mathrm{C}_{20} \mathrm{H}_{19} \mathrm{~N}_{2} \mathrm{OF}^{35} \mathrm{Cl}$, found 357.1159 . Purity HPLC $95 \%$ (method A) $R_{\mathrm{t}}=2.15 \mathrm{~min}$.

General Procedure for the Preparation of Compounds 15e-f. Quinolone $14(0.33 \mathrm{mmol})$ was added to DCM $(15 \mathrm{~mL})$ and $\mathrm{MeOH}$ $(4 \mathrm{~mL})$. NBS ( $58 \mathrm{mgs}, 0.33 \mathrm{mmol}$ ) was added at room temperature, and the resultant bright-yellow solution was allowed to stir overnight. The solvent was removed in vacuo, and the residue was dissolved in EtOAc $(100 \mathrm{~mL})$, followed by washing with water $(50 \mathrm{~mL})$ and brine $(50 \mathrm{~mL})$. The crude product was purified by column chromatography (eluting with $70 \%$ EtOAc in $n$-hexanes) to afford the desired product.

Preparation of 3-Bromo-2-(4-(piperidin-1-yl)phenyl)quinolin$4(1 \mathrm{H})$-one 15e. White solid (63\%). ${ }^{1} \mathrm{H}$ NMR (400 MHz, DMSO) $\delta$ $12.07(\mathrm{bs}, 1 \mathrm{H}), 8.15(\mathrm{~d}, J=8.1 \mathrm{~Hz}, 1 \mathrm{H}), 7.68(\mathrm{~m} 2 \mathrm{H}), 7.49(\mathrm{~d}, J=8.8 \mathrm{~Hz}$, $2 \mathrm{H}), 7.39$ (ddd, $J=8.6,7.9,4.1 \mathrm{~Hz}, 1 \mathrm{H}), 7.08(\mathrm{~d}, J=8.8 \mathrm{~Hz}, 2 \mathrm{H}), 3.31$ $(\mathrm{m}, 4 \mathrm{H}), 1.62(\mathrm{~m}, 6 \mathrm{H}) .{ }^{13} \mathrm{C}$ NMR $(100 \mathrm{MHz}, \mathrm{DMSO}) \delta_{\mathrm{C}} 172.1,152.5$, $150.4,139.4,132.3,130.6,125.6,124.2,124.0,123.2,118.8,114.5,105.5$, 49.0, 25.3, 24.4. MS $\left(\mathrm{ES}^{+}\right) \mathrm{m} / z 383(\mathrm{M}+\mathrm{H})^{+}$. HRMS calculated for 383.0759 $\mathrm{C}_{20} \mathrm{H}_{20} \mathrm{~N}_{2} \mathrm{O}^{79} \mathrm{Br}$, found 383.0748. Purity HPLC $98 \%$ (method A) $R_{\mathrm{t}}=1.75 \mathrm{~min}$.
Preparation of 3-Bromo-2-(4-(4-fluoropiperidin-1-yl)phenyl)quinolin-4(1H)-one $15 f$. Light-yellow solid $(0.20 \mathrm{~g}, 55 \%) .{ }^{1} \mathrm{H}$ NMR (400 MHz, DMSO) 12.26 (bs, $1 \mathrm{H}), 8.15$ (d, $J=8.8 \mathrm{~Hz}, 1 \mathrm{H}), 7.69$ $(\mathrm{m}, 1 \mathrm{H}), 7.50(\mathrm{~d}, J=8.8 \mathrm{~Hz}, 2 \mathrm{H}), 7.39(\mathrm{~m}, 2 \mathrm{H}), 7.14(\mathrm{~d}, J=8.8 \mathrm{~Hz}, 2 \mathrm{H})$, $4.89(\mathrm{~d}, J=48.0 \mathrm{~Hz}, 1 \mathrm{H}), 3.53(\mathrm{~m}, 2 \mathrm{H}), 3.30(\mathrm{~m}, 2 \mathrm{H}), 1.97(\mathrm{~m}, 2 \mathrm{H})$, $1.79(\mathrm{~m}, 2 \mathrm{H}) .{ }^{13} \mathrm{C}$ NMR $(100 \mathrm{MHz}, \mathrm{DMSO}) \delta_{\mathrm{C}} 179.7,150.3,132.3,130.2$, 125.6, 124.5, 114.6, 105.6, 89.7, 88.1, 44.6, 44.5, 30.8, 15.5. MS $\left(\mathrm{ES}^{+}\right) \mathrm{m} / z$ $401(\mathrm{M}+\mathrm{H})^{+}$. HRMS calculated for $401.0665 \mathrm{C}_{20} \mathrm{H}_{19} \mathrm{~N}_{2} \mathrm{OF}^{79} \mathrm{Br}$, found 401.0656. Purity HPLC 99\% (method A) $R_{\mathrm{t}}=2.15 \mathrm{~min}$.

Preparation of 5,7-Difluoro-3-methyl-2-(4-(4-(trifluoromethyl)piperidin-1-yl)phenyl)quinolin-4(1H)-one 17a. White solid (32\%); $\mathrm{mp}>350^{\circ} \mathrm{C} .{ }^{1} \mathrm{H}$ NMR $(400 \mathrm{MHz}, \mathrm{DMSO}) 11.52(\mathrm{~s}, 1 \mathrm{H}), 7.39(\mathrm{~m}, 2 \mathrm{H})$, $7.17(\mathrm{~m}, 3 \mathrm{H}), 7.00(\mathrm{~m}, 1 \mathrm{H}), 3.95(\mathrm{~m}, 2 \mathrm{H}), 2.85(\mathrm{~m}, 2 \mathrm{H}), 1.91(\mathrm{~m}, 2 \mathrm{H})$, $1.87(\mathrm{~s}, 3 \mathrm{H}), 1.55(\mathrm{~m}, 2 \mathrm{H}) .{ }^{13} \mathrm{C}$ NMR $(100 \mathrm{MHz}, \mathrm{DMSO}) \delta_{\mathrm{C}}$ not soluble in DMSO. MS $\left(\mathrm{ES}^{+}\right) \mathrm{m} / z 423(\mathrm{M}+\mathrm{H})^{+}$. HRMS calculated for 423.1496 $\mathrm{C}_{22} \mathrm{H}_{20} \mathrm{~N}_{2} \mathrm{OF}_{5}$, found 423.1483. Anal.: $\mathrm{C}_{22} \mathrm{H}_{19} \mathrm{~N}_{2} \mathrm{OF}_{5}$ requires C $62.56 \%$, H $4.53 \%$, N 6.63\%. Found: C 62.49\%, H 4.52\%, N $6.62 \%$.

Preparation of 5,7-Difluoro-3-methyl-2-(4-(4-methylpiperidin-1yl)phenyl)quinolin-4(1H)-one $17 \mathrm{~b}$. White solid (54\%); mp decomposed at $310^{\circ} \mathrm{C} .{ }^{1} \mathrm{H}$ NMR $(400 \mathrm{MHz}, \mathrm{DMSO}) \delta 11.50(\mathrm{~s}, 1 \mathrm{H}), 7.36(\mathrm{~d}$, $J=8.8 \mathrm{~Hz}, 2 \mathrm{H}), 7.16(\mathrm{~d}, J=10.0 \mathrm{~Hz}, 1 \mathrm{H}), 7.08(\mathrm{~d}, J=8.9 \mathrm{~Hz}, 2 \mathrm{H}), 7.00$ (ddd, $J=12.0,9.6,2.4 \mathrm{~Hz}, 1 \mathrm{H}), 3.83(\mathrm{~d}, J=12.8 \mathrm{~Hz}, 2 \mathrm{H}), 2.76(\mathrm{td}, J=$ $12.5,2.4 \mathrm{~Hz}, 2 \mathrm{H}), 1.87(\mathrm{~s}, 3 \mathrm{H}), 1.70(\mathrm{~d}, J=12.7 \mathrm{~Hz}, 2 \mathrm{H}), 1.63-1.49(\mathrm{~m}$, $1 \mathrm{H}), 1.21$ (qd, $J=12.7,4.0 \mathrm{~Hz}, 2 \mathrm{H}), 0.94(\mathrm{~d}, J=6.5 \mathrm{~Hz}, 3 \mathrm{H}) .{ }^{13} \mathrm{C} \mathrm{NMR}$ (101 MHz, DMSO) $\delta 175.37,163.51,160.76,152.01,147.65,142.84$, 130.21, 123.60, 116.33, 114.91, 110.49, 99.41, 98.81, 48.41, 33.55, 30.65, $22.18,12.51$. ES HRMS: $m / z$ found $369.1792, \mathrm{C}_{22} \mathrm{H}_{23} \mathrm{~N}_{2} \mathrm{OF}_{2}$ requires 369.1778. Anal.: $\mathrm{C}_{22} \mathrm{H}_{22} \mathrm{~N}_{2} \mathrm{OF}_{2}$ requires C 71.72\%, H 6.02\%, $\mathrm{N} 7.60 \%$. Found: C 71.66\%, H 5.95\%, N 7.52\%.

Preparation of 2-(4-(6-Azaspiro[2.5]octan-6-yl)phenyl)-5,7-difluoro-3-methylquinolin-4(1H)-one 17c. White solid (yield 34\%); $\mathrm{mp}>300^{\circ} \mathrm{C} .{ }^{1} \mathrm{H}$ NMR $(400 \mathrm{MHz}, \mathrm{DMSO}) \delta_{\mathrm{H}} 11.51(\mathrm{~s}, 1 \mathrm{H}, \mathrm{NH}), 7.38$ $(\mathrm{d}, J=8.7 \mathrm{~Hz}, 2 \mathrm{H}), 7.16(\mathrm{~d}, J=10.0 \mathrm{~Hz}, 1 \mathrm{H}), 7.11(\mathrm{~d}, J=8.8 \mathrm{~Hz}, 2 \mathrm{H})$, 7.00 (ddd, $J=11.9,9.6,2.3 \mathrm{~Hz}, 1 \mathrm{H}), 3.38-3.35(\mathrm{~m}, 4 \mathrm{H}), 1.88(\mathrm{~s}, 3 \mathrm{H}$, $\left.\mathrm{CH}_{3}\right), 1.53-1.36(\mathrm{~m}, 4 \mathrm{H}), 0.35$ (s, 4H). ${ }^{13} \mathrm{C}$ NMR (101 MHz, DMSO) $\delta_{\mathrm{C}} 175.52,163.75(\mathrm{~d}, J=61.6 \mathrm{~Hz}), 161.38(\mathrm{~d}, J=77.0 \mathrm{~Hz}), 152.14$, 
$147.75,142.80$ (dd, $J=14.7,6.3 \mathrm{~Hz}$ ), 130.34, 123.72, 116.45, 115.22, $110.59(\mathrm{~d}, J=2.4 \mathrm{~Hz}), 99.60(\mathrm{dd}, J=24.9,4.1 \mathrm{~Hz}), 98.95(\mathrm{dd}, J=28.7$, $25.6 \mathrm{~Hz}$ ), 48.40, 34.32, 18.15, 12.61, 11.59. HRMS (ESI) $\mathrm{C}_{23} \mathrm{H}_{22} \mathrm{~N}_{2} \mathrm{OF}^{23} \mathrm{Na}[\mathrm{M}+\mathrm{Na}]^{+}$requires 403.1598, found 403.1612. Anal.: $\mathrm{C}_{23} \mathrm{H}_{22} \mathrm{~N}_{2} \mathrm{OF}$ requires C $72.61 \%, \mathrm{H} 5.83 \%$, N 7.36\%. Found: $\mathrm{C}$ $72.41 \%$, H $5.91 \%$, N $7.31 \%$.

Preparation of 2-(4-(4,4-Difluoropiperidin-1-yl)phenyl)-5,7-difluoro-3-methylquinolin-4(1H)-one $17 d$. White solid $(0.30 \mathrm{~g}, 57 \%)$. ${ }^{1} \mathrm{H}$ NMR $(400 \mathrm{MHz}, \mathrm{DMSO}) \delta_{\mathrm{H}} 7.38(\mathrm{~d}, J=8.8 \mathrm{~Hz}, 2 \mathrm{H}), 7.10(\mathrm{~d}, J=$ $8.8 \mathrm{~Hz}, 2 \mathrm{H}), 7.07(\mathrm{~m}, 1 \mathrm{H}), 6.82(\mathrm{dd}, J=11.0,10.6 \mathrm{~Hz}, 1 \mathrm{H}), 3.43(\mathrm{~m}$, $4 \mathrm{H}), 2.07(\mathrm{~m}, 4 \mathrm{H}), 1.88(\mathrm{~s}, 3 \mathrm{H}) .{ }^{13} \mathrm{C}$ NMR $(100 \mathrm{MHz}, \mathrm{DMSO}) \delta_{\mathrm{C}}$ 174.2, 149.5, 129.9, 122.8, 118.5, 115.3, 115.0, 45.3, 33.0, 32.8, 32.5, 12.6. MS $\left(\mathrm{CI}^{+}\right) \mathrm{m} / z 391(\mathrm{M}+\mathrm{H})^{+}$. HRMS calculated for 391.1428 $\mathrm{C}_{21} \mathrm{H}_{19} \mathrm{~N}_{2} \mathrm{OF}_{4}$, found 391.1430. Purity HPLC 95\% (method A) $R_{\mathrm{t}}=$ 2.39 min.

Preparation of 5,7-Difluoro-2-(4-(3-fluoropiperidin-1-yl)phenyl)3-methylquinolin-4(1H)-one 17e. Light-brown solid $(0.12 \mathrm{~g}, 27 \%) .{ }^{1} \mathrm{H}$ NMR $(400 \mathrm{MHz}, \mathrm{DMSO}) \delta_{\mathrm{H}} 11.49(\mathrm{bs}, 1 \mathrm{H}), 7.38(\mathrm{~d}, J=8.8 \mathrm{~Hz}, 2 \mathrm{H})$, $7.10(\mathrm{~d}, J=8.8 \mathrm{~Hz}, 2 \mathrm{H}), 7.07(\mathrm{~m}, 1 \mathrm{H}), 6.99(\mathrm{dd}, J=11.0,10.6 \mathrm{~Hz}$, $1 \mathrm{H}), 4.82(\mathrm{~d}, J=48.8 \mathrm{~Hz}, 1 \mathrm{H}), 3.50-3.33(\mathrm{~m}, 4 \mathrm{H}), 1.87(\mathrm{~s}, 3 \mathrm{H}), 1.86-$ $1.62(\mathrm{~m}, 4 \mathrm{H}) .{ }^{13} \mathrm{C}$ NMR $(100 \mathrm{MHz}, \mathrm{DMSO}) \delta_{\mathrm{C}} 175.2,151.4,147.1$, 129.8, 123.6, 116.0, 114.6, 98.8, 88.1, 86.4, 51.8, 51.6, 47.3, 29.3, 29.1, 20.6, 20.5, 12.1. MS $\left(\mathrm{EI}^{+}\right) \mathrm{m} / z 373(\mathrm{M}+\mathrm{H})^{+}$. HRMS calculated for $373.1528 \mathrm{C}_{21} \mathrm{H}_{20} \mathrm{~N}_{2} \mathrm{OF}_{3}$, found 373.1524. Purity HPLC $97 \%$ (method A) $R_{\mathrm{t}}=2.42 \mathrm{~min}$.

Preparation of 5,7-Difluoro-3-methyl-2-(4-(3-methylpiperidin-1yl)phenyl)quinolin-4(1H)-one 17f. White solid (45\%); mp 280$282{ }^{\circ} \mathrm{C} .{ }^{1} \mathrm{H}$ NMR $(400 \mathrm{MHz}, \mathrm{DMSO}) \delta_{\mathrm{H}} 11.50(\mathrm{~s}, 1 \mathrm{H}), 7.36(\mathrm{~d}, J=$ $8.8 \mathrm{~Hz}, 2 \mathrm{H}), 7.16(\mathrm{~d}, J=9.0 \mathrm{~Hz}, 1 \mathrm{H}), 7.07(\mathrm{~d}, J=8.9 \mathrm{~Hz}, 2 \mathrm{H}), 7.00(\mathrm{ddd}$, $J=12.0,9.6,2.4 \mathrm{~Hz}, 1 \mathrm{H}), 3.77(\mathrm{t}, J=11.6 \mathrm{~Hz}, 2 \mathrm{H}), 2.72(\mathrm{td}, J=12.3$, $2.9 \mathrm{~Hz}, 1 \mathrm{H}), 2.42(\mathrm{dd}, J=12.4,10.7 \mathrm{~Hz}, 1 \mathrm{H}), 1.87(\mathrm{~s}, 3 \mathrm{H}), 1.82-$ $1.48(\mathrm{~m}, 4 \mathrm{H}), 1.09$ (ddd, $J=23.5,12.4,3.9 \mathrm{~Hz}, 1 \mathrm{H}), 0.93(\mathrm{~d}, J=6.6 \mathrm{~Hz}$, $3 \mathrm{H}) .{ }^{13} \mathrm{C}$ NMR $\left(101 \mathrm{MHz}\right.$, DMSO) $\delta_{\mathrm{C}} 175.37,164.10,161.50,152.00$, 147.66, 142.69, 130.22, 123.46, 116.33, 114.81, 110.59, 99.40, 98.79, 55.93, 48.45, 32.93, 30.35, 24.72, 19.58, 12.50. ES HRMS: $m / z$ found 369.1772, $\mathrm{C}_{22} \mathrm{H}_{23} \mathrm{~N}_{2} \mathrm{OF}_{2}$ requires 369.1778. Anal.: $\mathrm{C}_{22} \mathrm{H}_{22} \mathrm{~N}_{2} \mathrm{OF}_{2}$ requires C $71.72 \%, \mathrm{H} 6.02 \%, \mathrm{~N} 7.60 \%$. Found: C 71.76\%, H 5.94\%, N 7.58\%.

Preparation of (R)-5,7-Difluoro-3-methyl-2-(4-(3-methylpiperidin1 -yl)phenyl)quinolin-4(1H)-one $17 g$. White solid $(43 \%) .{ }^{1} \mathrm{H}$ and ${ }^{13} \mathrm{C}$ NMR data is the same as the racemic analogue. ES HRMS: $m / z$ found 369.1775, $\mathrm{C}_{22} \mathrm{H}_{23} \mathrm{~N}_{2} \mathrm{OF}_{2}$ requires 369.1778. Anal.: $\mathrm{C}_{22} \mathrm{H}_{22} \mathrm{~N}_{2} \mathrm{OF}_{2}$ requires C $71.72 \%, \mathrm{H} 6.02 \%$, N 7.60\%. Found: C 71.68\%, H 6.06\%, $\mathrm{N} 7.53 \%$. The optical rotation was measured as $[\alpha]_{\mathrm{D}}^{22}=+81.5^{\circ} \pm 0.9$ $(c=0.558 \mathrm{~g} / 100 \mathrm{~mL}$ in $\mathrm{MeOH})$.

Preparation of (S)-5,7-Difluoro-3-methyl-2-(4-(3-methylpiperidin1-yl)phenyl)quinolin-4(1H)-one 17h. White solid (40\%). ${ }^{1} \mathrm{H}$ and ${ }^{13} \mathrm{C}$ NMR data is the same as the racemic analogue. ES HRMS: $\mathrm{m} / \mathrm{z}$ found 369.1782, $\mathrm{C}_{22} \mathrm{H}_{23} \mathrm{~N}_{2} \mathrm{OF}_{2}$ requires 369.1778. Anal.: $\mathrm{C}_{22} \mathrm{H}_{22} \mathrm{~N}_{2} \mathrm{OF}_{2}$ requires $\mathrm{C} 71.72 \%, \mathrm{H} 6.02 \%, \mathrm{~N} 7.60 \%$. Found: $\mathrm{C} 71.77 \%, \mathrm{H} 6.0 \%$, $\mathrm{N} 7.64 \%$. The optical rotation was measured as $[\alpha]_{\mathrm{D}}{ }^{22}=-86.1^{\circ} \pm 0.7$ $(c=0.588 \mathrm{~g} / 100 \mathrm{~mL}$ in $\mathrm{MeOH})$.

Preparation of 5,7-Difluoro-3-methyl-2-(4-(4-methylpiperazin-1yl)phenyl)quinolin-4(1H)-one $17 \mathrm{i}$. White solid $(39 \%) ; \mathrm{mp}>350{ }^{\circ} \mathrm{C}$. ${ }^{1} \mathrm{H}$ NMR $(400 \mathrm{MHz}, \mathrm{DMSO}) \delta_{\mathrm{H}} 11.50(\mathrm{~s}, 1 \mathrm{H}), 7.89(\mathrm{~d}, J=9.0,2 \mathrm{H})$, $7.19(\mathrm{~m}, 1 \mathrm{H}), 7.05(\mathrm{~m}, 1 \mathrm{H}), 6.85(\mathrm{~d}, J=9.0,2 \mathrm{H}), 3.35(\mathrm{~m}, 4 \mathrm{H}), 2.55$ $(\mathrm{m}, 4 \mathrm{H}), 2.31(\mathrm{~s}, 3 \mathrm{H}), 1.90(\mathrm{~s}, 3 \mathrm{H}) .{ }^{13} \mathrm{C}$ NMR $(100 \mathrm{MHz}, \mathrm{DMSO}) \delta_{\mathrm{C}}$ not soluble in DMSO. MS $\left(\mathrm{ES}^{+}\right) \mathrm{m} / z 370(\mathrm{M}+\mathrm{H})^{+}$. HRMS calculated for $370.1717 \mathrm{C}_{21} \mathrm{H}_{22} \mathrm{~N}_{3} \mathrm{OF}_{2}$, found 370.1731. Purity HPLC 99\% (method A) $R_{\mathrm{t}}=1.59 \mathrm{~min}$.

Preparation of 2-(4-(Azepan-1-yl)phenyl)-5,7-difluoro-3-methylquinolin-4(1H)-one $17 \mathrm{j}$. White solid (41\%); $\mathrm{mp}>350{ }^{\circ} \mathrm{C}$. ${ }^{1} \mathrm{H}$ NMR $(400 \mathrm{MHz}, \mathrm{DMSO}) \delta_{\mathrm{H}} 11.45(\mathrm{~s}, 1 \mathrm{H}), 7.31(\mathrm{~d}, J=8.8,2 \mathrm{H}), 7.19(\mathrm{~m}$, $1 \mathrm{H}), 7.00(\mathrm{~m}, 1 \mathrm{H}), 6.85(\mathrm{~d}, J=8.9,2 \mathrm{H}), 3.55(\mathrm{~m}, 4 \mathrm{H}), 1.92(\mathrm{~s}, 3 \mathrm{H}), 1.75$ (bs, $4 \mathrm{H}), 1.45$ (bs, $4 \mathrm{H}) .{ }^{13} \mathrm{C}$ NMR $(100 \mathrm{MHz}, \mathrm{DMSO}) \delta_{\mathrm{C}} 175.4,149.4$, $147.8,130.5,120.5,116.1,110.8,99.54,98.9,98.7,49.1,48.1,47.9,47.7$, 47.5, 27.0, 26.6, 12.6. MS $\left(\mathrm{ES}^{+}\right) \mathrm{m} / z 369(\mathrm{M}+\mathrm{H})^{+}$. HRMS calculated for 369.1764 $\mathrm{C}_{22} \mathrm{H}_{23} \mathrm{~N}_{2} \mathrm{OF}_{2}$, found 369.1778. Anal.: $\mathrm{C}_{22} \mathrm{H}_{22} \mathrm{~N}_{2} \mathrm{OF}_{2}$ requires C $71.72 \%$, H $6.02 \%$, N 7.60\%. Found: C 71.36\%, H 5.97\%, N 7.39\%.
Preparation of 2-(4-(Benzylamino)phenyl)-5,7-difluoro-3-methylquinolin-4(1H)-one $17 \mathrm{k}$. White solid $(51 \%)$; mp 282-283 ${ }^{\circ} \mathrm{C} .{ }^{1} \mathrm{H}$ NMR $(400 \mathrm{MHz}, \mathrm{DMSO}) \delta_{\mathrm{H}} 11.39(\mathrm{~s}, 1 \mathrm{H}), 7.36(\mathrm{dt}, J=15.1,7.4 \mathrm{~Hz}$, $4 \mathrm{H}), 7.27-7.21(\mathrm{~m}, 3 \mathrm{H}), 7.13(\mathrm{~d}, J=9.0 \mathrm{~Hz}, 1 \mathrm{H}), 6.97$ (ddd, $J=12.0$, $9.8,2.3 \mathrm{~Hz}, 1 \mathrm{H}), 6.84(\mathrm{t}, J=6.1 \mathrm{~Hz}, 1 \mathrm{H}), 6.72(\mathrm{~d}, J=8.6 \mathrm{~Hz}, 2 \mathrm{H}), 4.36$ $(\mathrm{d}, J=6.1 \mathrm{~Hz}, 2 \mathrm{H}), 1.86(\mathrm{~s}, 3 \mathrm{H}) .{ }^{13} \mathrm{C}$ NMR $(101 \mathrm{MHz}, \mathrm{DMSO}) \delta_{\mathrm{C}}$ 175.36, 164.04, 161.44, 150.01, 148.03, 142.58, 141.46, 140.25, 130.20, $128.73,127.47,127.09,121.61,116.08,112.05,99.34,98.71,46.39$, 12.56. ES HRMS: $m / z$ found 377.1465, $\mathrm{C}_{23} \mathrm{H}_{19} \mathrm{~N}_{2} \mathrm{OF}_{2}$ requires 377.1465. Anal.: $\mathrm{C}_{23} \mathrm{H}_{18} \mathrm{~N}_{2} \mathrm{OF}_{2}$ requires $\mathrm{C} 73.39 \%, \mathrm{H} 4.82 \%, \mathrm{~N}$ 7.44\%. Found: C 73.18\%, H 4.74\%, N 7.41\%.

Preparation of 2-(4-(Dimethylamino)phenyl)-5,7-difluoro-3methylquinolin-4(1H)-one $17 \mathrm{l}$. White solid $(46 \%) ; \mathrm{mp} 294{ }^{\circ} \mathrm{C} .{ }^{1} \mathrm{H}$ NMR $(400 \mathrm{MHz}, \mathrm{DMSO}) \delta_{\mathrm{H}} 11.48(\mathrm{~s}, 1 \mathrm{H}), 7.37(\mathrm{~d}, J=8.8 \mathrm{~Hz}, 2 \mathrm{H})$, $7.17(\mathrm{~d}, J=10.1 \mathrm{~Hz}, 1 \mathrm{H}), 6.99(\mathrm{ddd}, J=12.1,9.6,2.4 \mathrm{~Hz}, 1 \mathrm{H}), 6.86$ $(\mathrm{d}, J=8.9 \mathrm{~Hz}, 2 \mathrm{H}), 2.99(\mathrm{~s}, 6 \mathrm{H}), 1.88(\mathrm{~s}, 3 \mathrm{H}) .{ }^{13} \mathrm{C}$ NMR $(101 \mathrm{MHz}$, DMSO) $\delta_{\mathrm{C}} 175.39,164.08,160.75,151.31,147.89,142.77,130.17$, $121.70,116.20,111.89,110.45,99.38,98.77,40.24,12.55$. ES HRMS: $m / z$ found 315.1319, $\mathrm{C}_{18} \mathrm{H}_{17} \mathrm{~N}_{2} \mathrm{OF}_{2}$ requires 315.1309. Anal.: $\mathrm{C}_{18} \mathrm{H}_{16} \mathrm{~N}_{2} \mathrm{OF}_{2}$ requires C $68.78 \%, \mathrm{H} 5.13 \%, \mathrm{~N} 8.91 \%$. Found: C $68.47 \%, \mathrm{H} 5.14 \%$, N $8.78 \%$.

Preparation of 2-(4-(4-Benzylpiperidin-1-yl)phenyl)-3-methylquinolin-4(1H)-one $21 a$. White powder (yield $33 \%$ ); $\mathrm{mp} 256-258^{\circ} \mathrm{C} .{ }^{1} \mathrm{H}$ $\operatorname{NMR}(400 \mathrm{MHz}, \mathrm{DMSO}) \delta_{\mathrm{H}} 11.39(\mathrm{~s}, 1 \mathrm{H}, \mathrm{NH}), 8.10(\mathrm{~d}, 1 \mathrm{H}, J=7.7 \mathrm{~Hz}$, $\mathrm{Ar}), 7.63-7.55(\mathrm{~m}, 2 \mathrm{H}, \mathrm{AR}), 7.37(\mathrm{~d}, 2 \mathrm{H}, J=8.9 \mathrm{~Hz}, \mathrm{Ar}), 7.33-7.24(\mathrm{~m}$, $3 \mathrm{H}, \mathrm{Ar}), 7.22-7.17(\mathrm{~m}, 3 \mathrm{H}, \mathrm{Ar}), 706(\mathrm{~d}, 2 \mathrm{H}, J=8.9 \mathrm{~Hz}, \mathrm{Ar}), 3.82(\mathrm{~d}, 2 \mathrm{H}$, $\left.J=12.8 \mathrm{~Hz}, \mathrm{CH}_{2}\right), 2.79-2.66\left(\mathrm{~m}, 2 \mathrm{H}, \mathrm{CH}_{2}\right), 2.56(\mathrm{~d}, 2 \mathrm{H}, J=7.0 \mathrm{~Hz}$, $\left.\mathrm{CH}_{2} \mathrm{Ar}\right), 1.96\left(\mathrm{~s}, 3 \mathrm{H}, \mathrm{CH}_{3}\right), 1.79-1.73(\mathrm{~m}, 1 \mathrm{H}, \mathrm{CH}), 1.67(\mathrm{~d}, 2 \mathrm{H}, J=$ $12.9 \mathrm{~Hz}, \mathrm{CH}_{2}$ ), 1.29 (qd, $\left.2 \mathrm{H}, J=12.6 \mathrm{~Hz}, 3.9 \mathrm{~Hz}, \mathrm{CH}_{2}\right) .{ }^{13} \mathrm{C} \mathrm{NMR}$ $(100 \mathrm{MHz}, \mathrm{DMSO}) \delta_{\mathrm{C}} 177.0,151.9,148.3,140.5,139.9,131.3,130.2$, $129.4,128.5,126.2,125.3,124.5,123.3,122.7,118.4,115.0,114.4,48.7$, 42.6, 37.7, 31.5, 12.8. MS (ES+), $[\mathrm{M}+\mathrm{H}]^{+}(100)$, 409.2. HRMS calculated for $409.2280 \mathrm{C}_{28} \mathrm{H}_{29} \mathrm{~N}_{2} \mathrm{O}$, found 409.2289. Anal.: $\mathrm{C}_{28} \mathrm{H}_{28} \mathrm{~N}_{2} \mathrm{O}$ requires C $82.32 \%$, H 6.91\%, N 6.86\%. Found: C 81.98\%, H 6.92\%, N $6.88 \%$.

Preparation of 2-(4-(4-Benzylpiperidin-1-yl)phenyl)-6-fluoro-3methylquinolin-4(1H)-one $21 \mathrm{~b}$. White powder (yield $40 \%$ ); mp 302-302 ${ }^{\circ} \mathrm{C} .{ }^{1} \mathrm{H}$ NMR $(400 \mathrm{MHz}, \mathrm{DMSO}) \delta_{\mathrm{H}} 11.55(\mathrm{~s}, 1 \mathrm{H}, \mathrm{NH})$, $7.73(\mathrm{dd}, 1 \mathrm{H}, J=9.5 \mathrm{~Hz}, 3.0 \mathrm{~Hz}, \mathrm{Ar}), 7.68(\mathrm{dd}, 1 \mathrm{H}, J=9.1 \mathrm{~Hz}, 4.7 \mathrm{~Hz}$, Ar), 7.54-7.48 (m, 1H, Ar), 7.38 (d, $2 \mathrm{H}, J=8.9 \mathrm{~Hz}, \mathrm{Ar}), 7.33-7.27$ (m, $2 \mathrm{H}, \mathrm{Ar}), 7.23-7.17(\mathrm{~m}, 3 \mathrm{H}, \mathrm{Ar}), 7.06(\mathrm{~d}, 2 \mathrm{H}, J=8.9 \mathrm{~Hz}, \mathrm{Ar}), 3.83(\mathrm{~d}$, $\left.2 \mathrm{H}, J=12.7 \mathrm{~Hz}, \mathrm{CH}_{2}\right), 2.79-2.67\left(\mathrm{~m}, 2 \mathrm{H}, \mathrm{CH}_{2}\right), 2.55(\mathrm{~d}, 2 \mathrm{H}, J=7.0 \mathrm{~Hz}$, $\left.\mathrm{CH}_{2} \mathrm{Ar}\right), 1.94\left(\mathrm{~s}, 3 \mathrm{H}, \mathrm{CH}_{3}\right), 1.80-1.68(\mathrm{~m}, 1 \mathrm{H}, \mathrm{CH}), 1.67(\mathrm{~d}, 2 \mathrm{H}, J=$ $\left.13.1 \mathrm{~Hz}, \mathrm{CH}_{2}\right), 1.28\left(\mathrm{qd}, 2 \mathrm{H}, J=12.6 \mathrm{~Hz}, 3.9 \mathrm{~Hz}, \mathrm{CH}_{2}\right) .{ }^{13} \mathrm{C}$ NMR $(100 \mathrm{MHz}, \mathrm{DMSO}) \delta_{\mathrm{C}} 176.2,157.1,152.0,148.6,140.5,136.6,130.2$, $129.4,128.5,126.2,124.3,121.2,120.4,115.0,113.9,109.1,48.4,42.6$, 37.7, 31.4, 12.7. MS (ES+), $[\mathrm{M}+\mathrm{H}]^{+}(100), 427.2$. HRMS calculated for 427.2186 $\mathrm{C}_{28} \mathrm{H}_{28} \mathrm{~N}_{2} \mathrm{O}_{4} \mathrm{~F}$, found 427.2177. Anal.: $\mathrm{C}_{28} \mathrm{H}_{27} \mathrm{~N}_{2} \mathrm{OF}$ requires C 78.85\%, H 6.38\%, N 6.57\%. Found: C 78.31\%, H 6.35\%, N 6.63\%.

Preparation of 2-(4-(4-Benzylpiperidin-1-yl)phenyl)-7-methoxy-3methylquinolin-4(1H)-one 21c. Light-yellow powder (yield $42 \%$ ); mp 218-220 ${ }^{\circ} \mathrm{C} .{ }^{1} \mathrm{H}$ NMR $(400 \mathrm{MHz}, \mathrm{DMSO}) \delta_{\mathrm{H}} 11.21(\mathrm{~s}, \mathrm{~s}, 1 \mathrm{H}, \mathrm{NH})$, $7.99(\mathrm{~d}, 1 \mathrm{H}, J=8.9 \mathrm{~Hz}, \mathrm{Ar}), 7.36(\mathrm{~d}, 2 \mathrm{H}, J=8.7 \mathrm{~Hz}, \mathrm{Ar}), 7.29$ (d, $2 \mathrm{H}, J=$ $7.2 \mathrm{~Hz}, \mathrm{Ar}), 7.20(\mathrm{~d}, 3 \mathrm{H}, J=6.4 \mathrm{~Hz}, \mathrm{Ar}), 7.05(\mathrm{~d}, 3 \mathrm{H}, J=8.6 \mathrm{~Hz}, \mathrm{Ar}), 6.87$ $(\mathrm{dd}, 1 \mathrm{H}, J=8.9 \mathrm{~Hz}, 2.4 \mathrm{~Hz}, \mathrm{Ar}), 3.82\left(\mathrm{~s}, 3 \mathrm{H}, \mathrm{OCH}_{3}\right), 2.71(\mathrm{t}, 2 \mathrm{H}, J=$ $\left.11.5 \mathrm{~Hz}, \mathrm{CH}_{2}\right), 2.56\left(\mathrm{~d}, 2 \mathrm{H}, J=6.9 \mathrm{~Hz}, \mathrm{CH}_{2} \mathrm{Ar}\right), 1.91\left(\mathrm{~s}, 3 \mathrm{H}, \mathrm{CH}_{3}\right)$, $1.79-1.71(\mathrm{~m}, 1 \mathrm{H}, \mathrm{CH}), 1.29\left(\mathrm{dt}, 2 \mathrm{H}, J=11.7 \mathrm{~Hz}, 8.9 \mathrm{~Hz}, \mathrm{CH}_{2}\right) .{ }^{13} \mathrm{C}$ NMR $(100 \mathrm{MHz}, \mathrm{DMSO}) \delta_{\mathrm{C}} 176.7,161.8,151.8,147.8,141.6,140.5$, $130.2,129.4,128.5,127.1,126.2,124.6,117.9,115.0,113.9,113.0,99.2$, 55.6, 48.5, 42.6, 37.7, 31.5, 12.7. MS (ES+), $[\mathrm{M}+\mathrm{H}]^{+}(100)$, 439.2. HRMS calculated for $439.2386 \mathrm{C}_{29} \mathrm{H}_{31} \mathrm{~N}_{2} \mathrm{O}_{2}$, found 439.2386. Purity HPLC 95\% (method B) $R_{\mathrm{t}}=2.43 \mathrm{~min}$.

Preparation of 2-(4-(4-Benzylpiperazin-1-yl)phenyl)-3-methylquinolin-4(1H)-one $21 \mathrm{~d}$. White powder (yield $30 \%) ; \mathrm{mp} 258-260{ }^{\circ} \mathrm{C} .{ }^{1} \mathrm{H}$ NMR $(400 \mathrm{MHz}, \mathrm{DMSO}) \delta_{\mathrm{H}} 11.40(\mathrm{~s}, 1 \mathrm{H}, \mathrm{NH}), 8.10(\mathrm{~d}, 1 \mathrm{H}, J=7.7 \mathrm{~Hz}$, AR), $7.63-7.55(\mathrm{~m}, 2 \mathrm{H}, \mathrm{Ar}), 7.40(\mathrm{~d}, 2 \mathrm{H}, J=8.9 \mathrm{~Hz}, \mathrm{Ar}), 7.37-7.33(\mathrm{~m}$, $3 \mathrm{H}, \mathrm{Ar}), 7.27$ (ddd, $2 \mathrm{H}, J=10.3 \mathrm{~Hz}, 5.5 \mathrm{~Hz}, 2.5 \mathrm{~Hz}, \mathrm{Ar}), 7.08(\mathrm{~d}, 2 \mathrm{H}, J=$ $8.9 \mathrm{~Hz}, \mathrm{Ar}), 3.54\left(\mathrm{~s}, 2 \mathrm{H}, \mathrm{CH}_{2} \mathrm{Ar}\right), 3.29-3.23\left(\mathrm{~m}, 4 \mathrm{H}, \mathrm{NCH}_{2}\right), 2.58-2.52$ $\left(\mathrm{m}, 4 \mathrm{H}, \mathrm{CH}_{2} \mathrm{~N}\right), 1.93\left(\mathrm{~s}, 3 \mathrm{H}, \mathrm{CH}_{3}\right) \cdot{ }^{13} \mathrm{C} \mathrm{NMR}(100 \mathrm{MHz}, \mathrm{DMSO}) \delta_{\mathrm{C}}$ $177.0,151.9,148.2,139.9,138.4,131.4,130.2,129.3,128.6,127.4,125.3$, 
123.3, 122.8, 118.4, 114.9, 114.4, 62.4, 52.8, 49.0, 48.1, 12.7. MS (ES+), $[\mathrm{M}+\mathrm{H}]^{+}(100)$, 410.2. HRMS calculated for $410.2232 \mathrm{C}_{27} \mathrm{H}_{28} \mathrm{~N}_{3} \mathrm{O}$, found 410.2234. Anal.: $\mathrm{C}_{27} \mathrm{H}_{27} \mathrm{~N}_{3} \mathrm{O}$ requires $\mathrm{C} 79.19 \%, \mathrm{H} 6.65 \%, \mathrm{~N}$ $10.26 \%$. Found: C $78.63 \%, \mathrm{H} 6.66 \%, \mathrm{~N} 10.21 \%$.

Preparation of 2-(4-(4-Benzylpiperazin-1-yl)phenyl)-6-fluoro-3methylquinolin-4(1H)-one 21e. White powder (yield 28\%); mp 306-308 ${ }^{\circ} \mathrm{C} .{ }^{1} \mathrm{H}$ NMR $(400 \mathrm{MHz}, \mathrm{DMSO}) \delta_{\mathrm{H}} 11.69(\mathrm{~s}, 1 \mathrm{H}, \mathrm{NH})$, 7.74-7.71 (m, 2H, Ar), 7.54-7.48 (m, 1H, Ar), $7.40(\mathrm{~d}, 2 \mathrm{H}, J=8.9 \mathrm{~Hz}$, Ar), 7.37-7.33 (m, 4H, Ar), 7.08 (d, $2 \mathrm{H}, J=8.9 \mathrm{~Hz}, \mathrm{Ar}), 3.54(\mathrm{~s}, 2 \mathrm{H}$, $\left.\mathrm{CH}_{2} \mathrm{Ar}\right), 3.30-3.22\left(\mathrm{~m}, 4 \mathrm{H}, \mathrm{CH}_{2} \mathrm{~N}\right), 2.59-2.52\left(\mathrm{~m}, 4 \mathrm{H}, \mathrm{NCH}_{2}\right), 1.94$ $\left(\mathrm{s}, 3 \mathrm{H}, \mathrm{CH}_{3}\right) .{ }^{13} \mathrm{C}$ NMR $(100 \mathrm{MHz}, \mathrm{DMSO}) \delta_{\mathrm{C}} 151.9,148.6,138.4$, $136.7,130.2,129.3$, 128.6, 127.4, 124.9, 124.2, 120.4, 114.8, 113.9, 109.0, 62.4, 55.3, 52.8, 48.0, 12.8. MS (ES+), $[\mathrm{M}+\mathrm{H}]^{+}(100)$, 428.2. HRMS calculated for $428.2138 \mathrm{C}_{27} \mathrm{H}_{27} \mathrm{~N}_{3} \mathrm{OF}$, found 428.2138 . Purity HPLC 98\% $(\operatorname{method} \mathrm{A}) R_{\mathrm{t}}=1.82$ min..

Preparation of 7-Methoxy-3-methyl-2-(4-(4-phenylpiperazin-1yl)phenyl)quinolin-4(1H)-one 21f. White powder (yield 30\%); mp $312-314{ }^{\circ} \mathrm{C} .{ }^{1} \mathrm{H}$ NMR $(400 \mathrm{MHz}, \mathrm{DMSO}) \delta_{\mathrm{H}} 11.25$ (s, $\left.1 \mathrm{H}, \mathrm{NH}\right), 8.01$ $(\mathrm{d}, 1 \mathrm{H}, J=9.0 \mathrm{~Hz}, \mathrm{Ar}), 7.43(\mathrm{~d}, 2 \mathrm{H}, J=8.8 \mathrm{~Hz}, \mathrm{Ar}), 7.26(\mathrm{dd}, 2 \mathrm{H}, J=$ $8.4 \mathrm{~Hz}, \mathrm{Ar}), 7.16(\mathrm{~d}, 2 \mathrm{H}, J=8.8 \mathrm{~Hz}, \mathrm{Ar}), 7.05$ (d, $1 \mathrm{H}, J=2.4 \mathrm{~Hz}, \mathrm{Ar}), 7.02$ $(\mathrm{d}, 2 \mathrm{H} . J=8.0 \mathrm{~Hz}, \mathrm{Ar}), 6.88(\mathrm{dd}, 1 \mathrm{H}, J=9.0 \mathrm{~Hz}, \mathrm{Ar}), 6.83(\mathrm{t}, 1 \mathrm{H}, J=$ $7.3 \mathrm{~Hz}, \mathrm{Ar}), 3.82\left(\mathrm{~s}, 3 \mathrm{H}, \mathrm{OCH}_{3}\right), 3.41(\mathrm{dd}, 4 \mathrm{H}, J=6.5 \mathrm{~Hz}, 3.5 \mathrm{~Hz}$, $\left.\mathrm{NCH}_{2}\right), 3.31\left(\mathrm{dd}, 4 \mathrm{H}, J=6.5 \mathrm{~Hz}, 3.5 \mathrm{~Hz}, \mathrm{CH}_{2} \mathrm{~N}\right), 1.92\left(\mathrm{~s}, 3 \mathrm{H}, \mathrm{CH}_{3}\right) .{ }^{13} \mathrm{C}$ NMR $\left(100 \mathrm{MHz}\right.$, DMSO) $\delta_{\mathrm{C}} 176.7,161.8,151.7,151.3,147.7,141.6$, 130.2, 129.4, 127.1, 125.6, 119.6, 117.9, 116.1, 115.1, 114.0, 113.0, 99.2, 55.7, 48.6, 48.1, 12.6. MS (ES+), $[\mathrm{M}+\mathrm{H}]^{+}(100), 426.2$. HRMS calculated for $426.2182 \mathrm{C}_{27} \mathrm{H}_{28} \mathrm{~N}_{3} \mathrm{O}_{2}$, found 426.2184. Purity HPLC $91 \%(\operatorname{method} \mathrm{A}) R_{\mathrm{t}}=1.80 \mathrm{~min}$.

Preparation of 2-(4-(4-Benzylpiperazin-1-yl)phenyl)-7-methoxy3-methylquinolin-4(1H)-one 21g. White powder (yield 38\%); mp $280-282{ }^{\circ} \mathrm{C} .{ }^{1} \mathrm{H}$ NMR $(400 \mathrm{MHz}, \mathrm{DMSO}) \delta_{\mathrm{H}} 11.22(\mathrm{~s}, 1 \mathrm{H}, \mathrm{NH}), 8.00$ $(\mathrm{d}, 1 \mathrm{H}, J=9.0 \mathrm{~Hz}, \mathrm{AR}), 7.38(\mathrm{~d}, 2 \mathrm{H}, J=8.9 \mathrm{~Hz}, \mathrm{Ar}), 7.37-7.33(\mathrm{~m}, 4 \mathrm{H}$, Ar), 7.31-7.24 (m, 1H, Ar), $7.07(\mathrm{~d}, 2 \mathrm{H}, J=8.9 \mathrm{~Hz}, \mathrm{Ar}), 7.04(\mathrm{~d}, 1 \mathrm{H}, J=$ $2.4 \mathrm{~Hz}, \mathrm{Ar}), 6.87(\mathrm{dd}, 1 \mathrm{H}, J=8.9 \mathrm{~Hz}, 2.4 \mathrm{~Hz}, \mathrm{Ar}), 3.82\left(\mathrm{~s}, 3 \mathrm{H}, \mathrm{OCH}_{3}\right)$, $3.54\left(\mathrm{~s}, 2 \mathrm{H}, \mathrm{NCH}_{2} \mathrm{Ar}\right), 3.29-3.23\left(\mathrm{~m}, 4 \mathrm{H}, \mathrm{NCH}_{2}\right), 2.57-2.52(\mathrm{~m}, 4 \mathrm{H}$, $\left.\mathrm{CH}_{2} \mathrm{~N}\right), 1.91\left(\mathrm{~s}, 3 \mathrm{H}, \mathrm{CH}_{3}\right) .{ }^{13} \mathrm{C}$ NMR $(100 \mathrm{MHz}, \mathrm{DMSO}) \delta_{\mathrm{C}} 176.7$, 161.8, 151.8, 147.7, 141.6, 138.4, 130.1, 129.3, 128.6, 127.4, 125.3, 117.9, 114.8, 113.0, 99.2, 62.4, 55.6, 52.8, 49.0, 48.0, 12.6. MS (ES+), $[\mathrm{M}+\mathrm{H}]^{+}$ (100), 440.2. HRMS calculated for $440.2338 \mathrm{C}_{28} \mathrm{H}_{30} \mathrm{~N}_{3} \mathrm{O}_{2}$, found 440.2344. Anal.: $\mathrm{C}_{28} \mathrm{H}_{29} \mathrm{~N}_{3} \mathrm{O}_{2}$ requires $\mathrm{C} 76.51 \%, \mathrm{H} 6.65 \%$, N 9.56\%. Found: C $76.12 \%$, H 6.63\%, N 9.48\%.

Preparation of 5,7-Difluoro-3-methyl-2-(3-(piperidin-1-yl)phenyl)quinolin-4(1H)-one 24. White solid (yield 45\%); mp 269$270{ }^{\circ} \mathrm{C} .{ }^{1} \mathrm{H}$ NMR $(400 \mathrm{MHz}, \mathrm{DMSO}) \delta_{\mathrm{H}} 11.63(\mathrm{~s}, 1 \mathrm{H}, \mathrm{NH}), 7.37(\mathrm{t}, J=$ $7.9 \mathrm{~Hz}, 1 \mathrm{H}, \mathrm{Ar}), 7.16(\mathrm{~d}, J=9.8 \mathrm{~Hz}, 1 \mathrm{H}, \mathrm{Ar}), 7.10(\mathrm{dd}, J=8.4,2.3 \mathrm{~Hz}$, $1 \mathrm{H}, \mathrm{Ar}), 7.06-6.97(\mathrm{~m}, 2 \mathrm{H}, \mathrm{Ar}), 6.86(\mathrm{~d}, J=7.5 \mathrm{~Hz}, 1 \mathrm{H}, \mathrm{Ar}), 3.27-3.19$ $\left(\mathrm{m}, 4 \mathrm{H}, \mathrm{CH}_{2}\right), 1.83\left(\mathrm{~s}, 3 \mathrm{H}, \mathrm{CH}_{3}\right), 1.62\left(\mathrm{~d}, J=4.0 \mathrm{~Hz}, 4 \mathrm{H}, \mathrm{CH}_{2}\right), 1.59-$ $1.50\left(\mathrm{~m}, 2 \mathrm{H}, \mathrm{CH}_{2}\right) \cdot{ }^{13} \mathrm{C}$ NMR $(101 \mathrm{MHz}, \mathrm{DMSO}) \delta_{\mathrm{C}} 175.48,163.86$ (dd, $J=65.8,15.2 \mathrm{~Hz}$ ), 161.33 (dd, $J=80.6,14.7 \mathrm{~Hz}$ ), 151.93, 148.14, 142.72 (dd, $J=14.7,6.4 \mathrm{~Hz}$ ), 135.62, 129.68, 118.86, 116.90, 116.66, $116.07,110.74(\mathrm{~d}, J=10.7 \mathrm{~Hz}), 99.66(\mathrm{dd}, J=24.4,4.5 \mathrm{~Hz}), 99.06$ (dd, $J=26.8,25.8 \mathrm{~Hz}$ ), 49.65, 25.57, 24.33, 12.44. HRMS (ESI) $\mathrm{C}_{21} \mathrm{H}_{20} \mathrm{~N}_{2} \mathrm{OF}_{2}^{23} \mathrm{Na}[\mathrm{M}+\mathrm{H}]^{+}$requires 377.1441 , found $377.1448(100 \%)$. Anal.: $\mathrm{C}_{21} \mathrm{H}_{20} \mathrm{~N}_{2} \mathrm{OF}_{2}$ requires C $71.17 \%, \mathrm{H} 5.69 \%, \mathrm{~N} 7.90 \%$. Found: C 70.78\%, H 5.59\%, N 7.64\%.

Preparation of 1-(4-(5,7-Difluoro-3-methyl-4-oxo-1,4-dihydroquinolin-2-yl)phenyl)-1H-pyrrole-2-carbonitrile 32a. White solid (55\%); $\mathrm{mp} 312{ }^{\circ} \mathrm{C} .{ }^{1} \mathrm{H}$ NMR $(400 \mathrm{MHz}, \mathrm{DMSO}) \delta_{\mathrm{H}} 11.81(\mathrm{~s}, 1 \mathrm{H}), 7.84-7.74$ $(\mathrm{m}, 4 \mathrm{H}), 7.67(\mathrm{dd}, J=2.8,1.6 \mathrm{~Hz}, 1 \mathrm{H}), 7.31(\mathrm{dd}, J=4.0,1.6 \mathrm{~Hz}, 1 \mathrm{H})$, $7.15(\mathrm{~d}, J=10.0 \mathrm{~Hz}, 1 \mathrm{H}), 7.06(\mathrm{ddd}, J=12.0,9.6,2.4 \mathrm{~Hz}, 1 \mathrm{H}), 6.52$ $(\mathrm{dd}, J=3.9,2.8 \mathrm{~Hz}, 1 \mathrm{H}), 1.86(\mathrm{~s}, 3 \mathrm{H}) .{ }^{13} \mathrm{C}$ NMR $(101 \mathrm{MHz}, \mathrm{DMSO}) \delta_{\mathrm{C}}$ $175.33,161.19,146.24,142.77,138.87,134.57,130.86,128.96,128.22$, 124.59, 123.61, 117.07, 114.20, 111.64, 110.81, 103.09, 99.47, 99.21, 12.25. HRMS (ESI) $\mathrm{C}_{21} \mathrm{H}_{14} \mathrm{~N}_{3} \mathrm{OF}_{2}[\mathrm{M}+\mathrm{H}]^{+}$requires 362.1099 , found 362.1108 (100\%). Anal.: $\mathrm{C}_{21} \mathrm{H}_{13} \mathrm{~N}_{3} \mathrm{OF}_{2}$ requires $\mathrm{C} 69.80 \%, \mathrm{H} 3.63 \%, \mathrm{~N}$ $11.63 \%$. Found: C $69.67 \%, \mathrm{H} 3.66 \%$, N $11.38 \%$.

Preparation of 2-(4-(1H-indol-1-yl)phenyl)-5,7-difluoro-3-methylquinolin-4(1H)-one $32 \mathrm{~b}$. White solid $(57 \%) ; \mathrm{mp}$ decomposed at $325^{\circ} \mathrm{C} .{ }^{1} \mathrm{H} \mathrm{NMR}(400 \mathrm{MHz}, \mathrm{DMSO}) \delta_{\mathrm{H}} 11.79(\mathrm{~s}, 1 \mathrm{H}), 7.84(\mathrm{~d}, J=8.5 \mathrm{~Hz}$, $2 \mathrm{H}), 7.81-7.74(\mathrm{~m}, 3 \mathrm{H}), 7.69(\mathrm{t}, J=8.6 \mathrm{~Hz}, 2 \mathrm{H}), 7.26(\mathrm{t}, J=7.7 \mathrm{~Hz}, 1 \mathrm{H})$, $7.22-7.14(\mathrm{~m}, 2 \mathrm{H}), 7.06$ (ddd, $J=12.0,9.7,2.4 \mathrm{~Hz}, 1 \mathrm{H}), 6.78(\mathrm{~d}, J=$ $3.3 \mathrm{~Hz}, 1 \mathrm{H}), 1.91(\mathrm{~s}, 3 \mathrm{H}) ;{ }^{13} \mathrm{C}$ NMR $(101 \mathrm{MHz}, \mathrm{DMSO}) \delta_{\mathrm{C}} 175.38$, 146.64, 142.71, 140.41, 137.96, 135.25, 132.43, 130.93, 129.74, 128.77, $123.87,122.96,121.51,120.98,117.40,117.01,110.75,104.64,99.47$, 99.13, 96.43, 12.35. HRMS (ESI) $\mathrm{C}_{24} \mathrm{H}_{17} \mathrm{~N}_{2} \mathrm{OF}_{2}[\mathrm{M}+\mathrm{H}]^{+}$requires 387.1303, found 387.1300 (100\%). Anal.: $\mathrm{C}_{24} \mathrm{H}_{16} \mathrm{~N}_{2} \mathrm{OF}_{2}$ requires $\mathrm{C}$ $74.60 \%$, H 4.17\%, N 7.25\%. Found: C 74.21\%, H 4.17\%, N 7.24\%.

Preparation of 2-(4-(1H-Pyrazol-1-yl)phenyl)-5,7-difluoro-3methylquinolin-4(1H)-one 32c. White solid (yield $35 \%$ ); mp $306{ }^{\circ} \mathrm{C}$. ${ }^{1} \mathrm{H}$ NMR $(400 \mathrm{MHz}, \mathrm{DMSO}) \delta_{\mathrm{H}} 11.73(\mathrm{~s}, 1 \mathrm{H}, \mathrm{NH}), 8.66(\mathrm{~d}, J=2.5 \mathrm{~Hz}$, $1 \mathrm{H}), 8.07(\mathrm{~d}, J=8.6 \mathrm{~Hz}, 2 \mathrm{H}), 7.83(\mathrm{~d}, J=1.6 \mathrm{~Hz}, 1 \mathrm{H}), 7.70(\mathrm{~d}, J=$ $8.5 \mathrm{~Hz}, 2 \mathrm{H}), 7.16(\mathrm{~d}, J=9.8 \mathrm{~Hz}, 1 \mathrm{H}), 7.05$ (ddd, $J=11.9,9.7,2.3 \mathrm{~Hz}$, $1 \mathrm{H}), 6.74-6.53(\mathrm{~m}, 1 \mathrm{H}), 1.87\left(\mathrm{~s}, 3 \mathrm{H}, \mathrm{CH}_{3}\right) .{ }^{13} \mathrm{C}$ NMR $(101 \mathrm{MHz}$, DMSO) $\delta_{\mathrm{C}} 175.47(\mathrm{C}=\mathrm{O}), 163.94(\mathrm{dd}, J=72.7,14.9 \mathrm{~Hz}, \mathrm{C}-\mathrm{F})$, 161.40 (dd, $J=87.4,15.3 \mathrm{~Hz}, \mathrm{C}-\mathrm{F}$ ), $146.70,142.81$ (dd, $J=14.6,6.2$ $\mathrm{Hz}), 142.04,140.83,132.36,130.81,128.55,118.62,117.04,110.80$ $(\mathrm{d}, J=8.8 \mathrm{~Hz}), 108.85,99.70(\mathrm{dd}, J=24.4,4.5 \mathrm{~Hz}), 99.09(\mathrm{~d}, J=$ $25.2 \mathrm{~Hz}), 12.40\left(\mathrm{CH}_{3}\right)$. HRMS (ESI) $\mathrm{C}_{19} \mathrm{H}_{13} \mathrm{~N}_{3} \mathrm{OF}_{2}^{23} \mathrm{Na}[\mathrm{M}+\mathrm{Na}]^{+}$ requires 360.0924, found 360.0935. Anal.: $\mathrm{C}_{19} \mathrm{H}_{13} \mathrm{~N}_{3} \mathrm{OF}_{2}$ requires $\mathrm{C}$ $67.65 \%$, H 3.88\%, N $12.46 \%$. Found: C 67.26\%, H 4.00\%, N $12.24 \%$.

Preparation of 2-(4-(1H-Pyrrol-1-yl)phenyl)-5-fluoro-3-methylquinolin-4(1H)-one $32 \mathrm{~d}$. White solid (yield $32 \%$ ); $\mathrm{mp}>300{ }^{\circ} \mathrm{C} .{ }^{1} \mathrm{H}$ NMR $(400 \mathrm{MHz}, \mathrm{DMSO}) \delta_{\mathrm{H}} 11.66(\mathrm{~s}, 1 \mathrm{H}, \mathrm{NH}), 7.96-7.73(\mathrm{~m}, 2 \mathrm{H}), 7.67-$ $7.61(\mathrm{~m}, 2 \mathrm{H}), 7.61-7.49(\mathrm{~m}, 3 \mathrm{H}), 7.42(\mathrm{~d}, J=8.4 \mathrm{~Hz}, 1 \mathrm{H}), 6.97(\mathrm{dd}, J=$ $12.1,7.9 \mathrm{~Hz}, 1 \mathrm{H}), 6.49-6.14(\mathrm{~m}, 2 \mathrm{H}), 1.88\left(\mathrm{~s}, 3 \mathrm{H}, \mathrm{CH}_{3}\right) .{ }^{13} \mathrm{C}$ NMR $(101 \mathrm{MHz}, \mathrm{DMSO}) \delta_{\mathrm{C}} 175.85(\mathrm{C}=\mathrm{O}), 162.15,159.57,146.57,142.23$, $142.21(\mathrm{~d}, J=4.4 \mathrm{~Hz}), 140.89,132.06(\mathrm{~d}, J=10.8 \mathrm{~Hz}), 131.60,130.84$, $119.35(\mathrm{~d}, J=12.6 \mathrm{~Hz}), 116.59,114.53,113.36(\mathrm{~d}, J=8.8 \mathrm{~Hz}), 111.37$, $108.68(\mathrm{~d}, J=20.9 \mathrm{~Hz}), 12.46\left(\mathrm{CH}_{3}\right)$. HRMS (ESI) $\mathrm{C}_{20} \mathrm{H}_{15} \mathrm{~N}_{2} \mathrm{OF}^{23} \mathrm{Na}$ $[\mathrm{M}+\mathrm{Na}]^{+}$requires 341.1066, found 341.1080. Anal.: $\mathrm{C}_{20} \mathrm{H}_{15} \mathrm{~N}_{2} \mathrm{OF}$ requires C $75.46 \%, \mathrm{H} 4.75 \%, \mathrm{~N} 8.80 \%$. Found: C 75.23\%, H 4.70\%, $\mathrm{N} 8.72 \%$.

Preparation of 2-(4-(1H-pyrrol-1-yl)phenyl)-5,7-difluoro-3-methylquinolin-4(1H)-one $32 \mathrm{e}$. White solid $(41 \mathrm{mg}, 30 \%) .{ }^{1} \mathrm{H}$ NMR $(400$ $\mathrm{MHz}, \mathrm{DMSO}) \delta_{\mathrm{H}} 11.65(\mathrm{~s}, 1 \mathrm{H}, \mathrm{NH}), 7.96-7.73(\mathrm{~m}, 2 \mathrm{H}), 7.69-7.63$ $(\mathrm{m}, 2 \mathrm{H}), 7.61-7.45(\mathrm{~m}, 2 \mathrm{H}), 7.42(\mathrm{~d}, \mathrm{~J}=8.3 \mathrm{~Hz}, 1 \mathrm{H}), 6.95(\mathrm{dd}, \mathrm{J}=12.1$, $8.0 \mathrm{~Hz}, 1 \mathrm{H}), 6.49-6.15(\mathrm{~m}, 2 \mathrm{H}), 1.87\left(\mathrm{~s}, 3 \mathrm{H}, \mathrm{CH}_{3}\right) ;{ }^{13} \mathrm{C}$ NMR $(101 \mathrm{MHz}, \mathrm{DMSO}) \delta_{\mathrm{C}} 175.85(\mathrm{C}=\mathrm{O}), 162.05,158.57,146.37,142.24$, $142.25,140.91,135.01,131.62,130.57,118.38,117.61,114.58,112.56$, $111.38,108.12,12.51$. HRMS (ESI) $\mathrm{C}_{20} \mathrm{H}_{14} \mathrm{~N}_{2} \mathrm{~F}_{2} \mathrm{O}^{23} \mathrm{Na}[\mathrm{M}+\mathrm{Na}]+$ requires 359.0972, found 359.0969. Purity HPLC 98\% (method A) Rt $=2.29 \mathrm{~min}$.

Preparation of 2-(3-Chloro-4-(1H-pyrrol-1-yl)phenyl)-5,7-difluoro-3-methylquinolin-4(1H)-one 32f. White solid (yield 39\%); mp 297-298 ${ }^{\circ} \mathrm{C} .{ }^{1} \mathrm{H}$ NMR (400 MHz, DMSO) $\delta_{\mathrm{H}} 11.79(\mathrm{~s}, 1 \mathrm{H}, \mathrm{NH})$, $7.92(\mathrm{~s}, 1 \mathrm{H}), 7.75-7.57(\mathrm{~m}, 2 \mathrm{H}), 7.19-7.01(\mathrm{~m}, 4 \mathrm{H}), 6.32(\mathrm{t}, J=2.1 \mathrm{~Hz}$, $2 \mathrm{H}), 1.87\left(\mathrm{~s}, 3 \mathrm{H}, \mathrm{CH}_{3}\right) \cdot{ }^{13} \mathrm{C}$ NMR $(101 \mathrm{MHz}, \mathrm{DMSO}) \delta_{\mathrm{C}} 175.42$, 164.30, 161.92 (d, $J=14.8 \mathrm{~Hz}), 160.97$ (d, $J=15.3 \mathrm{~Hz}), 145.27,142.84$, $139.25,134.90,131.52,129.60,128.42,128.35,122.63,117.30,110.23$, $99.72(\mathrm{~d}, J=19.1 \mathrm{~Hz}), 99.24(\mathrm{~d}, J=26.0 \mathrm{~Hz}), 12.30$. HRMS (ESI) $\mathrm{C}_{20} \mathrm{H}_{13} \mathrm{~N}_{2} \mathrm{OF}_{2}{ }^{35} \mathrm{Cl}^{23} \mathrm{Na}[\mathrm{M}+\mathrm{Na}]^{+}$requires 393.0582, found 393.0592. Anal.: $\mathrm{C}_{20} \mathrm{H}_{13} \mathrm{~N}_{2} \mathrm{OF}$ requires $\mathrm{C} 64.79 \%, \mathrm{H} 3.53 \%, \mathrm{~N} 7.56 \%$. Found: C $64.66 \%$, H3.69\%, N 7.39\%.

Preparation of 5,7-Difluoro-2-(2-fluoro-4-(1H-pyrrol-1-yl)phenyl)3-methylquinolin-4(1H)-one $32 \mathrm{~g}$. White solid (yield $39 \%$ ); mp $307^{\circ} \mathrm{C}$. ${ }^{1} \mathrm{H}$ NMR $(400 \mathrm{MHz}, \mathrm{DMSO}) \delta_{\mathrm{H}} 11.82(\mathrm{~s}, 1 \mathrm{H}, \mathrm{NH}), 7.84(\mathrm{dd}, J=11.8$, $1.9 \mathrm{~Hz}, 1 \mathrm{H}), 7.77-7.64(\mathrm{~m}, 2 \mathrm{H}), 7.62-7.55(\mathrm{~m}, 2 \mathrm{H}), 7.18-6.99$ $(\mathrm{m}, 2 \mathrm{H}), 6.40-6.23(\mathrm{~m}, 2 \mathrm{H}), 1.79\left(\mathrm{~s}, 3 \mathrm{H}, \mathrm{CH}_{3}\right)$. HRMS (ESI) $\mathrm{C}_{20} \mathrm{H}_{14} \mathrm{~N}_{2} \mathrm{OF}_{3}[\mathrm{M}+\mathrm{H}]^{+}$requires 355.1058 , found 355.1074. Anal.: $\mathrm{C}_{20} \mathrm{H}_{13} \mathrm{~N}_{2} \mathrm{OF}_{3}$ requires $\mathrm{C} 67.79 \%, \mathrm{H} 3.70 \%, \mathrm{~N} 7.91 \%$. Found: C 66.94\%, H 3.68\%, N 7.73\%.

Preparation of (R)-5,7-Difluoro-2-(4-(3-fluoropyrrolidin-1-yl)phenyl)-3-methylquinolin-4(1H)-one $38 a$. White solid (45\%); mp 313-314 ${ }^{\circ} \mathrm{C}$. ${ }^{1} \mathrm{H}$ NMR (400 MHz, DMSO) $\delta_{\mathrm{H}} 11.47(\mathrm{~s}, 1 \mathrm{H}), 7.38$ $(\mathrm{d}, J=8.7 \mathrm{~Hz}, 2 \mathrm{H}), 7.18(\mathrm{~d}, J=9.3 \mathrm{~Hz}, 1 \mathrm{H}), 6.99$ (ddd $J=12.0,9.6$, $2.4 \mathrm{~Hz}, 1 \mathrm{H}), 6.73(\mathrm{~d}, J=8.7 \mathrm{~Hz}, 2 \mathrm{H}), 5.50(\mathrm{~d}, J=54.1 \mathrm{~Hz}, 1 \mathrm{H}), 3.71-$ $3.36(\mathrm{~m}, 4 \mathrm{H}), 2.38-2.12(\mathrm{~m}, 2 \mathrm{H}), 1.89(\mathrm{~s}, 3 \mathrm{H}),{ }^{13} \mathrm{C}$ NMR $(101 \mathrm{MHz}$, DMSO) $\delta_{\mathrm{C}} 175.38,148.31,147.92,142.70,130.35,121.60,116.19$, $111.70,110.56,99.39,98.76,94.49,92.78,54.48,45.59,32.14$, 31.93, 12.58. ES HRMS: $m / z$ found $359.1385, \mathrm{C}_{20} \mathrm{H}_{18} \mathrm{~N}_{2} \mathrm{OF}_{3}$ requires 
359.1371. Anal.: $\mathrm{C}_{20} \mathrm{H}_{17} \mathrm{~N}_{2} \mathrm{OF}_{3}$ requires $\mathrm{C} 67.03 \%, \mathrm{H} 4.78 \%$, N 7.82\%. Found: C $67.26 \%$, H $4.73 \%$, N 7.81\%.

Preparation of (S)-5,7-Difluoro-2-(4-(3-fluoropyrrolidin-1-yl)phenyl)-3-methylquinolin-4(1H)-one 38b. White solid (47\%); mp 313-314 ${ }^{\circ} \mathrm{C} .{ }^{1} \mathrm{H}$ NMR $(400 \mathrm{MHz}, \mathrm{DMSO}) \delta_{\mathrm{H}} 11.47(\mathrm{~s}, 1 \mathrm{H}), 7.38$ $(\mathrm{d}, J=8.6 \mathrm{~Hz}, 2 \mathrm{H}), 7.18(\mathrm{~d}, J=9.2 \mathrm{~Hz}, 1 \mathrm{H}), 6.99$ (ddd, $J=12.0,9.7$, $2.4 \mathrm{~Hz}, 1 \mathrm{H}), 6.73(\mathrm{~d}, J=8.7 \mathrm{~Hz}, 2 \mathrm{H}), 5.50(\mathrm{~d}, J=54.3 \mathrm{~Hz}, 1 \mathrm{H}), 3.69-$ $3.36(\mathrm{~m}, 4 \mathrm{H}), 2.36-2.13(\mathrm{~m}, 2 \mathrm{H}), 1.89(\mathrm{~s}, 3 \mathrm{H}) .{ }^{13} \mathrm{C}$ NMR $(101 \mathrm{MHz}$, DMSO) $\delta_{\mathrm{C}} 175.38,148.32,147.93,142.78,130.36,121.60,116.19$, $111.70,110.54,99.36,98.76,94.49,92.78,54.48,45.59,32.14$, 31.93, 12.58. ES HRMS: $m / z$ found $359.1381, \mathrm{C}_{20} \mathrm{H}_{18} \mathrm{~N}_{2} \mathrm{OF}_{3}$ requires 359.1371. Anal.: $\mathrm{C}_{20} \mathrm{H}_{17} \mathrm{~N}_{2} \mathrm{OF}_{3}$ requires $\mathrm{C} 67.03 \%, \mathrm{H} 4.78 \%, \mathrm{~N} 7.82 \%$. Found: C $67.25 \%$, H 4.67\%, N 7.86\%.

Preparation of 2-(4-(3,3-Difluoroazetidin-1-yl)phenyl)-5,7-difluoro-3-methylquinolin-4(1H)-one 38c. White solid (33\%); mp 316-318 ${ }^{\circ} \mathrm{C} .{ }^{1} \mathrm{H}$ NMR:(400 MHz, DMSO) $\delta_{\mathrm{H}} 11.54(\mathrm{~s}, 1 \mathrm{H}), 7.43$ $(\mathrm{d}, J=8.4 \mathrm{~Hz}, 2 \mathrm{H}), 7.16(\mathrm{~d}, J=9.6 \mathrm{~Hz}, 1 \mathrm{H}), 7.01(\mathrm{t}, J=10.8 \mathrm{~Hz}, 1 \mathrm{H})$, $6.74(\mathrm{~d}, J=8.5 \mathrm{~Hz}, 2 \mathrm{H}), 4.37(\mathrm{t}, J=12.3 \mathrm{~Hz}, 4 \mathrm{H}), 1.86(\mathrm{~s}, 3 \mathrm{H}) .{ }^{13} \mathrm{C}$ $(101 \mathrm{MHz}, \mathrm{DMSO}) \delta_{\mathrm{C}} 175.39,150.88,147.53,142.81,130.18,124.67$, 117.01, 116.50, 112.70, 110.53, 99.41, 98.90, 90.56, 74.81, 63.29, 12.44 . ES HRMS: $m / z$ found $363.1130, \mathrm{C}_{19} \mathrm{H}_{15} \mathrm{~N}_{2} \mathrm{OF}_{4}$ requires 363.1121 . Anal.: $\mathrm{C}_{19} \mathrm{H}_{14} \mathrm{~N}_{2} \mathrm{OF}_{4}$ requires C $62.98 \%, \mathrm{H} 3.89 \%$, N 7.73\%. Found: C $63.03 \%$, H $3.79 \%$, N $7.71 \%$.

Preparation of 2-(4-(3,4-Difluoro-1H-pyrrol-1-yl)phenyl)-5,7-difluoro-3-methylquinolin-4(1H)-one $38 d$. White solid (38 mg, 30\%). ${ }^{1} \mathrm{H}$ NMR (400 MHz, DMSO) $\delta_{\mathrm{H}} 11.78$ (bs, $\left.1 \mathrm{H}\right), 7.83(\mathrm{~d}, J=8.8 \mathrm{~Hz}$, $2 \mathrm{H}), 7.72(\mathrm{~d}, J=8.8 \mathrm{~Hz}, 4 \mathrm{H}), 7.14(\mathrm{~d}, J=9.6 \mathrm{~Hz}, 1 \mathrm{H}), 7.11(\mathrm{dd}, J=11.0$, $10.6 \mathrm{~Hz}, 1 \mathrm{H}), 1.91(\mathrm{~s}, 3 \mathrm{H}) .{ }^{13} \mathrm{C}$ NMR $(100 \mathrm{MHz}, \mathrm{DMSO}) \delta_{\mathrm{C}} 175.1$, 146.8, 140.3, 131.8, 130.8, 118.7, 116.9, 103.0, 12.3. $\mathrm{MS}\left(\mathrm{ES}^{+}\right) \mathrm{m} / z 373$ $(\mathrm{M}+\mathrm{H})^{+}$. HRMS calculated for $373.0964 \mathrm{C}_{20} \mathrm{H}_{13} \mathrm{~N}_{2} \mathrm{OF}_{4}$, found 373.0965. Purity HPLC $98 \%\left(\operatorname{method}\right.$ A) $R_{\mathrm{t}}=2.60 \mathrm{~min}$.

Preparation of 2-(4-(3,4-Difluoro-1H-pyrrol-1-yl)phenyl)-7-methoxy-3-methylquinolin-4(1H)-one 38e. White solid (0.12 g, 32\%). ${ }^{1} \mathrm{H}$ NMR (400 MHz, DMSO) $\delta_{\mathrm{H}} 11.48(\mathrm{bs}, 1 \mathrm{H}), 8.02(\mathrm{~d}, J=9.2 \mathrm{~Hz}$, $1 \mathrm{H}), 7.75(\mathrm{~d}, J=8.8 \mathrm{~Hz}, 2 \mathrm{H}), 7.66(\mathrm{~m}, 4 \mathrm{H}), 7.01(\mathrm{~s}, 1 \mathrm{H}), 6.90(\mathrm{~d}, J=$ $9.0 \mathrm{~Hz}, 1 \mathrm{H}), 3.82(\mathrm{~s}, 3 \mathrm{H}), 1.90(\mathrm{~s}, 3 \mathrm{H}) .{ }^{13} \mathrm{C} \mathrm{NMR}(100 \mathrm{MHz}, \mathrm{DMSO})$ $\delta_{\mathrm{C}} 176.5,161.9,141.8,141.1,140.0,138.9,138.7,130.8,127.2,118.6$, 118.0, 114.3, 113.3, 102.7, 102.5, 102.4, 99.2,. 55.7, 12.5. MS $\left(\mathrm{ES}^{+}\right) \mathrm{m} / \mathrm{z}$ $367(\mathrm{M}+\mathrm{H})^{+}$. HRMS calculated for $367.1258 \mathrm{C}_{21} \mathrm{H}_{17} \mathrm{~N}_{2} \mathrm{O}_{2} \mathrm{~F}_{2}$, found 367.1257. Purity HPLC $99+\%(\operatorname{method} \mathrm{A}) R_{\mathrm{t}}=2.09 \mathrm{~min}$.

Preparation of 6-Chloro-2-(4-(3,4-difluoro-1H-pyrrol-1-yl)phenyl)-7-methoxy-3-methylquinolin-4(1H)-one 38f. White solid $(0.11 \mathrm{~g}, 30 \%) .{ }^{1} \mathrm{H}$ NMR $(400 \mathrm{MHz}, \mathrm{DMSO}) \delta_{\mathrm{H}} 11.75$ (bs, $\left.1 \mathrm{H}\right), 8.03$ $(\mathrm{s}, 1 \mathrm{H}), 7.71(\mathrm{~d}, J=8.8 \mathrm{~Hz}, 2 \mathrm{H}), 7.63(\mathrm{~m}, 4 \mathrm{H}), 7.15(\mathrm{~s}, 1 \mathrm{H}), 3.89(\mathrm{~s}$, $3 \mathrm{H}), 1.91(\mathrm{~s}, 3 \mathrm{H}) .{ }^{13} \mathrm{C}$ NMR $(100 \mathrm{MHz}, \mathrm{DMSO}) \delta_{\mathrm{C}} 175.1,156.3,139.7$, $138.7,130.8,126.0,118.5,114.2,102.7,102.5,102.4,56.5,12.9$. MS $\left(\mathrm{ES}^{+}\right) \mathrm{m} / z$ 401 $(\mathrm{M}+\mathrm{H})^{+}$. HRMS calculated for 401.0868 $\mathrm{C}_{21} \mathrm{H}_{16} \mathrm{~N}_{2} \mathrm{O}_{2} \mathrm{~F}_{2}{ }^{35} \mathrm{Cl}$, found 401.0870. Purity HPLC 97\% (method A) $R_{\mathrm{t}}=2.35$ min..

Preparation of 5,7-Difluoro-2-(4-(3-hydroxy-3-methylpiperidin-1yl)phenyl)-3-methylquinolin-4(1H)-one $38 \mathrm{~g}$. While solid (48\%); mp decomposed at $284^{\circ} \mathrm{C} .{ }^{1} \mathrm{H}$ NMR $(400 \mathrm{MHz}, \mathrm{DMSO}) \delta_{\mathrm{H}} 11.47(\mathrm{~s}, 1 \mathrm{H})$, $7.35(\mathrm{~d}, J=8.8 \mathrm{~Hz}, 2 \mathrm{H}), 7.16(\mathrm{~d}, J=9.2 \mathrm{~Hz}, 1 \mathrm{H}), 7.07-6.94(\mathrm{~m}, 3 \mathrm{H})$, $4.46(\mathrm{~s}, 1 \mathrm{H}), 3.30-3.02(\mathrm{~m}, 4 \mathrm{H}), 1.88(\mathrm{~s}, 3 \mathrm{H}), 1.86-1.75(\mathrm{~m}, 1 \mathrm{H})$, $1.63-1.48(\mathrm{~m}, 3 \mathrm{H}), 1.17(\mathrm{~s}, 3 \mathrm{H}) .{ }^{13} \mathrm{C}$ NMR $(101 \mathrm{MHz}, \mathrm{DMSO}) \delta_{\mathrm{C}}$ $175.37,163.50,161.49,152.33,147.68,142.79,130.15,123.19,116.27$, $114.64,110.56,99.34,98.82,67.64,59.76,47.81,37.73,27.28$, 22.10, 12.52. ES HRMS: $m / z$ found $385.1738, \mathrm{C}_{22} \mathrm{H}_{23} \mathrm{~N}_{2} \mathrm{O}_{2} \mathrm{~F}_{2}$ requires 385.1728. Anal.: $\mathrm{C}_{22} \mathrm{H}_{22} \mathrm{~N}_{2} \mathrm{O}_{2} \mathrm{~F}_{2}$ requires C $68.74 \%$, $\mathrm{H} 5.77 \%$, N 7.29\%. Found: C $68.49 \%$, H 5.84\%, N 7.39\%.

Preparation of 5,7-Difluoro-2-(4-(3-hydroxy-3-methylpyrrolidin1-yl)phenyl)-3-methylquinolin-4(1H)-one $38 \mathrm{~h}$. White solid $(50 \%)$; mp 288-290 ${ }^{\circ} \mathrm{C}$. ${ }^{1} \mathrm{H}$ NMR (400 MHz, DMSO) $\delta_{\mathrm{H}} 11.43(\mathrm{~s}, 1 \mathrm{H}), 7.35$ $(\mathrm{d}, J=8.7 \mathrm{~Hz}, 2 \mathrm{H}), 7.18(\mathrm{~d}, J=10.1 \mathrm{~Hz}, 1 \mathrm{H}), 6.98(\mathrm{ddd}, J=12.0,9.6,2.5$ $\mathrm{Hz}, 1 \mathrm{H}), 6.62(\mathrm{~d}, J=8.8 \mathrm{~Hz}, 2 \mathrm{H}), 4.85(\mathrm{~s}, 1 \mathrm{H}), 3.48-3.36(\mathrm{~m}, 2 \mathrm{H}), 3.24$ $(\mathrm{s}, 2 \mathrm{H}), 2.01-1.92(\mathrm{~m}, 2 \mathrm{H}), 1.89(\mathrm{~s}, 3 \mathrm{H}), 1.37(\mathrm{~s}, 3 \mathrm{H}) .{ }^{13} \mathrm{C}$ NMR $(101$ $\mathrm{MHz}, \mathrm{DMSO}) \delta_{\mathrm{C}} 175.38,160.89,155.31,148.73,148.07,130.29$, $120.65,116.06,111.02,99.38,96.34,94.24,91.71,75.74,60.95,55.28$, 46.88, 26.29, 12.63. ES HRMS: $m / z$ found 399.1391, $\mathrm{C}_{21} \mathrm{H}_{20} \mathrm{~N}_{2} \mathrm{O}_{2} \mathrm{~F}_{2}{ }^{23} \mathrm{Na}$ requires 393.1391. Purity HPLC $98 \%(\operatorname{method} \mathrm{A}) R_{\mathrm{t}}=2.25 \mathrm{~min}$.
Preparation of 5,7-Difluoro-2-(4-(3-hydroxy-3-methylazetidin-1yl)phenyl)-3-methylquinolin-4(1H)-one 38i. White solid (43\%); mp decomposed at $289^{\circ} \mathrm{C} .{ }^{1} \mathrm{H}$ NMR $(400 \mathrm{MHz}, \mathrm{DMSO}) \delta_{\mathrm{H}} 11.48(\mathrm{~s}, 1 \mathrm{H})$, $7.35(\mathrm{~d}, J=8.6 \mathrm{~Hz}, 2 \mathrm{H}), 7.16(\mathrm{~d}, J=9.1 \mathrm{~Hz}, 1 \mathrm{H}), 6.99$ (ddd, $J=12.0,9.6$, $2.4 \mathrm{~Hz}, 1 \mathrm{H}), 6.58(\mathrm{~d}, J=8.6 \mathrm{~Hz}, 2 \mathrm{H}), 5.60(\mathrm{~s}, 1 \mathrm{H}), 3.83(\mathrm{~d}, J=7.9 \mathrm{~Hz}$, $2 \mathrm{H}), 3.69(\mathrm{~d}, J=7.7 \mathrm{~Hz}, 2 \mathrm{H}), 1.86(\mathrm{~s}, 3 \mathrm{H}), 1.48(\mathrm{~s}, 3 \mathrm{H}) .{ }^{13} \mathrm{C}$ NMR $(101 \mathrm{MHz}, \mathrm{DMSO}) \delta_{\mathrm{C}} 175.38,160.90,152.74,147.89,142.69,136.81$, 134.24, 130.07, 122.72, 116.28, 111.45, 99.62, 98.81, 67.73, 66.17, 27.02, 12.52. ES HRMS: $m / z$ found $379.1237, \mathrm{C}_{20} \mathrm{H}_{18} \mathrm{~N}_{2} \mathrm{O}_{2} \mathrm{~F}_{2}{ }^{23} \mathrm{Na}$ requires 379.1234. Anal.: $\mathrm{C}_{20} \mathrm{H}_{18} \mathrm{~N}_{2} \mathrm{O}_{2} \mathrm{~F}_{2}$ requires C 67.41\%, $\mathrm{H}$ 5.09\%, N 7.86\%. Found: C $67.18 \%$, H 5.49\%, N 7.24\%.

Preparation of (S)-2-(4-(2-((Benzyloxy)methyl)pyrrolidin-1-yl)phenyl)-5,7-difluoro-3-methylquinolin-4(1H)-one 38j. Cream solid $(0.10 \mathrm{~g}, 20 \%) .{ }^{1} \mathrm{H}$ NMR $(400 \mathrm{MHz}, \mathrm{DMSO}) \delta_{\mathrm{H}} 10.60(\mathrm{bs}, 1 \mathrm{H}), 7.33(\mathrm{~m}$, $6 \mathrm{H}), 7.22(\mathrm{~d}, J=8.8 \mathrm{~Hz}, 2 \mathrm{H}), 6.56(\mathrm{dd}, J=11.0,10.6 \mathrm{~Hz}, 1 \mathrm{H}), 6.44$ $(\mathrm{d}, J=8.8 \mathrm{~Hz}, 2 \mathrm{H}), 4.52(\mathrm{~s}, 2 \mathrm{H}), 3.84(\mathrm{~m}, 1 \mathrm{H}), 3.51(\mathrm{dd}, J=8.8,4.5 \mathrm{~Hz}$, $1 \mathrm{H}), 3.30(\mathrm{~m}, 2 \mathrm{H}), 3.05(\mathrm{~m}, 1 \mathrm{H}), 2.05(\mathrm{~m}, 4 \mathrm{H}), 1.92(\mathrm{~s}, 3 \mathrm{H}) .{ }^{13} \mathrm{C}$ NMR $(100 \mathrm{MHz}, \mathrm{DMSO}) \delta_{\mathrm{C}} 177.1,148.8,147.9,138.1,129.7,128.4,127.8$, 127.6, 121.5, 117.2, 111.3, 99.2, 73.4, 70.0, 58.2, 48.3, 28.9, 23.2, 12.4. MS $\left(\mathrm{ES}^{+}\right) m / z 461(\mathrm{M}+\mathrm{H})^{+}$. HRMS calculated for 461.2041 $\mathrm{C}_{28} \mathrm{H}_{27} \mathrm{~N}_{2} \mathrm{O}_{2} \mathrm{~F}_{2}$, found 461.2055 .

General Procedure for the Preparation of Compounds 39a-c. Preparation of (S)-5,7-Difluoro-2-(4-(2-(hydroxymethyl)pyrrolidin-1yl)phenyl)-3-methylquinolin-4(1H)-one 39a. Cream solid $(50 \mathrm{mg}$, $90 \%) .{ }^{1} \mathrm{H}$ NMR (400 MHz, DMSO) $\delta_{\mathrm{H}} 11.45(\mathrm{bs}, 1 \mathrm{H}), 7.35$ (d, $J=$ $8.8 \mathrm{~Hz}, 2 \mathrm{H}), 7.20(\mathrm{dd}, J=8.0,4.5 \mathrm{~Hz}, 1 \mathrm{H}), 7.01(\mathrm{dd}, J=11.0,10.6 \mathrm{~Hz}$, $1 \mathrm{H}), 6.75(\mathrm{~d}, J=8.8 \mathrm{~Hz}, 2 \mathrm{H}), 4.90(\mathrm{~m}, 1 \mathrm{H}), 3.81(\mathrm{~m}, 1 \mathrm{H}), 3.75(\mathrm{~m}, 1 \mathrm{H})$, $3.50(\mathrm{~m}, 1 \mathrm{H}), 3.22(\mathrm{~m}, 1 \mathrm{H}), 3.10(\mathrm{~m}, 1 \mathrm{H}), 2.03(\mathrm{~m}, 4 \mathrm{H}), 1.92(\mathrm{~s}, 3 \mathrm{H})$. ${ }^{13} \mathrm{C}$ NMR $(100 \mathrm{MHz}, \mathrm{DMSO}) \delta_{\mathrm{C}} 175.4,148.4,148.0,130.3,121.1$, 116.1, 111.7, 99.3, 61.3, 60.5, 48.5, 28.3, 23.0, 12.6. MS $\left(\mathrm{ES}^{+}\right) \mathrm{m} / z 371$ $(\mathrm{M}+\mathrm{H})^{+}$. HRMS calculated for $371.1571 \mathrm{C}_{21} \mathrm{H}_{21} \mathrm{~N}_{2} \mathrm{O}_{2} \mathrm{~F}_{2}$, found 371.1568. Purity HPLC $96 \%$ (method A) $R_{\mathrm{t}}=2.25 \mathrm{~min}$.

Preparation of (R)-5,7-Difluoro-2-(4-(2-(hydroxymethyl)pyrrolidin-1-yl)phenyl)-3-methylquinolin-4(1H)-one 39b. Light-yellow solid $(0.065 \mathrm{~g}, 85 \%) .{ }^{1} \mathrm{H}$ NMR $(400 \mathrm{MHz}, \mathrm{DMSO}) \delta_{\mathrm{H}} 11.44$ (bs, $1 \mathrm{H}), 7.35(\mathrm{~d}, J=8.8 \mathrm{~Hz}, 2 \mathrm{H}), 7.17(\mathrm{~d}, J=8.0 \mathrm{~Hz}, 1 \mathrm{H}), 6.99(\mathrm{dd}, J=11.0$, $10.6 \mathrm{~Hz}, 1 \mathrm{H}), 6.75(\mathrm{~d}, J=8.8 \mathrm{~Hz}, 2 \mathrm{H}), 4.84(\mathrm{dd}, J=5.8,5.8 \mathrm{~Hz}, 1 \mathrm{H})$, $3.77(\mathrm{~m}, 1 \mathrm{H}), 3.51(\mathrm{~m}, 1 \mathrm{H}), 3.42(\mathrm{~m}, 1 \mathrm{H}), 3.25(\mathrm{~m}, 1 \mathrm{H}), 3.08(\mathrm{~m}, 1 \mathrm{H})$, $1.98(\mathrm{~m}, 4 \mathrm{H}), 1.89(\mathrm{~s}, 3 \mathrm{H}) .{ }^{13} \mathrm{C}$ NMR $(100 \mathrm{MHz}, \mathrm{DMSO}) \delta_{\mathrm{C}} 175.7$, $148.8,148.0,130.3,121.1,116.2,111.7,99.9,61.5,60.5,28.5,23.6,12.6$. MS $\left(\mathrm{ES}^{+}\right) \mathrm{m} / \mathrm{z} 371(\mathrm{M}+\mathrm{H})^{+}$. HRMS calculated for 371.1571 $\mathrm{C}_{21} \mathrm{H}_{21} \mathrm{~N}_{2} \mathrm{O}_{2} \mathrm{~F}_{2}$, found 371.1572. Purity HPLC 97\% (method A) $R_{\mathrm{t}}=$ 2.24 min.

Preparation of (R)-2-(4-(3-(Aminomethyl)pyrrolidin-1-yl)phenyl)5,7-difluoro-3-methylquinolin-4(1H)-one 39c. White solid $(21 \mathrm{mg}$, 93\%). ${ }^{1} \mathrm{H}$ NMR (400 MHz, DMSO) $\delta_{\mathrm{H}} 11.48$ (bs, $\left.1 \mathrm{H}\right), 7.40(\mathrm{~m}, 1 \mathrm{H})$, $7.38(\mathrm{~d}, J=8.8 \mathrm{~Hz}, 2 \mathrm{H}), 7.21(\mathrm{~d}, J=8.4 \mathrm{~Hz}, 1 \mathrm{H}), 6.99(\mathrm{dd}, J=11.0$, $10.6 \mathrm{~Hz}, 1 \mathrm{H}), 6.86(\mathrm{~d}, J=8.8 \mathrm{~Hz}, 2 \mathrm{H}), 4.09(\mathrm{~m}, 1 \mathrm{H}), 3.20(\mathrm{~m}, 1 \mathrm{H}), 2.99$ $(\mathrm{m}, 1 \mathrm{H}), 2.51(\mathrm{~d}, J=10.4 \mathrm{~Hz}, 1 \mathrm{H}), 2.31(\mathrm{dd}, J=14.4,10.9 \mathrm{~Hz}, 1 \mathrm{H}), 2.13$ $(\mathrm{m}, 1 \mathrm{H}), 1.98(\mathrm{~s}, 3 \mathrm{H}), 1.82(\mathrm{~m}, 2 \mathrm{H}), 1.63(\mathrm{~m}, 2 \mathrm{H}) .{ }^{13} \mathrm{C}$ NMR $(100 \mathrm{MHz}, \mathrm{DMSO}) \delta_{\mathrm{C}} 175.4,147.8,130.4,116.2,112.0,111.6,99.7$, 56.5, 56.2, 48.3, 34.6, 28.5, 12.6. MS (ES $\left.{ }^{+}\right) \mathrm{m} / z 370(\mathrm{M}+\mathrm{H})^{+}$. HRMS calculated for $370.1731 \mathrm{C}_{21} \mathrm{H}_{22} \mathrm{~N}_{3} \mathrm{OF}_{2}$, found 370.1738 . Purity HPLC $96 \%(\operatorname{method} \mathrm{A}) R_{\mathrm{t}}=1.61 \mathrm{~min}$.

Preparation of 2-(4-(3,3-Difluoropyrrolidin-1-yl)phenyl)-5,7-difluoro-3-methylquinolin-4(1H)-one 42a. White solid (56\%); mp decomposed at $316^{\circ} \mathrm{C} .{ }^{1} \mathrm{H}$ NMR $(400 \mathrm{MHz}, \mathrm{DMSO}) \delta_{\mathrm{H}} 7.41(\mathrm{~d}, J=$ $8.7 \mathrm{~Hz}, 2 \mathrm{H}), 7.17(\mathrm{~d}, J=9.0 \mathrm{~Hz}, 1 \mathrm{H}), 7.01$ (ddd, $J=12.0,9.6,2.4 \mathrm{~Hz}$, $1 \mathrm{H}), 6.78(\mathrm{~d}, J=8.8 \mathrm{~Hz}, 2 \mathrm{H}), 3.79(\mathrm{t}, J=13.3 \mathrm{~Hz}, 1 \mathrm{H}), 3.56(\mathrm{t}, J=$ $7.2 \mathrm{~Hz}, 1 \mathrm{H}), 2.59(\mathrm{tt}, J=14.5,7.3 \mathrm{~Hz}, 1 \mathrm{H}), 1.87(\mathrm{~s}, 1 \mathrm{H}) .{ }^{13} \mathrm{C}$ NMR $(101 \mathrm{MHz}, \mathrm{DMSO}) \delta 175.38,164.09,148.09,147.72,142.82,130.34$, $129.16,126.71,122.79,116.32,111.98,111.61,99.37,98.82,54.96$, 45.75, 33.72, 12.54. ES HRMS: $m / z$ found $399.1093, \mathrm{C}_{20} \mathrm{H}_{16} \mathrm{~N}_{2} \mathrm{OF}_{4}{ }^{23} \mathrm{Na}$ requires 399.1096. Anal.: $\mathrm{C}_{20} \mathrm{H}_{16} \mathrm{~N}_{2} \mathrm{OF}_{4}$ requires $\mathrm{C} 63.83 \%, \mathrm{H} 4.29 \%$, N 7.44\%. Found: C 63.49\%, H 4.31\%, N 7.28\%.

Preparation of 2-(4-(3,3-Difluoropiperidin-1-yl)phenyl)-5,7-difluoro-3-methylquinolin-4(1H)-one 42b. White solid (47\%); mp decomposed at $297{ }^{\circ} \mathrm{C} .{ }^{1} \mathrm{H}$ NMR (400 MHz, DMSO) $\delta_{\mathrm{H}} 11.54$ $(\mathrm{s}, 1 \mathrm{H}), 7.39(\mathrm{~d}, J=8.8 \mathrm{~Hz}, 2 \mathrm{H}), 7.20-7.11(\mathrm{~m}, 3 \mathrm{H}), 7.01(\mathrm{ddd}, J=12.0$, 9.6, 2.4 Hz, 1H), $3.65(\mathrm{t}, J=11.9 \mathrm{~Hz}, 2 \mathrm{H}), 3.43-3.37(\mathrm{~m}, 2 \mathrm{H}), 2.16-$ $2.01(\mathrm{~m}, 2 \mathrm{H}), 1.87(\mathrm{~s}, 3 \mathrm{H}), 1.85-1.75(\mathrm{~m}, 2 \mathrm{H}) .{ }^{13} \mathrm{C}$ NMR (101 MHz, 
DMSO) $\delta_{\mathrm{C}} 175.38,152.75,150.88,147.47,142.69,130.26,124.51$, 121.44, 116.43, 115.09, 113.88, 110.51, 99.67, 98.87, 53.21, 52.92, 46.93, 32.09, 21.59, 12.47. ES HRMS: $m / z$ found 391.1441, $\mathrm{C}_{21} \mathrm{H}_{19} \mathrm{~N}_{2} \mathrm{OF}_{4}$ requires 391.1434. Anal.: $\mathrm{C}_{21} \mathrm{H}_{18} \mathrm{~N}_{2} \mathrm{OF}_{4}$ requires $\mathrm{C} 64.61 \%, \mathrm{H} 4.65 \%$, N 7.18\%. Found: C 64.06\%, H 4.61\%, N 7.05\%.

Preparation of (R)-N-(tert-Butyl)-1-(4-(3-methyl-4-oxo-1,4-dihydroquinolin-2-yl)phenyl)pyrrolidine-2-carboxamide 45a. Pale-yellow powder (yield 20\%); mp $164-166{ }^{\circ} \mathrm{C} .{ }^{1} \mathrm{H} \mathrm{NMR}\left(400 \mathrm{MHz}, \mathrm{CDCl}_{3}-\mathrm{d}_{6}\right)$ $\delta_{\mathrm{H}} 11.11(\mathrm{~s}, 1 \mathrm{H}, \mathrm{NH}), 7.43(\mathrm{~d}, 2 \mathrm{H}, J=8.6 \mathrm{~Hz}, \mathrm{Ar}), 7.34(\mathrm{~d}, 1 \mathrm{H}, J=$ $9.6 \mathrm{~Hz}, \mathrm{Ar}), 6.71-6.61(\mathrm{~m}, 1 \mathrm{H}, \mathrm{Ar}), 6.55(\mathrm{~d}, 2 \mathrm{H}, J=8.6 \mathrm{~Hz}, \mathrm{Ar}), 6.28(\mathrm{~s}$ $1 \mathrm{H}, \mathrm{NH}), 3.59(\mathrm{t}, 1 \mathrm{H}, J=7.2 \mathrm{~Hz}, \mathrm{CH}), 2.99(\mathrm{dd}, 1 \mathrm{H}, J=15.4 \mathrm{~Hz}, 8.9 \mathrm{~Hz}$, $\left.\mathrm{CH}_{2}\right), 2.89\left(\mathrm{~d}, 1 \mathrm{H}, J=8.6 \mathrm{~Hz}, \mathrm{CH}_{2}\right), 2.03\left(\mathrm{~s}, 3 \mathrm{H}, \mathrm{CH}_{3}\right), 1.92-1.65(\mathrm{~m}$, $\left.4 \mathrm{H}, \mathrm{CH}_{2}\right), 1.34\left(\mathrm{~m}, 9 \mathrm{H}, \mathrm{CH}_{3}\right) .{ }^{13} \mathrm{C} \mathrm{NMR}\left(100 \mathrm{MHz}, \mathrm{CDCl}_{3}-d_{6}\right) \delta_{\mathrm{c}}$ 173.1, 148.0, 130.1, 125.3, 117.7, 113.1, 64.6, 51.3, 49.8, 31.4, 28.6, 24.0, 12.3. MS (ES+), $[\mathrm{M}+\mathrm{Na}]^{+}(100)$ 462.2. HRMS calculated for 462.1969 $\mathrm{C}_{25} \mathrm{H}_{27} \mathrm{O}_{2} \mathrm{~N}_{3} \mathrm{~F}_{2} \mathrm{Na}$, found 462.1955. Anal.: $\mathrm{C}_{25} \mathrm{H}_{27} \mathrm{~N}_{3} \mathrm{O}_{2} \mathrm{~F}_{2}$ requires $\mathrm{C}$ 68.32\%, H 6.19\%, N 9.56\%. Found: C 68.13\%, H 6.10\%, N 9.11\%.

Preparation of (R)-1-(4-(5,7-Difluoro-3-methyl-4-oxo-1,4-dihydroquinolin-2-yl)phenyl)- $N, N$-dimethylpyrrolidine-2-carboxamide 45b. Pale-yellow powder (yield 34\%); mp 176-178 ${ }^{\circ} \mathrm{C}$. ${ }^{1} \mathrm{H}$ NMR (400 $\left.\mathrm{MHz}, \mathrm{CDCl}_{3}-d_{6}\right) \delta_{\mathrm{H}} 10.40(\mathrm{~s}, 1 \mathrm{H}, \mathrm{NH}), 7.24-7.22(\mathrm{~m}, 1 \mathrm{H}, \mathrm{Ar}), 7.12$ $(\mathrm{d}, 2 \mathrm{H}, J=8.6 \mathrm{~Hz}, \mathrm{Ar}), 6.73-6.56(\mathrm{~m}, 1 \mathrm{H}, \mathrm{Ar}), 6.13(\mathrm{~d}, 2 \mathrm{H}, J=8.6 \mathrm{~Hz}$, $\mathrm{Ar}), 4.22(\mathrm{dd}, 1 \mathrm{H} . J=8.8 \mathrm{~Hz}, 2.1 \mathrm{~Hz}, \mathrm{CH}), 3.46-3.39\left(\mathrm{~m}, 1 \mathrm{H}, \mathrm{CH}_{2}\right)$, $3.25\left(\mathrm{dd}, 1 \mathrm{H}, J=16.0 \mathrm{~Hz}, 8.4 \mathrm{~Hz}, \mathrm{CH}_{2}\right), 3.16\left(\mathrm{~s}, 3 \mathrm{H}, \mathrm{NCH}_{3}\right), 2.85(\mathrm{~s}$, $\left.3 \mathrm{H}, \mathrm{NCH}_{3}\right), 2.35-2.23\left(\mathrm{~m}, 1 \mathrm{H}, \mathrm{CH}_{2}\right), 2.20-1.95\left(\mathrm{~m}, 3 \mathrm{H}, \mathrm{CH}_{2}\right), 1.90$ $\left(\mathrm{s}, 3 \mathrm{H}, \mathrm{CH}_{3}\right) .{ }^{13} \mathrm{C} \mathrm{NMR}\left(100 \mathrm{MHz}, \mathrm{CDCl}_{3}-d_{6}\right) \delta_{\mathrm{C}} 177.7,172.7,147.9$, 129.6, 122.1, 117.1, 111.0, 58.6, 48.5, 36.9, 36.0, 30.5, 23.6, 15.3, 12.5 . MS (ES+), $[\mathrm{M}+\mathrm{Na}]^{+}(100)$ 434.2. HRMS calculated for 434.1656 $\mathrm{C}_{23} \mathrm{H}_{23} \mathrm{O}_{2} \mathrm{~N}_{3} \mathrm{~F}_{2} \mathrm{Na}$, found 434.1669. Purity HPLC 97\% (method B) $R_{\mathrm{t}}=1.95 \mathrm{~min}$.

Preparation of (R)-1-(4-(5,7-Difluoro-3-methyl-4-oxo-1,4-dihydroquinolin-2-yl)phenyl)- $\mathrm{N}$-(tetrahydro-2H-pyran-4-yl)pyrrolidine2-carboxamide 45 c. Pale-yellow powder (yield $25 \%$ ); mp $228-230^{\circ} \mathrm{C}$. ${ }^{1} \mathrm{H} \mathrm{NMR}\left(400 \mathrm{MHz}, \mathrm{CDCl}_{3}-d_{6}\right) \delta_{\mathrm{H}} 10.82(\mathrm{~s}, 1 \mathrm{H}, \mathrm{NH}), 7.36(\mathrm{~d}, 2 \mathrm{H}, J=$ $8.7 \mathrm{~Hz}, \mathrm{Ar}), 7.25$ (d, $1 \mathrm{H}, J=9.6 \mathrm{~Hz}, \mathrm{Ar}), 6.68-6.59$ (m, 1H, Ar), 6.56 $(\mathrm{s}, 1 \mathrm{H}, \mathrm{NH}), 6.53(\mathrm{~d}, 2 \mathrm{H}, \mathrm{J}=8.7 \mathrm{~Hz}, \mathrm{Ar}), 4.06-3.82\left(\mathrm{~m}, 2 \mathrm{H}, \mathrm{CH} / \mathrm{CH}_{2}\right)$, 3.66-3.56 (m, $\left.1 \mathrm{H}, \mathrm{CH}_{2}\right), 3.52-3.39\left(\mathrm{~m}, 3 \mathrm{H}, \mathrm{CH}_{2}\right), 3.30(\mathrm{~d}, 1 \mathrm{H}, J=$ $\left.6.7 \mathrm{~Hz}, \mathrm{CH}_{2}\right), 3.11-3.02\left(\mathrm{~m}, 1 \mathrm{H}, \mathrm{CH}_{2}\right), 2.05-1.71\left(\mathrm{~m}, 9 \mathrm{H}, \mathrm{CH}_{2} / \mathrm{CH}_{3}\right)$, $1.53-1.30\left(\mathrm{~m}, 2 \mathrm{H}, \mathrm{CH}_{2}\right) .{ }^{13} \mathrm{C} \mathrm{NMR}\left(100 \mathrm{MHz}, \mathrm{CDCl}_{3}-d_{6}\right) \delta_{\mathrm{C}} 177.1$, 173.1, 148.0, 147.2, 130.0, 124.9, 117.6, 112.9, 66.6, 65.9, 64.1, 49.7, 46.0, 32.9, 31.4, 24.1, 15.3, 12.3. MS (ES+), $[\mathrm{M}+\mathrm{Na}]^{+}(100) 490.2$. HRMS calculated for $490.1018 \mathrm{C}_{26} \mathrm{H}_{27} \mathrm{O}_{3} \mathrm{~N}_{3} \mathrm{~F}_{2} \mathrm{Na}$, found 490.1932 . Purity HPLC 93\% (method B) $R_{\mathrm{t}}=1.92$ min.

Preparation of (R)-5,7-Difluoro-3-methyl-2-(4-(2-(morpholine-4carbonyl)pyrrolidin-1-yl)phenyl)quinolin-4(1H)-one 45d. Pale-yellow powder (yield 18\%); mp $236-238^{\circ} \mathrm{C} .{ }^{1} \mathrm{H}$ NMR $\left(400 \mathrm{MHz}, \mathrm{CDCl}_{3}-d_{6}\right)$ $\delta_{\mathrm{H}} 10.26(\mathrm{~s}, 1 \mathrm{H}, \mathrm{NH}), 7.20(\mathrm{~d}, 1 \mathrm{H}, J=9.2 \mathrm{~Hz}, \mathrm{Ar}), 7.14(\mathrm{~d}, 2 \mathrm{H}, J=8.6$ $\mathrm{Hz}, \mathrm{Ar}$ ), $6.67-6.59$ (m, 1H, Ar), 6.17 (d, $2 \mathrm{H}, J=8.6 \mathrm{~Hz}, \mathrm{Ar}), 4.44-4.37$ (m, 1H, CH), 3.78 (dd, $\left.1 \mathrm{H}, \mathrm{CH}_{2}\right), 3.74-3.55\left(\mathrm{~m}, 6 \mathrm{H}, \mathrm{CH}_{2}\right), 3.46-3.35$ $\left(\mathrm{m}, 2 \mathrm{H}, \mathrm{CH}_{2}\right), 3.27\left(\mathrm{dd}, 1 \mathrm{H}, J=16.1 \mathrm{~Hz}, 8.3 \mathrm{~Hz}, \mathrm{CH}_{2}\right), 2.36-2.24(\mathrm{~m}$, $\left.1 \mathrm{H}, \mathrm{CH}_{2}\right), 2.18-2.04\left(\mathrm{~m}, 2 \mathrm{H}, \mathrm{CH}_{2}\right), 2.03-1.96\left(\mathrm{~m}, 1 \mathrm{H}, \mathrm{CH}_{2}\right), 1.90(\mathrm{~s}$, $\left.3 \mathrm{H}, \mathrm{CH}_{3}\right) .{ }^{13} \mathrm{C}$ NMR $\left(100 \mathrm{MHz}, \mathrm{CDCl}_{3}-d_{6}\right) \delta_{\mathrm{C}} 171.2,147.7,147.0$, 129.6, 122.2, 117.2, 111.1, 67.0, 66.5, 58.7, 48.5, 45.8, 42.5, 30.8, 23.6, 12.4. MS (ES+), $[\mathrm{M}+\mathrm{Na}]^{+}(100)$ 476.2. HRMS calculated for $476.1762 \mathrm{C}_{25} \mathrm{H}_{25} \mathrm{O}_{3} \mathrm{~N}_{3} \mathrm{~F}_{2} \mathrm{Na}$, found 476.1778 . Purity HPLC $93 \%$ (method B) $R_{\mathrm{t}}=1.90 \mathrm{~min}$.

Preparation of (R)-5,7-Difluoro-2-(4-(2-(4-fluoropiperidine-1carbonyl)pyrrolidin-1-yl)phenyl)-3-methylquinolin-4(1H)-one 45e. Pale-yellow powder (yield 24\%); mp 238-240 ${ }^{\circ} \mathrm{C} .{ }^{1} \mathrm{H}$ NMR $\left(400 \mathrm{MHz}, \mathrm{CDCl}_{3}-d_{6}\right) \delta_{\mathrm{H}} 10.21(\mathrm{~s}, 1 \mathrm{H}, \mathrm{NH}), 7.24-7.08(\mathrm{~m}, 3 \mathrm{H}, \mathrm{Ar})$, $6.63(\mathrm{t}, 1 \mathrm{H}, \mathrm{Ar}), 6.18(\mathrm{dd}, 2 \mathrm{H}, J=7.7 \mathrm{~Hz}, 5.0 \mathrm{~Hz}, \mathrm{Ar}), 5.04-4.81(\mathrm{~m}, 1 \mathrm{H}$, CHF), $4.44(\mathrm{~d}, 1 \mathrm{H}, \mathrm{CH}), 3.88-5.59\left(\mathrm{~m}, 3 \mathrm{H}, \mathrm{CH}_{2}\right), 3.58-3.32(\mathrm{~m}, 1 \mathrm{H}$, $\left.\mathrm{CH}_{2}\right), 3.31-3.19\left(\mathrm{~m}, 1 \mathrm{H}, \mathrm{CH}_{2}\right), 2.40-2.24\left(\mathrm{~m}, 1 \mathrm{H}, \mathrm{CH}_{2}\right), 2.18-1.61$ $\left(\mathrm{m}, 11 \mathrm{H}, \mathrm{CH}_{2}\right) .{ }^{13} \mathrm{C} \mathrm{NMR}\left(100 \mathrm{MHz}, \mathrm{CDCl}_{3}-d_{6}\right) \delta_{\mathrm{C}} 171.4,148.0,147.7$, 129.6, 122.4, 116.9, 111.1, 65.9, 58.8, 48.5, 38.8, 30.9, 23.9, 12.4. MS $(\mathrm{ES}+),[\mathrm{M}+\mathrm{Na}]^{+}(100)$ 492.2. HRMS calculated for 492.1875 $\mathrm{C}_{26} \mathrm{H}_{26} \mathrm{O}_{2} \mathrm{~N}_{3} \mathrm{~F}_{3} \mathrm{Na}$, found 492.1872. Purity HPLC 96\% (method A) $R_{\mathrm{t}}=2.20 \mathrm{~min}$.

Preparation of 4(R)-1-(4-(5,7-Difluoro-3-methyl-4-oxo-1,4-dihydroquinolin-2-yl)phenyl)- $N, N$-dimethylazetidine-2-carboxamide 45f. White solid $(0.056 \mathrm{~g}, 14 \%) .{ }^{1} \mathrm{H}$ NMR $\left(400 \mathrm{MHz},\left(\mathrm{CD}_{3}\right)_{2} \mathrm{SO}\right) \delta_{\mathrm{H}}$ $1.87\left(3 \mathrm{H}, \mathrm{s}, \mathrm{CH}_{3} \mathrm{C}\right), 2.30-2.40,2.60-2.75\left(2 \mathrm{H}, 2 \mathrm{~m}, \mathrm{CCH}_{2} \mathrm{C}\right), 2.88$, $2.94\left(6 \mathrm{H}, 2 \mathrm{~s}, \mathrm{Me}_{2} \mathrm{~N}\right), 3.72,3.93\left(2 \mathrm{H}, 2 \mathrm{~m}, \mathrm{CH}_{2} \mathrm{~N}\right), 4.92(1 \mathrm{H}$, approximately t, CHN), $6.51(2 \mathrm{H}, \mathrm{d}, \mathrm{ArH}), 7.00(1 \mathrm{H}, \mathrm{m}, \mathrm{ArH}), 7.17(1$ $\mathrm{H}, \mathrm{m}, \mathrm{ArH}), 7.33(2 \mathrm{H}, \mathrm{d}, \mathrm{ArH})$ and $11.49(1 \mathrm{H}, \mathrm{br} \mathrm{s}, \mathrm{NH}) .{ }^{13} \mathrm{C} \mathrm{NMR}$ $\left(100 \mathrm{MHz},\left(\mathrm{CD}_{3}\right)_{2} \mathrm{SO}\right) \delta_{\mathrm{C}} 12.5,22.1,35.4,35.8,49.0,63.2,111.5,116.3$, 123.0, 129.8, 148.0, 151.9, 170.5 and 175.4; not all the aromatic carbons were seen; $m / z\left(E S+\right.$ ve mode) $398\left(\mathrm{MH}^{+}, 100 \%\right)$. Found: $m / z$, 398.1667. $\mathrm{C}_{22} \mathrm{H}_{22} \mathrm{~N}_{3} \mathrm{O}_{2} \mathrm{~F}_{2}$ requires $m / z$, 398.1680. Anal.: $\mathrm{C}_{22} \mathrm{H}_{21} \mathrm{~N}_{3} \mathrm{O}_{2} \mathrm{~F}_{2}$ requires C $66.49 \%$, H 5.33\%, N 10.57\%. Found: C 66.15\%, H 5.36\%, $\mathrm{N} 9.88 \%$.

Preparation of (R)-N-(tert-Butyl)-1-(4-(5,7-difluoro-3-methyl-4oxo-1,4-dihydroquinolin-2-yl)phenyl)azetidine-2-carboxamide $\mathbf{4 5 g}$. Pale-yellow powder $(0.033 \mathrm{~g}, 12 \%) .{ }^{1} \mathrm{H}$ NMR $\left(400 \mathrm{MHz}, \mathrm{CDCl}_{3}\right) \delta_{\mathrm{H}}$ $1.42\left(9 \mathrm{H}, \mathrm{s}, \mathrm{Me}_{3} \mathrm{C}\right), 2.00\left(3 \mathrm{H}, \mathrm{s}, \mathrm{CH}_{3} \mathrm{C}=\right), 2.20-2.30(2 \mathrm{H}, \mathrm{m}$, $\left.\mathrm{CCH}_{2} \mathrm{C}\right), 3.26(1 \mathrm{H}, \mathrm{m}), 3.58(1 \mathrm{H}, \mathrm{m}), 3.95(1 \mathrm{H}, \mathrm{m}), 6.52(2 \mathrm{H}, \mathrm{d}$, ArH ), 6.60-6.70 (1 H, m, ArH), $7.19(1 \mathrm{H}, \mathrm{m}, \mathrm{ArH}), 7.40$ (2 H, d, ArH) and $10.43(1 \mathrm{H}, \mathrm{br} \mathrm{s}, \mathrm{NH}) \cdot \mathrm{m} / z$ (CI, methane) $426\left(\mathrm{MH}^{+}\right.$, base peak). Found: $m / z, 426.1988 . \mathrm{C}_{24} \mathrm{H}_{26} \mathrm{~F}_{2} \mathrm{~N}_{3} \mathrm{O}_{2}$ requires $m / z, 426.1986$. Anal.: $\mathrm{C}_{24} \mathrm{H}_{25} \mathrm{~N}_{3} \mathrm{O}_{2} \mathrm{~F}_{2}$ requires $\mathrm{C} 67.75 \%, \mathrm{H} 5.92 \%$, N 9.88\%. Found: C $67.26 \%$, H $5.88 \%$, N 9.56\%.

Preparation of 2-(4-(3,3-Difluoropyrrolidin-1-yl)phenyl)-5,7-difluoro-3-methylquinolin-4-yl acetate 46. To a suspension of 2-(4(3,3-difluoropyrrolidin-1-yl)phenyl)-5,7-difluoro-3-methylquinolin4(1H)-one (280 mg, $0.74 \mathrm{mmol})$ in THF $(15 \mathrm{~mL}),{ }^{t} \mathrm{BuOK}(172 \mathrm{mg}$, $1.5 \mathrm{mmol}$ ) was added. The resulting mixture was kept stirring at room temperature for $1 \mathrm{~h}$. After that, excess acetyl chloride $(0.2 \mathrm{~mL})$ was added, and the reaction mixture was kept stirring for $3 \mathrm{~h}$ at room temperature. After that, $\mathrm{H}_{2} \mathrm{O}(15 \mathrm{~mL})$ was used to quench the reaction and $\mathrm{Et}_{2} \mathrm{O}(50 \mathrm{~mL})$ was used to dilute the mixture. Organic layer was separated from the water layer, and $\mathrm{DCM} / \mathrm{MeOH}(1: 1,20 \mathrm{~mL})$ was added to the organic layer to dissolve any precipitation. The organic solution was dried with $\mathrm{MgSO}_{4}$ and concentrated in vacuo to give the crude product. The crude product we purified by flash column chromatograph eluting with $20 \% \mathrm{EtOAc}$ in hexane to give the title product a pale-yellow solid (290 mg, 94\%). ${ }^{1} \mathrm{H}$ NMR (400 MHz, $\left.\mathrm{CDCl}_{3}\right) \delta_{\mathrm{H}} 7.72-7.53(\mathrm{~m}, 3 \mathrm{H}), 6.99(\mathrm{dd}, J=15.1,5.7 \mathrm{~Hz}, 1 \mathrm{H}), 6.66$ $(\mathrm{d}, J=8.6 \mathrm{~Hz}, 2 \mathrm{H}), 3.75(\mathrm{t}, J=13.2 \mathrm{~Hz}, 2 \mathrm{H}), 3.61(\mathrm{t}, J=7.1 \mathrm{~Hz}, 2 \mathrm{H})$, 2.54 (ddd, $J=21.2,14.0,7.3 \mathrm{~Hz}, 2 \mathrm{H}), 2.46(\mathrm{~s}, 3 \mathrm{H}), 2.32(\mathrm{~s}, 3 \mathrm{H}) .{ }^{13} \mathrm{C}$ NMR $\left(101 \mathrm{MHz}, \mathrm{CDCl}_{3}\right) \delta_{\mathrm{C}} 168.52,163.55,161.69(\mathrm{dd}, J=249.3$, $14.3 \mathrm{~Hz}), 157.00(\mathrm{dd}, J=258.3,14.3 \mathrm{~Hz}), 150.99(\mathrm{t}, J=1.8 \mathrm{~Hz}), 149.05$ $(\mathrm{dd}, J=14.2,2.6 \mathrm{~Hz}), 147.41,130.57,128.55,128.04,125.58,121.90$, $111.53,109.74(\mathrm{dd}, J=20.6,5.0 \mathrm{~Hz}), 109.51(\mathrm{dd}, J=9.3,1.8 \mathrm{~Hz}), 103.05$ $(\mathrm{dd}, J=29.3,25.9 \mathrm{~Hz}), 55.33(\mathrm{t}, J=31.6 \mathrm{~Hz}), 45.54(\mathrm{t}, J=3.2 \mathrm{~Hz}), 34.28$ $(\mathrm{t}, J=24.0 \mathrm{~Hz}), 20.71,13.71$. HRMS (ES) $\mathrm{C}_{22} \mathrm{H}_{18} \mathrm{~N}_{2} \mathrm{O}_{2} \mathrm{~F}_{3}{ }^{23} \mathrm{Na}[\mathrm{M}+$ $\mathrm{Na}]^{+}$requires 441.1202, found 441.1212. Anal.: $\mathrm{C}_{22} \mathrm{H}_{18} \mathrm{~N}_{2} \mathrm{O}_{2} \mathrm{~F}_{4}$ requires C 63.16\%, H 4.34\%, N 6.70\%. Found: C 62.77\%, H 4.29\%, N 6.53\%.

Biology. Drug Susceptibility Assays Using Replicating and Hypoxic Mtb. For drug susceptibility assays, aerobic cultures of Mtb H37Rv were cultured as described previously. ${ }^{14}$ Cultures were grown until a mid log growth phase was reached (Middlebrook 7H9 broth with addition of $10 \%$ albumin-dextrose-catalase solution (Becton Dickinson), $0.2 \%$ ( $\mathrm{vol} / \mathrm{vol}]$ ) glycerol, and $0.05 \%$ ( $\mathrm{vol} / \mathrm{vol}$ ) Tween 80 ). Hypoxic cultures of Mtb were produced using the same growth media but the method described by Wayne and Hayes was utilized, ${ }^{58}$ where oxygen supply was limited over 6 weeks and cultures were mixed using $8 \mathrm{~mm}$ Teflon-coated magnetic stirring bars $\left(120 \mathrm{rpm}, 37^{\circ} \mathrm{C}\right)$.

The effectiveness of test drugs to prevent $\mathrm{Mtb}$ growth was determined using a microplate AlamarBlue assay (MABA) as described previously. ${ }^{14} \mathrm{~A}$ range of test drug concentrations $(10-0.08 \mu \mathrm{M}, 2 \%$ DMSO) were coincubated with replicating Mtb (OD 0.01, 7 days, $37{ }^{\circ} \mathrm{C}$ ) followed by a MABA. Measurements of well absorbance at 570 and $600 \mathrm{~nm}$ were recorded using an Opsys MR plate reader were determined to calculate $\mathrm{IC}_{50}$ values for the inhibitors. For anaerobic cultures, coincubations of hypoxic Mtb and test drug were performed as described for replicating Mtb, however, the plates were sealed within GasPak EZ pouches containing an indicator to ensure anaerobic conditions were maintained. The plates were subsequently incubated anaerobically $\left(7\right.$ days, $37^{\circ} \mathrm{C}$ ) before being moved to an aerobic environment for a further 7 days. The $\mathrm{IC}_{50}$ values were calculated as described for aerobic cultures. 
In Vitro Metabolic Stability. Mixed pools of microsomes from multiple donors were purchased from BD Biosciences, USA (human, rat, and mouse) (protein content $20 \mathrm{mg} / \mathrm{mL}$ ). Compounds of interest were tested at 10,1 , and $0.1 \mu \mathrm{M}$ with a final concentration of microsomal protein of $1 \mathrm{mg} / \mathrm{mL}$. The reaction was initiated by the addition of $\mathrm{NADPH}(1 \mathrm{mM})$, and samples were incubated for up to $60 \mathrm{~min}$ at $37^{\circ} \mathrm{C}$ in a shaking incubator. The reaction was terminated at $0,10,30$, and $60 \mathrm{~min}$ by the addition of ice-cold $\mathrm{ACN} / \mathrm{MeOH}$ (50:50) spiked with internal standard. Sample preparation for mass spectrometry involved the addition of an equivalent amount of water to each sample before extraction using ethyl acetate $(3 \times 500 \mu \mathrm{L})$. The organic layer was then dried under nitrogen before reconstitution in $\mathrm{MeOH} / \mathrm{H}_{2} \mathrm{O}$ (50:50).

Cytotoxicity Assay in HEPG2 Using MTT. The cellular toxicity of test compounds were determined using the MTT assay, with modifications, using HEPG 2 cells which were either resistant (cultured using glucosecontaining media) or susceptible (cultured using galactose-containing media) to mitochondrial-toxicity-induced cell death. ${ }^{59,60}$ Briefly, HepG2 cells cultured in glucose media (high-glucose Dulbecco's Modified Eagle's Medium (DMEM) containing $25 \mathrm{mM}$ glucose and $1 \mathrm{mM}$ sodium pyruvate, supplemented with $5 \mathrm{mM}$ HEPES, $10 \%$ (vol/vol) fetal bovine serum (FBS), and $100 \mu \mathrm{g} / \mathrm{mL}$ penicillin-streptomycin) or galactose media (glucose-free DMEM supplemented with $10 \mathrm{mM}$ galactose, $5 \mathrm{mM}$ HEPES, 10\% (vol/vol) FBS, $1 \mathrm{mM}$ sodium pyruvate, and $100 \mu \mathrm{g} / \mathrm{mL}$ penicillin-streptomycin) were added to 96 -well plates $\left(60 \mu \mathrm{L}, 1 \times 10^{4}\right.$ cells/well $)$ and incubated for $24 \mathrm{~h}$. Log-range concentrations of each test compound $(1-100 \mu \mathrm{M})$ were then added to the plates and a further incubation of $24 \mathrm{~h}$ performed. Plates were subsequently incubated for $2 \mathrm{~h}$ in the presence $1 \mathrm{mg} / \mathrm{mL} 3-(4,5$ dimethylthiazol-2-yl)-2,5-diphenyltetrazolium bromide (MTT) solution. Cell lysis solution $(50 \mu \mathrm{L}, 50 \%$ ( $\mathrm{vol} / \mathrm{vol})$ dimethylformamide in distilled water, $20 \%$ (wt/vol) sodium dodecyl sulfate) was added to wells, and plates were wrapped in metallic foil and mixed at $60 \mathrm{rpm}$ for $2 \mathrm{~h}$ at room temperature. Well absorbance at $560 \mathrm{~nm}$ was determined using a Varioskan plate reader (ThermoScientific) and were used to determine $\mathrm{IC}_{50}$ values using a four-parameter logistic function using Prism 5 software. All incubations were performed at $37{ }^{\circ} \mathrm{C}$ in a $\mathrm{CO}_{2}$ incubator and compounds were solubilized in DMSO ( $1 \%$ (vol/vol) final concentration). The cytotoxic control compounds rotenone (0.001-1 $\mu \mathrm{M}$, toxic to mitochondria) and tamoxifen $(1-100 \mu \mathrm{M}$, no specific mitochondrial toxicity) were included as controls, as was a drugfree control containing $1 \%$ (vol/vol) DMSO.

Caco-2 Trans-Epithelial Drug Transport. Caco-2 monolayer experiments were performed as previously described, ${ }^{61}$ with modifications. When confluent, Caco-2 cells were seeded onto polycarbonate membrane transwells at a density of $2.6 \times 10^{5} \mathrm{cells} / \mathrm{cm}^{2}$ (DMEM, 15\% (vol/vol) FCS) and incubated $\left(37{ }^{\circ} \mathrm{C}, 5 \% \mathrm{CO}_{2}\right)$ for $16 \mathrm{~h}$. Following this incubation, media was replaced to remove dead cells and to prevent the formation of multiple layers of cells settling on the filter. Plate media was changed every $48 \mathrm{~h}$ and plates used in experiments 21 days from initial seeding. Monolayer integrity was checked using a MillicellERS instrument (Millipore) to determine the trans-epithelial electrical resistance (TEER) across the monolayer. A TEER of more than $400 \Omega / \mathrm{cm}^{2}$ was deemed acceptable.

On the day of the experiment, the TEER was assessed and the media replaced with warm transport buffer (HBSS, $25 \mathrm{mM}$ HEPES, 0.1\% (wt/vol) bovine serum albumin, $\mathrm{pH} 7$ ) and allowed to equilibrate $\left(37^{\circ} \mathrm{C}, 30 \mathrm{~min}\right)$. The transport buffer in the chambers was replaced with transport buffer containing either the test compound or the control drug verapamil $(5 \mu \mathrm{M})$. Samples $(50 \mu \mathrm{L})$ were taken from the receiver compartment at $0,60,120$, and $180 \mathrm{~min}$ and replaced with an equal volume of transport buffer. Samples were analyzed using LC-MS/MS. Data were used to determine apparent permeability $\left(P_{\text {app }}, 10^{-6} \mathrm{~cm} / \mathrm{s}\right)$ for each direction and efflux ratio (ratio of basolateral to apical $P_{\text {app }}$ compared with apical to basolateral $\left.P_{\text {app }}\right)$. $P_{\text {app }}$ was calculated using the following equation as described previously: ${ }^{62}$

$$
P_{\text {app }}=\frac{(\mathrm{d} Q / \mathrm{d} t) \times V}{A \times C_{0}}
$$

$\mathrm{dQ} / \mathrm{d} t$ is the change in drug concentration in the receiver chamber over time $(\mathrm{nM} / \mathrm{s}), V$ is the volume in the receiver compartment $(\mathrm{mL}), A$ is the total surface area of the transwell membrane $\left(\mathrm{cm}^{2}\right), C_{0}$ is the initial drug concentration in the donor compartment $(\mathrm{nM})$, and $P_{\text {app }}$ is the apparent permeability $\left(\times 10^{-6} \mathrm{~cm} / \mathrm{s}\right)$.

Plasma Protein Binding Using Equilibrium Dialysis. The extent of plasma protein binding for each test compounds was determined by equilibrium dialysis. Test compound was added to human plasma which was mixed and heated $\left(1 \mu \mathrm{M}, 1 \%\right.$ (vol/vol) DMSO, $\left.37{ }^{\circ} \mathrm{C}\right)$. Regenerated cellulose membranes (5000 Da, Harvard Apparatus) were soaked in phosphate buffer for 5 min and placed within Fast MicroEquilibrium Dialyzers (Harvard Apparatus). One milliliter of plasma containing the test drug was added to the first compartment, and $1 \mathrm{~mL}$ of phosphate buffer $\left(1 \%(\mathrm{vol} / \mathrm{vol}) \mathrm{DMSO}, 37^{\circ} \mathrm{C}\right)$ was added to the second compartment. Equilibrium dialysis was undertaken by incubation $\left(18 \mathrm{~h}, 37^{\circ} \mathrm{C}\right)$, and samples were removed from each compartment for LC-MS/MS analysis.

Plasma Stability. Compounds were incubated in rat or human plasma $(1 \mu \mathrm{M})$ at $37^{\circ} \mathrm{C}$ for up to $3 \mathrm{~h}$. At various time points $(0,10,30$, $60,120$, and $180 \mathrm{~min})$ an aliquot $(100 \mu \mathrm{L})$ was taken and the reaction was terminated by the addition of ice-cold $\mathrm{ACN} / \mathrm{MeOH}(300 \mu \mathrm{L}$, 50\%:50\% (vol/vol)) spiked with internal standard. Samples underwent centrifugation to remove the protein precipitate and were analyzed directly using LC-MS/MS analysis.

In Vitro CYPP450 Inhibition. CYPP450 VIVID inhibition kits were purchased from Invitrogen Life Technologies. Briefly, compounds were tested at a final concentration of 10,1 , and $0.1 \mu \mathrm{M}$ alongside a relevant positive control for the isoform of interest and a solvent control. The assay utilized a substrate, specific to the isoform, which produced a fluorescent metabolite as it underwent oxidation by the P450 enzyme. Inhibition of the enzyme led to reduced fluorescent output. The assay was carried out in kinetics mode, with a reading being taken every minute for a total of $1 \mathrm{~h}$.

Pharmacokinetic Studies in Rats. Male Wistar rats (180-250 g) $(n=4)$ were purchased from Charles River Laboratories, UK, and allowed to acclimatize for 1 week in controlled conditions $\left(23 \pm 3{ }^{\circ} \mathrm{C}\right.$; relative humidity $50 \pm 10 \%$; light-dark cycle $12 \mathrm{~h}$ ). Animals were provided with feed pellet and filtered water ad libitum. Each rat received an oral dose of the relevant compound ( 10 or $50 \mathrm{mg} / \mathrm{kg}$ ) in PEG400 $(100 \%)(5 \mathrm{~mL} / \mathrm{kg})$ via gavage needle or an IV injection of the relevant compound $(0.5 \mathrm{mg} / \mathrm{kg})$ in $5 \%$ PEG400 and $5 \%$ solutol in water. At various time-points, the rats were anaesthetized using isoflurane and a blood sample $(<300 \mu \mathrm{L})$ was taken from a superficial vein in the tail. The blood was immediately stored on ice before undergoing centrifugation at $13000 \mathrm{rpm}$, for $10 \mathrm{~min}$. An aliquot of $100 \mu \mathrm{L}$ of plasma was removed and added to $\mathrm{ACN} / \mathrm{MeOH}(300 \mu \mathrm{L}, 50 \%: 50 \%$ (vol/vol)) spiked with internal standard. Samples were then analyzed using LC-MS/MS within $24 \mathrm{~h}$ of obtaining the final sample.

PK data were modeled using the package Pmetrics ${ }^{63}$ utilizing a one compartment gut absorption model. Separate doses were modeled separately to differentiate the effect of dose upon the pharmacokinetic profile of each compound.

LC-MS/MS. Drug concentration analyses were performed on a TSQ Quantum Access mass spectrometer (Thermo, UK). Chromatographic separation for all test compounds and control compounds was performed at $30^{\circ} \mathrm{C}$ on a Fortis C- $183 \mu \mathrm{m}$ column $(50 \mathrm{~mm} \times 2.1 \mathrm{~mm}$ i.d., Fortis technologies, UK). Mobile phases were solution A $(100 \%$ acetonitrile) and solution B (100\% LC-MS/MS-grade water, $0.05 \%$ formic acid), and flow rate was $0.3 \mathrm{~mL} / \mathrm{min}$. Separation was achieved with a gradient elution beginning with $90 \%$ solution D and $10 \%$ solution A, which was maintained for $1 \mathrm{~min}$. Solution A was then gradually increased to $80 \%$ over $1.9 \mathrm{~min}$ and maintained for a further $1.4 \mathrm{~min}$. Solution B was increased to $90 \%$ over $0.7 \mathrm{~min}$ and maintained for $0.2 \mathrm{~min}$, giving a total run time of $5.2 \mathrm{~min}$. Robustness of analyses were assessed using standard concentration curves and quality control concentrations, where concentration standard deviations were required to be within $20 \%$ for generated results to be accepted. 


\section{ASSOCIATED CONTENT}

\section{S Supporting Information}

The Supporting Information is available free of charge on the ACS Publications website at DOI: 10.1021/acs.jmedchem.6b01718.

Quinolone screening summary; full experimental for all intermediates; metabolite identification report for MTC420 (PDF)

Molecular formula strings (CSV)

\section{AUTHOR INFORMATION}

\section{Corresponding Authors}

*For G.L.N.: phone, +44 (0)151 794 3496; fax, +44 (0) 151794 3588; E-mail, gnixon@liverpool.ac.uk.

*For G.A.B.: phone, ++44 (0)151 705 3151; E-mail, giancarlo. biagini@lstmed.ac.uk.

\section{ORCID}

Gemma L. Nixon: 0000-0002-9730-0960

\section{Author Contributions}

"These authors contributed equally to the study.

\section{Notes}

The authors declare no competing financial interest.

\section{ACKNOWLEDGMENTS}

Peter Webborn, Mark Wenlock, and Stefan Kavanagh (Astrazeneca) are thanked for their assistance in providing in vitro predicted and measured DMPK data. This work was supported by National Institute of Health Research (NIHR, BRC Liverpool (G.A.B.)) and by the Medical Research Council (MRC DPFS-G1002586 (G.A.B., S.A.W., P.O.N.) and MRC CiC (G.A.B.)).

\section{ABBREVIATIONS USED}

$\mathrm{TB}$, tuberculosis; MDR, multidrug resistant; XDR, extensively drug resistant; Mtb, Mycobacterium tuberculosis; $\mathrm{NADH}$, nicotinamide adenine dinucleotide; ETC, electron transport chain; ATP, adenosine triphosphate; ETF, electron transferring flavoprotein; FRD, fumarate reductase; nar, nitrate reductase; HTS, high throughput screen; DMPK, drug metabolism and pharmacokinetics; SAR, structure-activity relationship; DMF, dimethylformamide; GSK, GlaxoSmithKline; NBS, N-bromo succinamide; DCM, dichloromethane; PCC, pyridinium chlorochromate; EDC, 1-ethyl-3-(3-(dimethylamino)propyl)carbodiimide; NHS, N-hydroxy succinamide; GLU, glucose; $\mathrm{PPB}$, plasma protein binding; CL, clearance; AUC, area under the curve; TI, therapeutic index; hERG, human ether-à-go-gorelated gene; NC, not calculated; ND, not determined; ID, identification; M, metabolite; SD, Sprague-Dawley; HPLC, high performance liquid chromatography; TLC, thin layer chromatography; DMSO, dimethyl sulfoxide; NADPH, nicotinamide adenine dinucleotide phosphate; MTT, 3-(4,5-dimethylthiazol2-yl)-2,5-diphenyltetrazolium bromide; DMEM, Dulbecco's Modified Eagle's Medium; FBS, fetal bovine serum; HEPES, (4-(2-hydroxyethyl)-1-piperazineethanesulfonic acid; FCS, fetal calf serum; TEER, trans-epithelial electrical resistance; HBSS, Hank's balance salt solution; LC-MS, liquid chromatographmass spectrometry

\section{REFERENCES}

(1) Global Tuberculosis Report 2015: Executive Summary, 20th ed.; World Health Organisation: Geneva, Switzerland, 2015; pp 1-4.
(2) Streicher, E. M.; Müller, B.; Chihota, V.; Mlambo, C.; Tait, M.; Pillay, M.; Trollip, A.; Hoek, K. G. P.; Sirgel, F. A.; Gey van Pittius, N. C.; van Helden, P. D.; Victor, T. C.; Warren, R. M. Emergence and treatment of multidrug resistant (MDR) and extensively drug-resistant (XDR) tuberculosis in South Africa. Infect., Genet. Evol. 2012, 12, 686694.

(3) Koul, A.; Arnoult, E.; Lounis, N.; Guillemont, J.; Andries, K. The challenge of new drug discovery for tuberculosis. Nature 2011, 469, 483-490.

(4) Goel, D. Bedaquiline: A novel drug to combat multiple drugresistant tuberculosis. J. Pharmacol. Pharmacother. 2014, 5, 76-78.

(5) Guillemont, J.; Meyer, C.; Poncelet, A.; Bourdrez, X.; Andries, K. Diarylquinolines, synthesis pathways and quantitative structure-activity relationship studies leading to the discovery of TMC207. Future Med. Chem. 2011, 3, 1345-1360.

(6) Xavier, A. S.; Lakshmanan, M. Delamanid: A new armor in combating drug-resistant tuberculosis. J. Pharmacol. Pharmacother. 2014, 5, 222-224.

(7) Matsumoto, M.; Hashizume, H.; Tomishige, T.; Kawasaki, M.; Tsubouchi, H.; Sasaki, H.; Shimokawa, Y.; Komatsu, M. OPC-67683, a nitro-dihydro-imidazooxazole derivative with promising action against tuberculosis in vitro and in mice. PLoS Med. 2006, 3, e466.

(8) Fox, G. J.; Menzies, D. A Review of the evidence for using bedaquiline (TMC207) to treat multi-drug resistant tuberculosis. Infect. Dis. Ther. 2013, 2, 123-144.

(9) Weinstein, E. A.; Yano, T.; Li, L. S.; Avarbock, D.; Avarbock, A.; Helm, D.; McColm, A. A.; Duncan, K.; Lonsdale, J. T.; Rubin, H. Inhibitors of type II NADH:menaquinone oxidoreductase represent a class of antitubercular drugs. Proc. Natl. Acad. Sci. U. S. A. 2005, 102, $4548-4553$.

(10) Koul, A.; Dendouga, N.; Vergauwen, K.; Molenberghs, B.; Vranckx, L.; Willebrords, R.; Ristic, Z.; Lill, H.; Dorange, I.; Guillemont, J.; Bald, D.; Andries, K. Diarylquinolines target subunit $c$ of mycobacterial ATP synthase. Nat. Chem. Biol. 2007, 3, 323-324.

(11) Haagsma, A. C.; Abdillahi-Ibrahim, R.; Wagner, M. J.; Krab, K.; Vergauwen, K.; Guillemont, J.; Andries, K.; Lill, H.; Koul, A.; Bald, D. Selectivity of TMC207 towards mycobacterial ATP synthase compared with that towards the eukaryotic homologue. Antimicrob. Agents Chemother. 2009, 53, 1290-1292.

(12) Koul, A.; Vranckx, L.; Dendouga, N.; Balemans, W.; Van den Wyngaert, I.; Vergauwen, K.; Gohlmann, H. W.; Willebrords, R.; Poncelet, A.; Guillemont, J.; Bald, D.; Andries, K. Diarylquinolines are bactericidal for dormant mycobacteria as a result of disturbed ATP homeostasis. J. Biol. Chem. 2008, 283, 25273-25280.

(13) Diacon, A. H.; Pym, A.; Grobusch, M.; Patientia, R.; Rustomjee, R.; Page-Shipp, L.; Pistorius, C.; Krause, R.; Bogoshi, M.; Churchyard, G.; Venter, A.; Allen, J.; Palomino, J. C.; De Marez, T.; van Heeswijk, R. P.; Lounis, N.; Meyvisch, P.; Verbeeck, J.; Parys, W.; de Beule, K.; Andries, K.; McNeeley, D. F. The diarylquinoline TMC207 for multidrug-resistant tuberculosis. N. Engl. J. Med. 2009, 360, 2397-2405.

(14) Warman, A. J.; Rito, T. S.; Fisher, N. E.; Moss, D. M.; Berry, N. G.; O'Neill, P. M.; Ward, S. A.; Biagini, G. A. Antitubercular pharmacodynamics of phenothiazines. J. Antimicrob. Chemother. 2013, 68, 869-880.

(15) Pethe, K.; Bifani, P.; Jang, J.; Kang, S.; Park, S.; Ahn, S.; Jiricek, J.; Jung, J.; Jeon, H. K.; Cechetto, J.; Christophe, T.; Lee, H.; Kempf, M.; Jackson, M.; Lenaerts, A. J.; Pham, H.; Jones, V.; Seo, M. J.; Kim, Y. M.; Seo, M.; Seo, J. J.; Park, D.; Ko, Y.; Choi, I.; Kim, R.; Kim, S. Y.; Lim, S.; Yim, S.-A.; Nam, J.; Kang, H.; Kwon, H.; Oh, C.-T.; Cho, Y.; Jang, Y.; Kim, J.; Chua, A.; Tan, B. H.; Nanjundappa, M. B.; Rao, S. P. S.; Barnes, W. S.; Wintjens, R.; Walker, J. R.; Alonso, S.; Lee, S.; Kim, J.; Oh, S.; Oh, T.; Nehrbass, U.; Han, S.-J.; No, Z.; Lee, J.; Brodin, P.; Cho, S.-N.; Nam, K.; Kim, J. Discovery of Q203, a potent clinical candidate for the treatment of tuberculosis. Nat. Med. 2013, 19, 1157-1160.

(16) Abrahams, K. A.; Cox, J. A.; Spivey, V. L.; Loman, N. J.; Pallen, M. J.; Constantinidou, C.; Fernandez, R.; Alemparte, C.; Remuinan, M. J.; Barros, D.; Ballell, L.; Besra, G. S. Identification of novel imidazo[1,2a]pyridine inhibitors targeting M. tuberculosis QcrB. PLoS One 2012, 7, e52951. 
(17) Kana, B. D.; Machowski, E. E.; Schechter, N.; Shin, J.-T.; Rubin, H.; Mizrahi, V. Electron transport and respiration. In Mycobacterium: Genomics and Molecular Biology; Parish, T., Brown, A., Eds.; Horizon Press, London, UK, 2009; pp 35-64.

(18) Rao, S. P. S.; Alonso, S.; Rand, L.; Dick, T.; Pethe, K. The protonmotive force is required for maintaining ATP homeostasis and viability of hypoxic, nonreplicating Mycobacterium tuberculosis. Proc. Natl. Acad. Sci. U. S. A. 2008, 105, 11945-11950.

(19) Lloyd, D.; Hayes, A. J. Vigor, vitality and viability of microorganisms. FEMS Microbiol. Lett. 1995, 133, 1-7.

(20) Griffin, J. E.; Gawronski, J. D.; DeJesus, M. A.; Ioerger, T. R.; Akerley, B. J.; Sassetti, C. M. High-resolution phenotypic profiling defines genes essential for Mycobacterial growth and cholesterol catabolism. PLoS Pathog. 2011, 7, e1002251.

(21) Awasthy, D.; Ambady, A.; Narayana, A.; Morayya, S.; Sharma, U. Roles of the two type II NADH dehydrogenases in the survival of Mycobacterium tuberculosis in vitro. Gene 2014, 550, 110-116.

(22) Betts, J. C.; Lukey, P. T.; Robb, L. C.; McAdam, R. A.; Duncan, K. Evaluation of a nutrient starvation model of Mycobacterium tuberculosis persistence by gene and protein expression profiling. Mol. Microbiol. 2002, 43, 717-731.

(23) Winder, F. G.; Collins, P. B. Inhibition by isoniazid of synthesis of mycolic acids in Mycobacterium tuberculosis. J. Gen. Microbiol. 1970, 63, $41-48$.

(24) Brennan, P. J.; Crick, D. C. The cell-wall core of mycobacterium tuberculosis in the context of drug discovery. Curr. Top. Med. Chem. 2007, 7, 475-488.

(25) Mdluli, K.; Ma, Z. Mycobacterium tuberculosis DNA Gyrase as a target for drug discovery. Infect. Disord.: Drug Targets 2007, 7, 159-168.

(26) Aubry, A.; Pan, X.-S.; Fisher, L. M.; Jarlier, V.; Cambau, E. Mycobacterium tuberculosis DNA Gyrase: Interaction with quinolones and correlation with antimycobacterial drug activity. Antimicrob. Agents Chemother. 2004, 48, 1281-1288.

(27) Shi, W.; Zhang, X.; Jiang, X.; Yuan, H.; Lee, J. S.; Barry, C. E.; Wang, H.; Zhang, W.; Zhang, Y. Pyrazinamide inhibits trans-translation in Mycobacterium tuberculosis. Science 2011, 333, 1630-1632.

(28) Campbell, E. A.; Korzheva, N.; Mustaev, A.; Murakami, K.; Nair, S.; Goldfarb, A.; Darst, S. A. Structural mechanism for rifampicin inhibition of bacterial RNA polymerase. Cell 2001, 104, 901-912.

(29) Fisher, N.; Warman, A. J.; Ward, S. A.; Biagini, G. A. Chapter 17 Type II NADH: quinone oxidoreductases of Plasmodium falciparum and Mycobacterium tuberculosis kinetic and high-throughput assays. Methods Enzymol. 2009, 456, 303-320.

(30) Warman, A. J.; Rito, T. S.; Fisher, N. E.; Moss, D. M.; Berry, N. G.; O'Neill, P. M.; Ward, S. A.; Biagini, G. A. Antitubercular pharmacodynamics of phenothiazines. J. Antimicrob. Chemother. 2013, 68, 869-880.

(31) Kristiansen, J. E.; Dastidar, S. G.; Palchoudhuri, S.; Roy, D. S.; Das, S.; Hendricks, O.; Christensen, J. B. Phenothiazines as a solution for multidrug resistant tuberculosis: From the origin to present. Int. Microbiol. 2015, 18, 1-12.

(32) Durant, J. L.; Leland, B. A.; Henry, D. R.; Nourse, J. G. Reoptimization of MDL keys for use in drug discovery. J. Chem. Inf. Comput. Sci. 2002, 42, 1273-1280.

(33) Willett, P. Similarity-based virtual screening using 2D fingerprints. Drug Discovery Today 2006, 11, 1046-1053.

(34) Geppert, H.; Vogt, M.; Bajorath, J. Current trends in ligand-based virtual screening: molecular representations, data mining methods, new application areas, and performance evaluation. J. Chem. Inf. Model. 2010, 50, 205-216.

(35) Liu, K.; Feng, J.; Young, S. S. PowerMV: a software environment for molecular viewing, descriptor generation, data analysis and hit evaluation. J. Chem. Inf. Model. 2005, 45, 515-522.

(36) Lipinski, C. A. Drug-like properties and the causes of poor solubility and poor permeability. J. Pharmacol. Toxicol. Methods 2000, 44, 235-249.

(37) Veber, D. F.; Johnson, S. R.; Cheng, H. Y.; Smith, B. R.; Ward, K. W.; Kopple, K. D. Molecular properties that influence the oral bioavailability of drug candidates. J. Med. Chem. 2002, 45, 2615-2623.
(38) Gleeson, M. P. Generation of a set of simple, interpretable ADMET rules of thumb. J. Med. Chem. 2008, 51, 817-834.

(39) Hughes, J. D.; Blagg, J.; Price, D. A.; Bailey, S.; DeCrescenzo, G. A.; Devraj, R. V.; Ellsworth, E.; Fobian, Y. M.; Gibbs, M. E.; Gilles, R. W.; Greene, N.; Huang, E.; Krieger-Burke, T.; Loesel, J.; Wager, T.; Whiteley, L.; Zhang, Y. Physiochemical drug properties associated with in vivo toxicological outcomes. Bioorg. Med. Chem. Lett. 2008, 18, 48724875.

(40) Waring, M. J. Lipophilicity in drug discovery. Expert Opin. Drug Discovery 2010, 5, 235-248.

(41) Pidathala, C.; Amewu, R.; Pacorel, B.; Nixon, G. L.; Gibbons, P.; Hong, W. D.; Leung, S. C.; Berry, N. G.; Sharma, R.; Stocks, P. A.; Srivastava, A.; Shone, A. E.; Charoensutthivarakul, S.; Taylor, L.; Berger, O.; Mbekeani, A.; Hill, A.; Fisher, N. E.; Warman, A. J.; Biagini, G. A.; Ward, S. A.; O'Neill, P. M. Identification, design and biological evaluation of bisaryl quinolones targeting Plasmodium falciparum Type II NADH:quinone oxidoreductase (PfNDH2). J. Med. Chem. 2012, 55, $1831-1843$.

(42) Leung, S. C.; Gibbons, P.; Amewu, R.; Nixon, G. L.; Pidathala, C.; Hong, W. D.; Pacorel, B.; Berry, N. G.; Sharma, R.; Stocks, P. A.; Srivastava, A.; Shone, A. E.; Charoensutthivarakul, S.; Taylor, L.; Berger, O.; Mbekeani, A.; Hill, A.; Fisher, N. E.; Warman, A. J.; Biagini, G. A.; Ward, S. A.; O’Neill, P. M. Identification, design and biological evaluation of heterocyclic quinolones targeting Plasmodium falciparum Type II NADH:quinone oxidoreductase (PfNDH2). J. Med. Chem. 2012, 55, 1844-1857.

(43) Biagini, G. A.; Fisher, N.; Shone, A. E.; Mubaraki, M. A.; Srivastava, A.; Hill, A.; Antoine, T.; Warman, A. J.; Davies, J.; Pidathala, C.; Amewu, R. K.; Leung, S. C.; Sharma, R.; Gibbons, P.; Hong, D. W.; Pacorel, B.; Lawrenson, A. S.; Charoensutthivarakul, S.; Taylor, L.; Berger, O.; Mbekeani, A.; Stocks, P. A.; Nixon, G. L.; Chadwick, J.; Hemingway, J.; Delves, M. J.; Sinden, R. E.; Zeeman, A.-M.; Kocken, C. H. M.; Berry, N. G.; O’Neill, P. M.; Ward, S. A. Generation of quinolone antimalarials targeting the Plasmodium falciparum mitochondrial respiratory chain for the treatment and prophylaxis of malaria. Proc. Natl. Acad. Sci. U. S. A. 2012, 109, 8298-8303.

(44) Sharma, R.; Lawrenson, A. S.; Fisher, N. E.; Warman, A. J.; Shone, A. E.; Hill, A.; Mbekeani, A.; Pidathala, C.; Amewu, R. K.; Leung, S.; Gibbons, P.; Hong, D. W.; Stocks, P.; Nixon, G. L.; Chadwick, J.; Shearer, J.; Gowers, I.; Cronk, D.; Parel, S. P.; O’Neill, P. M.; Ward, S. A.; Biagini, G. A.; Berry, N. G. Identification of novel antimalarial chemotypes via chemoinformatic compound selection methods for a high-throughput screening program against the novel malarial target, $\mathrm{PfNDH}$ 2: Increasing hit rate via virtual screening methods. J. Med. Chem. 2012, 55, 3144-3154.

(45) Nilsen, A.; LaCrue, A. N.; White, K. L.; Forquer, I. P.; Cross, R. M.; Marfurt, J.; Mather, M. W.; Delves, M. J.; Shackleford, D. M.; Saenz, F. E.; Morrisey, J. M.; Steuten, J.; Mutka, T.; Li, Y.; Wirjanata, G.; Ryan, E.; Duffy, S.; Kelly, J. X.; Sebayang, B. F.; Zeeman, A. M.; Noviyanti, R.; Sinden, R. E.; Kocken, C. H.; Price, R. N.; Avery, V. M.; AnguloBarturen, I.; Jimenez-Diaz, M. B.; Ferrer, S.; Herreros, E.; Sanz, L. M.; Gamo, F. J.; Bathurst, I.; Burrows, J. N.; Siegl, P.; Guy, R. K.; Winter, R. W.; Vaidya, A. B.; Charman, S. A.; Kyle, D. E.; Manetsch, R.; Riscoe, M. K. Quinolone-3-diarylethers: a new class of antimalarial drug. Sci. Transl. Med. 2013, 5, 177ra37.

(46) Nilsen, A.; Miley, G. P.; Forquer, I. P.; Mather, M. W.; Katneni, K.; Li, Y.; Pou, S.; Pershing, A. M.; Stickles, A. M.; Ryan, E.; Kelly, J. X.; Doggett, J. S.; White, K. L.; Hinrichs, D. J.; Winter, R. W.; Charman, S. A.; Zakharov, L. N.; Bathurst, I.; Burrows, J. N.; Vaidya, A. B.; Riscoe, M. K. Discovery, synthesis, and optimization of antimalarial $4(1 \mathrm{H})$ quinolone-3-diarylethers. J. Med. Chem. 2014, 57, 3818-3834.

(47) Monastyrskyi, A.; Kyle, D. E.; Manetsch, R. 4(1H)-Pyridone and $4(1 \mathrm{H})$-quinolone derivatives as antimalarials with erythrocytic, exoerythrocytic, and transmission blocking activities. Curr. Top. Med. Chem. 2014, 14, 1693-1705.

(48) Monastyrskyi, A.; LaCrue, A. N.; Mutka, T. S.; Sakhno, Y.; Kyle, D. E.; Manetsch, R. Synthesis and evaluation of $4(1 H)$-quinolone prodrugs targeting multi-drug resistance $P$. falciparum malaria. 245 th 
ACS National Meeting New Orleans, LA, April 7-11, 2013; American Chemical Society: Washington, DC, 2013; MEDI-388.

(49) Bueno, J. M.; Herreros, E.; Angulo-Barturen, I.; Ferrer, S.; Fiandor, J. M.; Gamo, F. J.; Gargallo-Viola, D.; Derimanov, G. Exploration of $4(1 \mathrm{H})$-pyridones as a novel family of potent antimalarial inhibitors of the plasmodial cytochrome bcl. Future Med. Chem. 2012, 4, 2311-2323.

(50) Charoensutthivarakul, S.; David Hong, W.; Leung, S. C.; Gibbons, P. D.; Bedingfield, P. T. P.; Nixon, G. L.; Lawrenson, A. S.; Berry, N. G.; Ward, S. A.; Biagini, G. A.; O’Neill, P. M. 2-Pyridylquinolone antimalarials with improved antimalarial activity and physicochemical properties. MedChem Comm 2015, 6, 1252-1259.

(51) Marwaha, J.; Palmer, M.; Hoffer, B.; Freedman, R.; Rice, K.; Paul, S.; Skolnick, P. Differential electrophysiological and behavioral responses to optically active derivatives of phencyclidine. NaunynSchmiedeberg's Arch. Pharmacol. 1981, 315, 203-209.

(52) Antilla, J. C.; Baskin, J. M.; Barder, T. E.; Buchwald, S. L. Copperdiamine-catalyzed $\mathrm{N}$-arylation of pyrroles, pyrazoles, indazoles, imidazoles, and triazoles. J. Org. Chem. 2004, 69, 5578-5587.

(53) Antilla, J. C.; Klapars, A.; Buchwald, S. L. The copper-catalyzed Narylation of indoles. J. Am. Chem. Soc. 2002, 124, 11684-11688.

(54) Kerekes, A. D.; Esposite, S. J.; Doll, R. J.; Tagat, J. R.; Yu, T.; Xiao, Y.; Zhang, Y.; Prelusky, D. B.; Tevar, S.; Gray, K.; Terracina, G. A.; Lee, S.; Jones, J.; Liu, M.; Basso, A. D.; Smith, E. B. Aurora kinase inhibitors based on the imidazo[1,2-a]pyrazine core: Fluorine and deuterium incorporation improve oral absorption and exposure. J. Med. Chem. 2011, 54, 201-210.

(55) Klapars, A.; Buchwald, S. L. Copper-catalyzed halogen exchange in aryl halides: An aromatic Finkelstein reaction. J. Am. Chem. Soc. 2002, 124, 14844-14845.

(56) Taniguchi, T.; Kawada, A.; Kondo, M.; Quinn, J. F.; Kunitomo, J.; Yoshikawa, M.; Fushimi, M. Preparation of pyridazinone compounds as phosphodiesterase 10A inhibitors for preventing and treating schizophrenia. US20100197651A1, 2010.

(57) Miley, G. P.; Pou, S.; Winter, R.; Nilsen, A.; Li, Y. X.; Kelly, J. X.; Stickles, A. M.; Mather, M. W.; Forquer, I. P.; Pershing, A. M.; White, K.; Shackleford, D.; Saunders, J.; Chen, G.; Ting, L. M.; Kim, K.; Zakharov, L. N.; Donini, C.; Burrows, J. N.; Vaidya, A. B.; Charman, S. A.; Riscoe, M. K. ELQ-300 prodrugs for enhanced delivery and single-dose cure of Malaria. Antimicrob. Agents Chemother. 2015, 59, 5555-5560.

(58) Wayne, L. G.; Hayes, L. G. An in vitro model for sequential study of shiftdown of Mycobacterium tuberculosis through two stages of nonreplicating persistence. Infect. Immun. 1996, 64, 2062-2069.

(59) Mosmann, T. Rapid colorimetric assay for cellular growth and survival: application to proliferation and cytotoxicity assays. J. Immunol. Methods 1983, 65, 55-63.

(60) Marroquin, L. D.; Hynes, J.; Dykens, J. A.; Jamieson, J. D.; Will, Y. Circumventing the Crabtree effect: replacing media glucose with galactose increases susceptibility of HepG2 cells to mitochondrial toxicants. Toxicol. Sci. 2007, 97, 539-547.

(61) Moss, D. M.; Kwan, W. S.; Liptrott, N. J.; Smith, D. L.; Siccardi, M.; Khoo, S. H.; Back, D. J.; Owen, A. Raltegravir is a substrate for SLC22A6: a putative mechanism for the interaction between raltegravir and tenofovir. Antimicrob. Agents Chemother. 2011, 55, 879-887.

(62) Elsby, R.; Surry, D. D.; Smith, V. N.; Gray, A. J. Validation and application of Caco-2 assays for the in vitro evaluation of development candidate drugs as substrates or inhibitors of P-glycoprotein to support regulatory submissions. Xenobiotica 2008, 38, 1140-1164.

(63) Neely, M. N.; van Guilder, M. G.; Yamada, W. M.; Schumitzky, A.; Jelliffe, R. W. Accurate detection of outliers and subpopulations with Pmetrics, a nonparametric and parametric pharmacometric modeling and simulation package for R. Ther. Drug Monit. 2012, 34, 467-476. 